NASA Contractor Report 182184

\title{
A Millimeter-Wave TunneLadder TWT
}

(NASA-CR-182184) A MIILINEIEE- AVE

1 CNNELEDEER IVT Final Feport (Varian

Associates) $73 \mathrm{~F}$
N8 $8-282.39$

CSCL O9A

\author{
Unclas \\ G3/33 0158876
}

A. Jacquez, A. Karp, D. Wilson, and A. Scott

Varian Associates, Inc.

Palo Alto, California

August 1988

Prepared for

Lewis Research Center

Under Contract NAS3-22466

\section{N/SA}

National Aeronautics and

Space Administration 


\section{PREFACE}

The effort reported here was supported by NASA-Lewis Research Laboratory on Contracts NAS-3-21930 and NAS-3-22445. The technological advance of assembling the diamond cubes with the chemically milled Amzirc ladders and the waveguide ridges was achieved by Mr. Dan T. Andker. His suggestions and capability greatly promoted the successful completion of the Tunneladder amplifier tubes. Contributors in computational, cold-test, mechanical design and other areas included G. A. Biggs, T. J. Grant, Y. Mizuhara, J. L. Putz and D. West. 

TABLE OF CONTENTS

Section Page

1. SUMMaRY $\ldots \ldots \ldots \ldots \ldots \ldots \ldots \ldots \ldots \ldots \ldots \ldots \ldots \ldots \ldots \ldots$

2. INTRODUCTION $\ldots \ldots \ldots \ldots \ldots \ldots \ldots \ldots \ldots \ldots \ldots \ldots \ldots \ldots \ldots$

2.1 General $\ldots \ldots \ldots \ldots \ldots \ldots \ldots \ldots \ldots \ldots \ldots \ldots \ldots \ldots \ldots$

2.2 Background History $\ldots \ldots \ldots \ldots \ldots \ldots \ldots \ldots \ldots . \ldots . \ldots . \ldots$

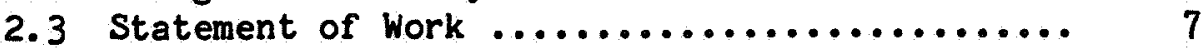

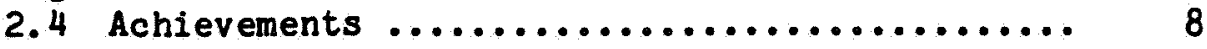

3. ACCOMPLISHMENTS $\ldots \ldots \ldots \ldots \ldots \ldots \ldots \ldots \ldots \ldots \ldots \ldots \ldots$

3. 1 Cold-Test Experiments ................. 11

3.2 Tube Design ......................... 21

3.3 Experimental Data .................... 53

4. CONCLUSIONS AND RECOMMENDATIONS ............. 65

4.1 Conclusions $\ldots \ldots \ldots \ldots \ldots \ldots \ldots \ldots \ldots \ldots \ldots \ldots \ldots$

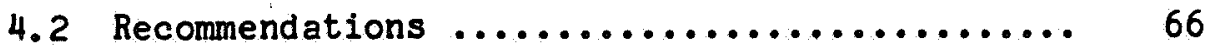

REFERENCES .............................. 67

PRECEDING PAGR BLANR NOT FILMED

iii 
This contract final report reviews the development of a low-cost, traveling-wave amplifier to be used in narrow-band space communication at millimeter-wave frequencies. The design was based on a NASA-recommended, narrow-band fundamental (nonspace harmonic) interaction circuit and used an appropriate ladder-based periodic structure. The first analysis was based on the forward-wave "Karp Structure".(1) These results were verified and extended in a NASA-sponsored study in which a circuit derivative, the Tunneladder, was suggested and examined experimentally in scaled cold-test versions. (2)

This follow-on feasibility program produced two operative engineering models. The focusing design was a PM-based electron-optical system providing a $0.47 \mathrm{~mm}(18.5 \mathrm{mils})$ diameter beam at $10 \mathrm{kV}$ and microperveance 0.2 . The $P M$ axial field was 3200 gauss or twice the Brillouin value over a $59.8 \mathrm{~mm}(2.355$ inches) gap.

The Tunneladder circuit is a diamond supported periodic structure. It is discussed extensively in the August 1980 final report for Contract NAS-3-21930. The tunnel cross section adapted for the $29 \mathrm{GHz}$ tube approximates a flattened hexagon circumscribing an ellipse $0.61 \times 0.86 \mathrm{~mm}$. The crucial program effort, however, was the fabrication of a full-scale millimeter-wave circuit using a copper and Amzirc body and Amzirc-foil ladder rungs, brazed to diamond-dice supports.

The full-scale, ladder-like circuit elements were successfully fabricated and the technology to active-braze the foil to diamond dice was made a reproducible operation. The final machining of the ladder halfcircuit was accomplished and a braze technique developed for brazing of the two halves with alignment of the individual rungs.

The waveguide transition was initially developed using cold-test models scaled 10:1. These models were also used to verify the circuit propagation 
characteristics. The final TWT circuit assemblies used scaled waveguide/circuit transitions to achieve acceptable matches and insertion loss.

The first tube used two circuit assemblies separated by a sever gap, with a "beam shaver" and "tail pipe" assembly before and after the active circuit sections. The planned "external sever" required that the tube use four waveguide/circuit transitions. The insertion loss of each section and the rf power delivered to the two sever loads were measured through these sever-waveguide parts. The second tube was built with only minor improvements for vacuum integrity.

Both tubes tested very much as predicted and provided broader bandwidth than expected. The gain/inch and the electronic efficiency were very high compared with a space-harmonic TWT and very close to predicted values. 


\section{INTRODUCTION}

This final report covers a study program supporting the development of an unconventional, narrow-band communication traveling wave tube (TWT). The principal task was the construction of two tubes with an interaction circuit comprising two formed ladder elements supported on diamond cubes within a double-ridge waveguide. The formed ladders allowed a conventional pencil beam to be used. The pencil beam was focused by a permanent magnet providing two times the Brillouin axial field.

\subsection{GENERAL}

The base-line efforts were motivated by interest in a low-cost alternative to coupled-cavity TWTs for millimeter wavelengths and high power levels. A previous eleven-month study program (NAS 3-21930) addressed this alternative. The study proposed a ladder-based circuit for operation in the forward/fundamental mode. The obvious advantages would be high interaction impedance, gain/inch and interaction efficiency. A short circuit length and minimum beam power to achieve $r f$ rated power, as well as a conventional pencil beam focused by a radially magnetized permanent magnet, would be implemented. The predicted bandwidth of only $1 \%$ would be sufficient for millimeter-wave communication amplification.

\subsection{BACKGROUND HISTORY}

In the early 1950s, the thin, flat ladder was recognized as a practical periodic element at millimeter wavelengths, provided one could invent a slow-wave interaction circuit incorporating it. $(3,4)$

The first ladder-based slow-wave circuit studied was a plain, rectangular waveguide with the ladder installed in the broad wall. The rung span was less than the waveguide breadth. (5) Slow-wave propagation -was achieved over a useful bandwidth extending downward from the half-wave resonance frequency of the rung. The bandwidth became greater yet when $a$ ridge was introduced within the waveguide. (6) The propagation was "forward wave" and the bandwidth depended on both the ridge-to-ladder capacitance and 
the space available for loops of $\mathrm{rf}$ magnetic field to expand beyond the rung anchor points.

During this period and beyond, a single ridge plus a thin, flat ladder combination appeared in low-voltage tubes - primarily backward-wave oscillators (BWOs) for frequencies up to $300 \mathrm{GHz} \cdot(7-9)$ In these designs, the disposition of metal around the rung anchor points varied, $(10)$ bence the bandwidth contribution relative to that from the ladder-to-ridge capacitance was not constant. (11) The current desire for higher power levels requires that the rungs be anchored directly and perpendicular to flat, solid walls to maximize rung cooling, (12) so that the bandwidth must be determined solely by the ridge capacitance. Most analytic efforts to model the structure's field and impedances stipulated extensive flat walls normal to the array of rungs. (12-15) Beam voltages of at most a few kilovolts were characteristic of millimeter-wave tubes in the 1950 s and early 1960s. In order to avoid an unreasonably fine ladder pitch, only space-harmonic interaction was considered at these low beam velocities. The beam-wave phase shift per period was between $\pi$ and $2 \pi$ for a BWO and $2 \pi$ to $3 \pi$ for an amplifier. Thus the first point made in H. G. Kosmahl's 1978 presentation was that the tens-of- $\mathrm{kV}$ beam voltages favored today would permit nonspace-harmonic operation at millimeter wavelengths of a "forward-wave" ladder-based amplifier with a relatively coarse pitch. (15)

"Fundamental/forward" TWT interaction implies per se a relatively high gain/inch, but Kosmahl's second point was that the gain rate would benefit further from the high interaction impedance associated with the ladder. This impedance is due, in part, to the rung resonance at a frequency close to the operating frequency and the consequent high dispersion and low group velocities. These properties also predict a rather narrow "hot" bandwidth which might, however, be acceptable for certain applications.

The principles above led to the previous study program $(2)$ and to the present development program. In the study program, prior to devising and evaluating TWT designs that were practical embodiments of Kosmahl's principles, some cold-test experimentation with an intentionally simplified slow-wave structure was done. These experiments showed the effects of 
dimensional changes in a geometry featuring the basic structural elements -- rungs, ridge and side walls (see Figure 1). Other tests included measurements of the effects of double ridges on the $\omega-\beta$ curve and interaction impedance.

The move from the earlier space-harmonic and low-power approaches to the forward/fundamental approach and high power for millimeter wavelengths created a very different situation. Beam power densities on the order of a few MW/cm2 were necessary and pencil-beam optics were the only means for making this manageable from the viewpoint of both the gun and the interaction structure. On the interaction structure side, a low percentage interception is consistent with having a pencil beam in a round "tunnel." on the gun side, a conventional axisymmetric gun, sufficiently convergent to avoid undue cathode loading, permitted the requisite $100 \mathrm{~A} / \mathrm{cm}^{2}$ or more of beam current.

The simple ladder-plus-ridge design is shown at the left in Figure 1. The ladder is then formed and doubled to allow the passage of a pencil beam; and to increase thermal capacity for handling beam interception, there is thermal anchoring to dielectric posts. The forming of the ladder produces a non-circular tunnel for the beam. This design provides thermal paths through the dielectric posts to the ridges for beam-interception heating localized where the rungs are closest to the beam. $R F$ heating in the rungs occurs mainly near the side walls to which there is a direct connection.

These ideas underly the basic "Tunneladder" interaction structure at the right in Figure 1, with two ridges and a ladder assembled from two identical components. As stated, the shaping of the ladder halves provides a more or less oval beam tunnel (with beam interception occurring predominantly at the two positions where heat can travel directly outward through the dielectric support rods). The double-ridge system now does . permit propagation of a mode which is $T E$ at the lowest propagating frequency and whose fields are antisymetric with respect to the ladder -- in addition to the desired mode which is similarly TE-derived but symmetric with respect to the ladder. With the new ladder-half shaping, the passband upper edge for the desired (symmetric) mode is lower than if the rungs were straight, 


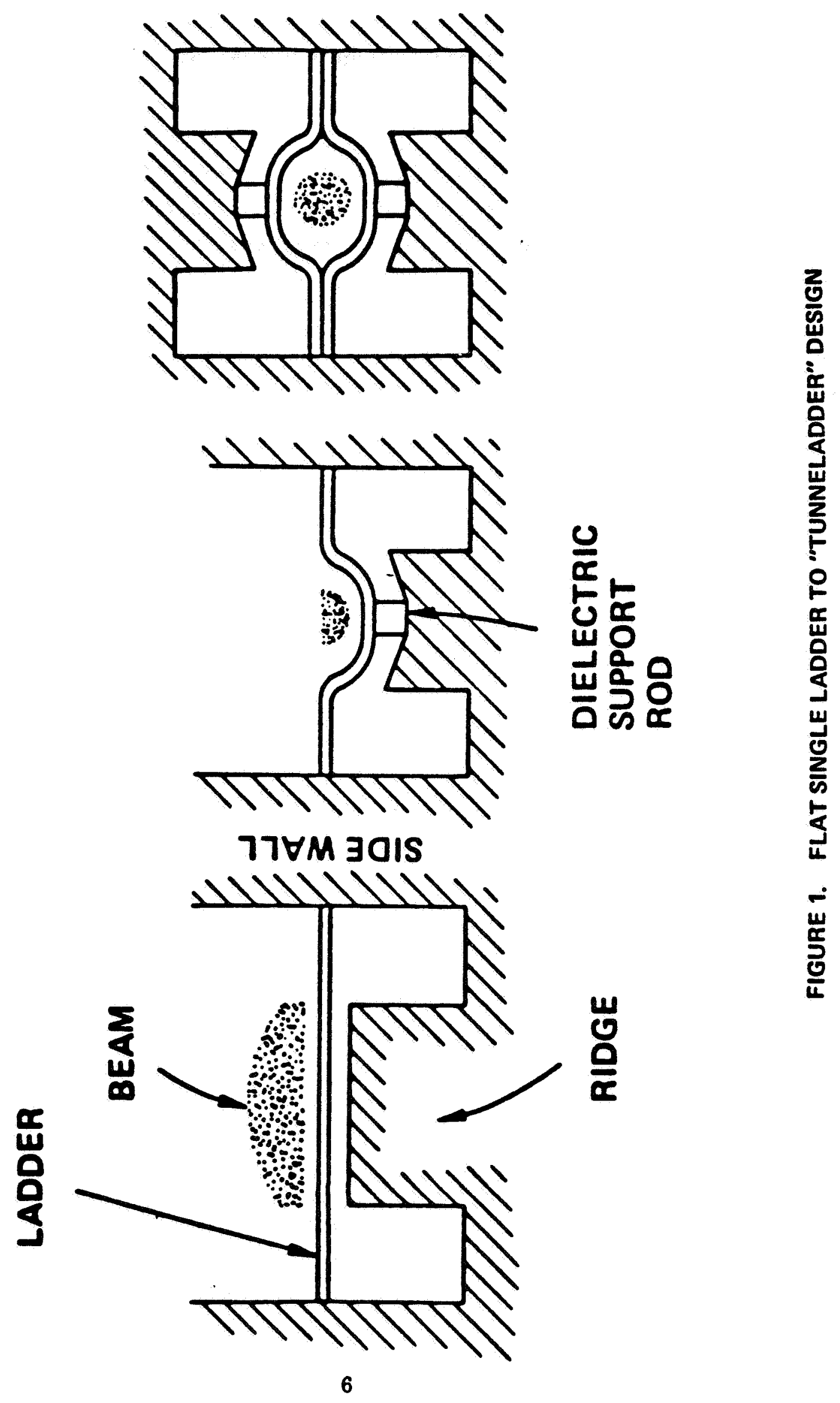


requiring inward adjustment of the enclosure side walls. However, the passband upper edge for the antisymmetric mode is considerably and safely higher -- by the ratio of the total rung length to half the circumference of the more or less oval tunnel.

The dielectric supports proposed are of high-thermal-conductivity Type IIA diamond, nominally $0.25 \mathrm{~mm}$ square in cross-section. The copper of the ladder rungs and ridges is zirconium doped to effect a strong thermocompression bond to the diamond without risk of contaminating nearby exposed diamond surfaces. Details relating to these supports and the bonding are given in section 3.

\subsection{STATEMENT OF WORK}

The main objectives of this follow-on program to NAS-3-21930 are:

- Design a $29 \mathrm{GHz}$ TWT based on the data obtained on NASA.

Contract 3-21930.

- Fabricate two finished TWTs for delivery to NASA. "Finished tube" means a completely assembled TWT with gun, collector, slow-wave circuit, and input and output couplers.

- The TWTs shall be performance-tested against the required objectives. The main objectives are:

- RF output power at saturation: $200 \mathrm{~W}$

- Minimum electronic efficiency at saturation: $5 \%$

- Operating frequency: $29 \mathrm{GHz}$

- Bandwidth ( $1.0 \mathrm{~dB}$ below peak power): 1.0 percent of operating frequency

- Gain at saturation: $25 \mathrm{~dB}$ 
- Tube capable of operating without damage into a load with a VSWR of up to 1.25 .

- Power and gain specified for a maximum load VSWR of 1.25.

- Tube length to accommodate focusing with a lightweight permanent-magnet circuit.

- Electron gun to incorporate an anode isolated from ground.

- Collector to be "undepressed" bucket type, isolated from tube body.

- Electron beam transmission: in dc operation $\geq 99 \%$, at $\mathrm{rf}$ saturation $\geq 95 \%$.

- Input and output couplers shall mate with standard RG-96/U waveguide.

\section{4 ACHIEVEMENTS}

The program achieved nearly all of the objectives, and surpassed most of them. Matched against the statement of work, the following items indicate objectives met or exceeded:

- Two $29 \mathrm{GHz}$ tubes, based on the earlier contract results, were designed, built, tested and delivered to NASA.

- The tubes were tested and performance exceeded all test specifications except for a few minor ones. Tube performance, as matched against the objectives, was:

- Saturated output was $400 \mathrm{~W}$, compared with the desired 200 watts. 
- Minimum electronic efficiency was $>17 \%$, compared with the 5\% desired minimum.

- Operating frequency was centered at $28.2 \mathrm{GHz}$, compared with $29 \mathrm{GHz}$. This difference could easily be compensated with minor circuit geometry changes.

- Instantaneous "hot" bandwidth was $2.27 \%$, compared with the 1.0\% minimum objective.

- Gain at rated power was $28 \mathrm{dE}$, compared with the $25 \mathrm{~dB}$ objective.

- The tube length accomodated focusing with an existing permanent-magnet circuit.

- The electron gun incorporated an anode isolated from ground.

- The collector was isolated from the tube body.

- Beam transmission was $97 \%$ in dc operation and $90 \%$ in rf operation. Tests indicated that this could be improved in later tubes to meet the $99 \%$ in dc operation and the $95 \%$ in $\mathrm{rf}$ operation.

- All tube couplers mated with standard RG-96/U waveguide.

Apart from the degree to which performance exceeded that of the Statement of Work, the tubes proved extremely stable at the operating voltage with no drive-induced oscillation. Tube amplification was linear within $2 \mathrm{~dB}$ at $53 \mathrm{dBm}$ output. Tube performance had been computer-predicted in small- and large-signal calculations. Agreement between predicted and actual performance values is excellent, considering this is a new device. The design parameters and predicted and actual performance data are given in Table 1 . 
Table 1

Predicted Actual

\begin{tabular}{llc}
$\quad$ & \multicolumn{1}{c}{$\begin{array}{c}\text { Operating Voltage } \\
\text { Microperveance }\end{array}$} & $10 \mathrm{kV}$ \\
Gain/inch & 0.2 & 0.215 \\
$1 \mathrm{~dB}$ Bandwidth & $58 \mathrm{~dB} / \mathrm{in}$ & $\geq 52 \mathrm{~dB} / \mathrm{in}$ \\
Saturated Power & $1+\%$ & $2.27 \%$ \\
Electronic Efficiency & 480 watts & 400 watts \\
& $24 \%$ & $>17 \%$ measured \\
Rated Operating Power & 200 watts & effective efficiency \\
- & & 200 watts \\
Details of the actual performance, cold-test work and design are \\
covered in Section 3.
\end{tabular}




\section{ACCOMPLISHMENTS}

This section describes the technical and new technological achievements of this development program. The cold-test work which defined the circuits used in the first two tubes is discussed in Section.3.1. Gun design, focusing design and circuit fabrication details are discussed in Sections 3.2.1 through 3.3.3, while the experimental test results for the two tubes are given in Section 3.3. The success of this program critically depended on the actual-size fabrication of the shaped and chemically milled ladders, the brazing of these ladders to the diamond cube supports, and the brazing of these supports to the waveguide ridges. The details of these milestone achievements are discussed in Section 3.2 .3 .

\subsection{COLD-TEST EXPERIMENTS}

The actual circuit design resulted from cold-test experiments with a 10-times scaled model of a $29 \mathrm{GHz}$ circuit whose geometry was determined from the results of previous NASA Contract 3-21930. As mentioned earlier, the interaction structure used two shaped ladder elements, each supported by diamond cubes brazed to half of a double-ridge waveguide. Two symmetrical halves were mated, forming a Tunneladder circuit with its two sets of diamond cube supports in a double-ridge waveguide. The prior NASA contract also established that the dielectric cubes would be made from Type IIA nonsynthetic gem-quality diamond because of its exceptionally high thermal conductivity.

The first cold-test model in this program was based on the prior NASA model. The $29 \mathrm{GHz}$ tube used:

- Formed ladders made by chemical milling.

- Type IIA diamond support cubes.

- Amzirc alloy for active brazes to the ladder rungs and waveguide ridges.

However the first scale model used Stycast to represent the diamond cubes and machined copper for the chemically milled Amzirc ladders. The rest of 
the cold-test model was of aluminum. Parts of the waveguide sidewalls were movable to establish the frequency band. Sidewall dimensions were the same in the final waveguide design to simplify parts and subassembly fabrication. The $\omega \beta$ diagram for a typical Tunneladder circuit is shown in Figure 2.

Tests included varying the diamond-cube width and the ridged-waveguide wall spacing with results as shown in Figure 3, which established the circuit dimensions for the tubes of this program. The half-structure drawing of Figure 4 gives the 10X-scaled dimensions. The cold-test $\omega-\beta$ and perturbation data were used in the small- and large-signal programs to establish tube performance, with computer-predicted data as shown in Figure 5.

After completing the circuit design, cold-test effort concentrated on the waveguide/circuit transition. The 10X-scaled circuit model is shown in Figure 6 . The scaled waveguide-transition model is shown with it in Figure 7. The final cold-test coupler design is shown in Figure 8, including the dimensions of the coupler tuning elements: inductive iris, capacitive post and reduced-height waveguide short. After optimizing the tuning elements of the transition, the result of this matching effort is as shown in Figure 9.

The VSWR is better than 1.6:1 over a $5 \%$ bandwidth and better than $2: 1$ over 10\%. This is more than satisfactory for the expected 1 to 3\% "hot" bandwidth. It should be possible to achieve a maximum VSWR better than $2: 1$ for the actual $29 \mathrm{GHz}$ circuit, even with a double-ended matched circuit as implemented for the first models. The only other cold-test experiments were undertaken after later work showed that the diamond cubes would have to have metalized caps to accomplish brazing to the Amzirc ladder rungs. These tests forecast a 2 to 5\% lowering of the operating frequency band, as later verified in actual tube tests. The necessary changes to the circuit design to move the operating frequency band back to $29 \mathrm{GHz}$ would be a shortening of the ladder rungs and a corresponding decrease in the width of the doubleridge waveguide halves. There would be a machining change in the circuit half blocks only and no changes in any assembly fixture. 


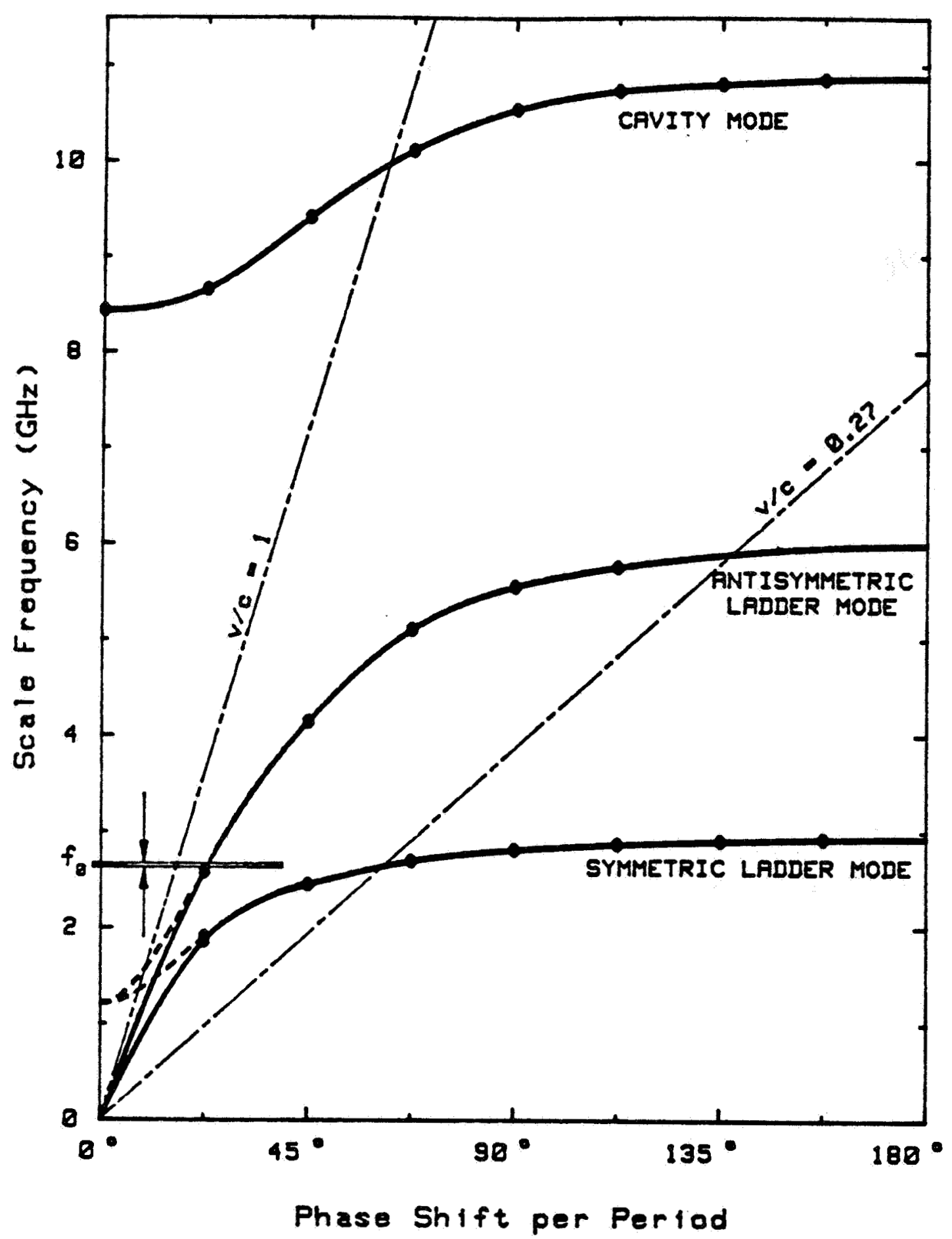

FIGURE 2. $\omega$ - $\beta$ DIAGRAM FOR TYPICAL "TUNNELADDER" CIRCUIT 


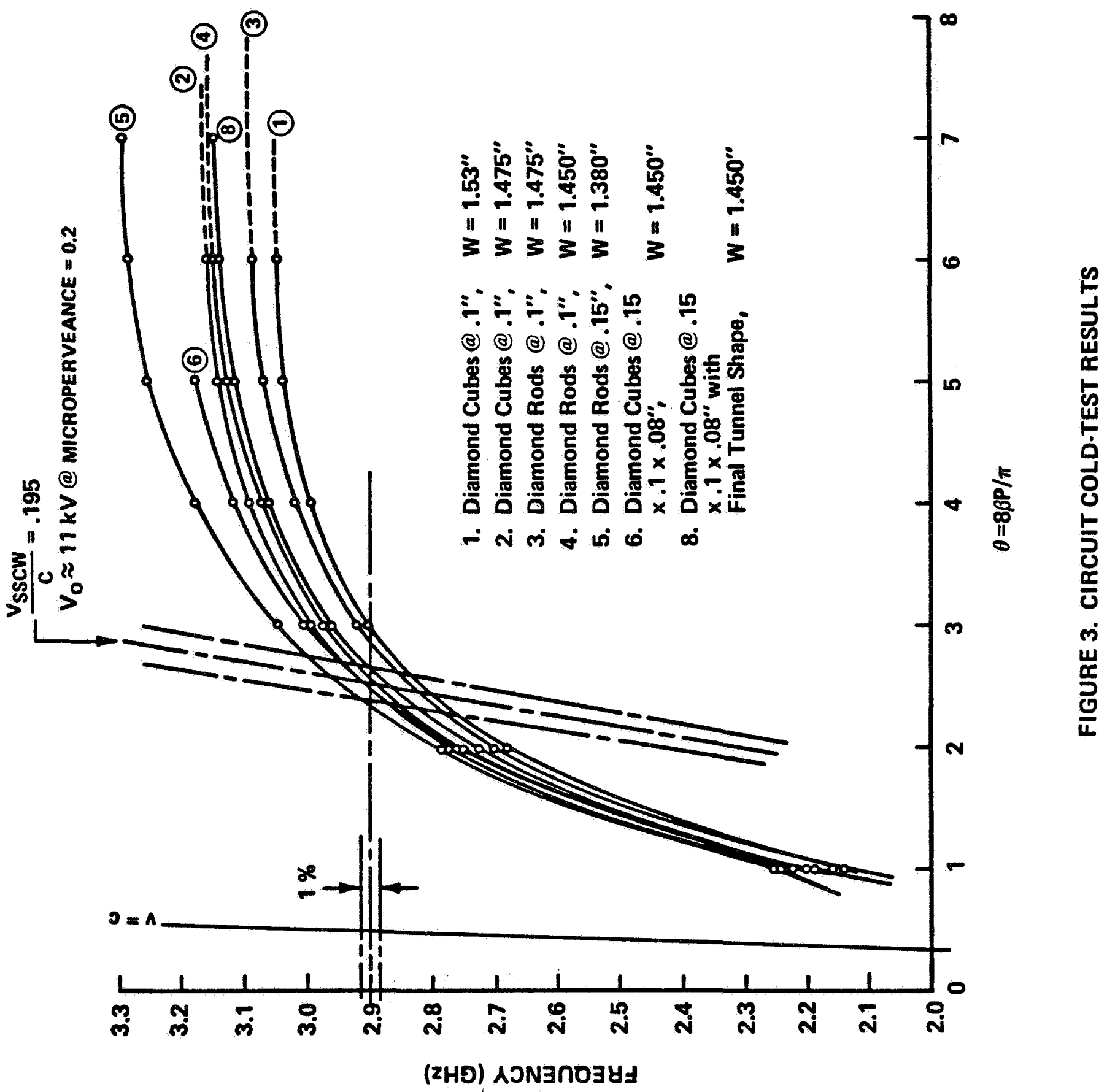



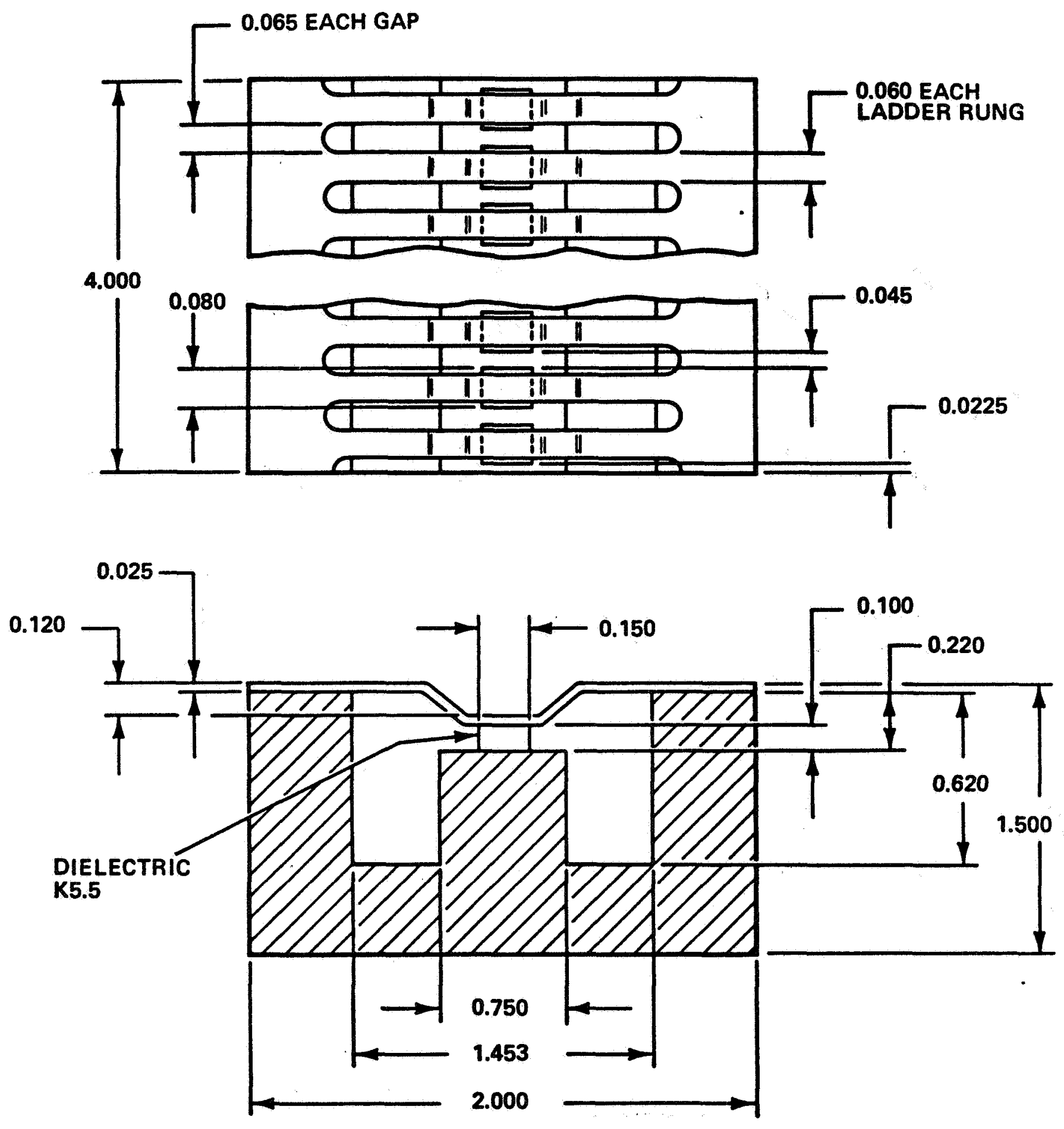

FIGURE 4. HALF OF THE FINAL SCALED COLD-TEST MODEL 


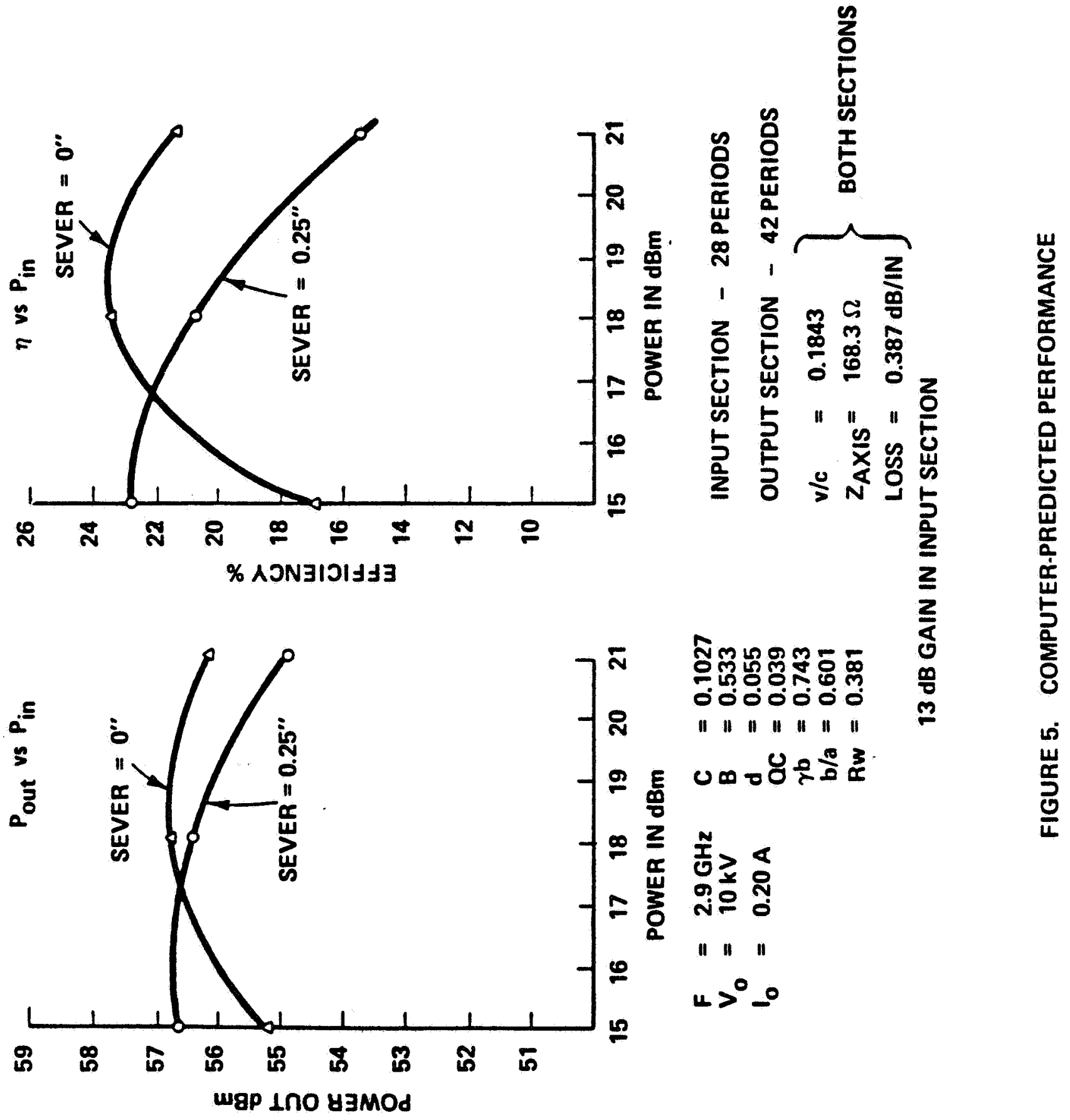




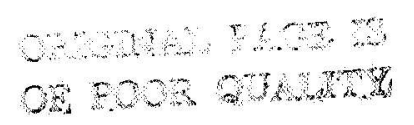

ORIGINAL PAGE IS

OF POOR QUALITY

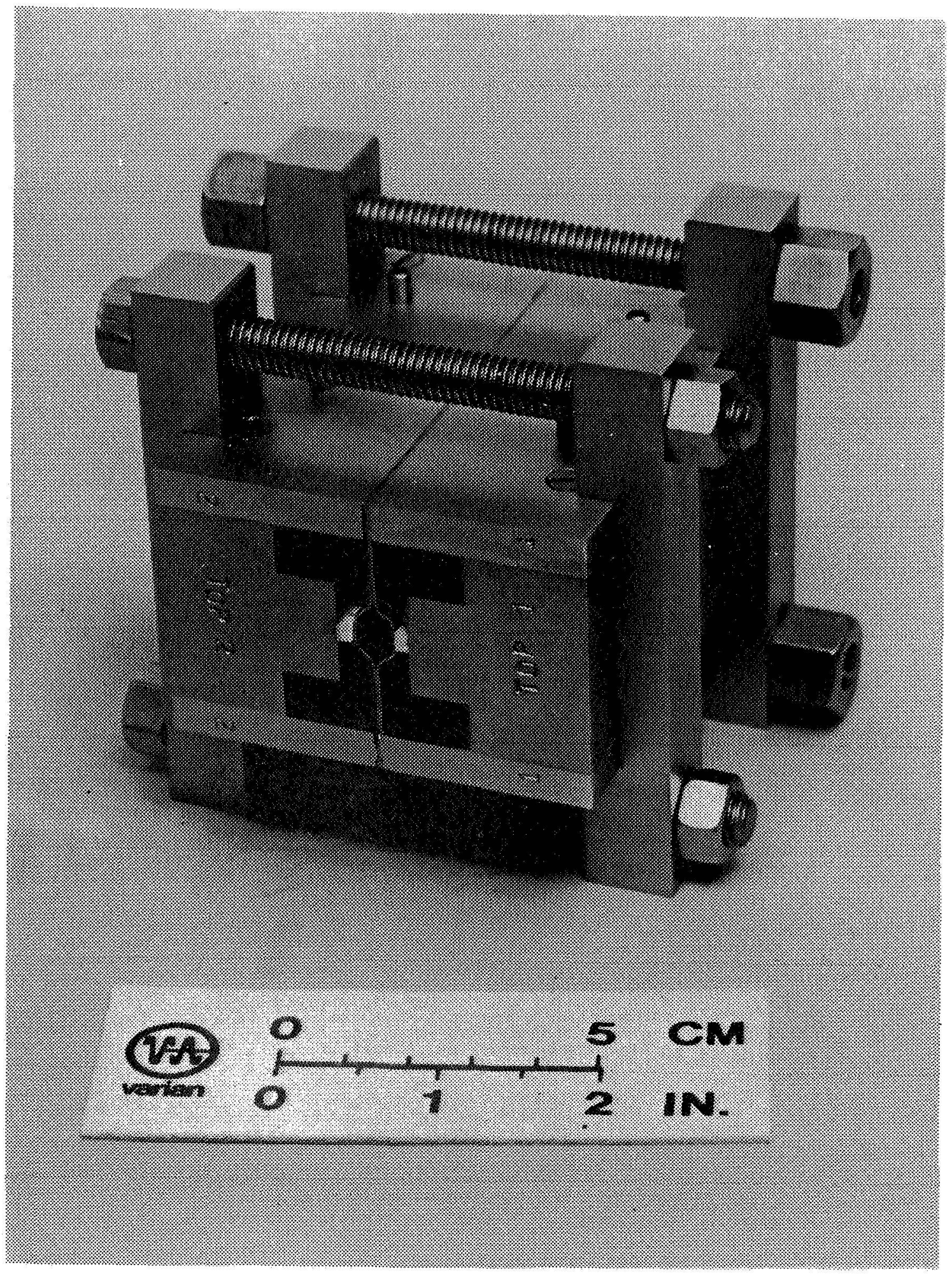

FIGURE 6. $29 \mathrm{GHz} / 10 \mathrm{kV}$ TUNNELADDER CIRCUIT GEOMETRY IN $10 X$ COLD-TEST SCALE MODEL IDIAMONDS

SIMULATED BY STYCAST BLOCKS) 
ORIGINAL PAGE IS

OE POOR QUALITY

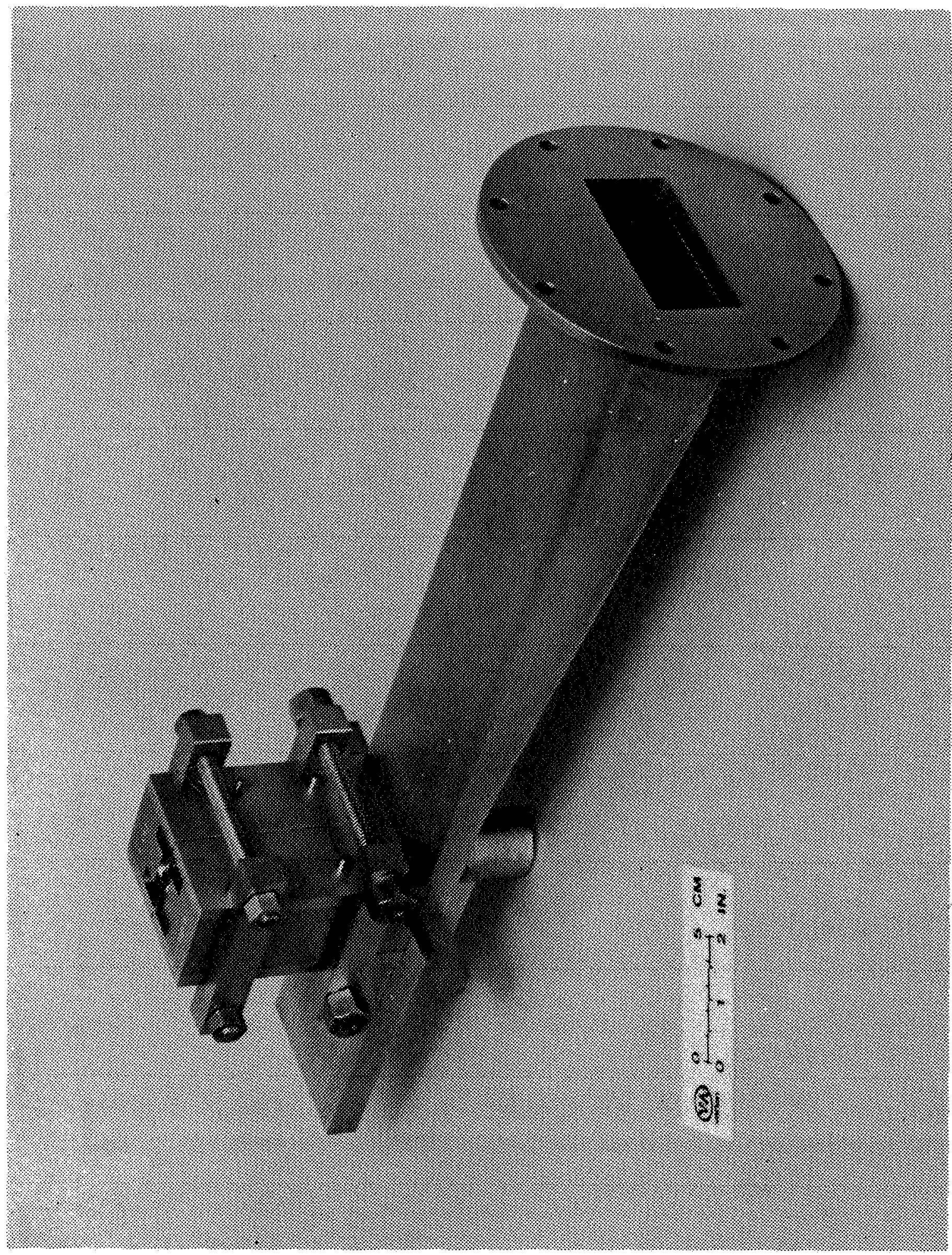

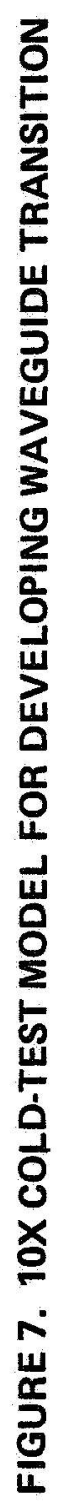




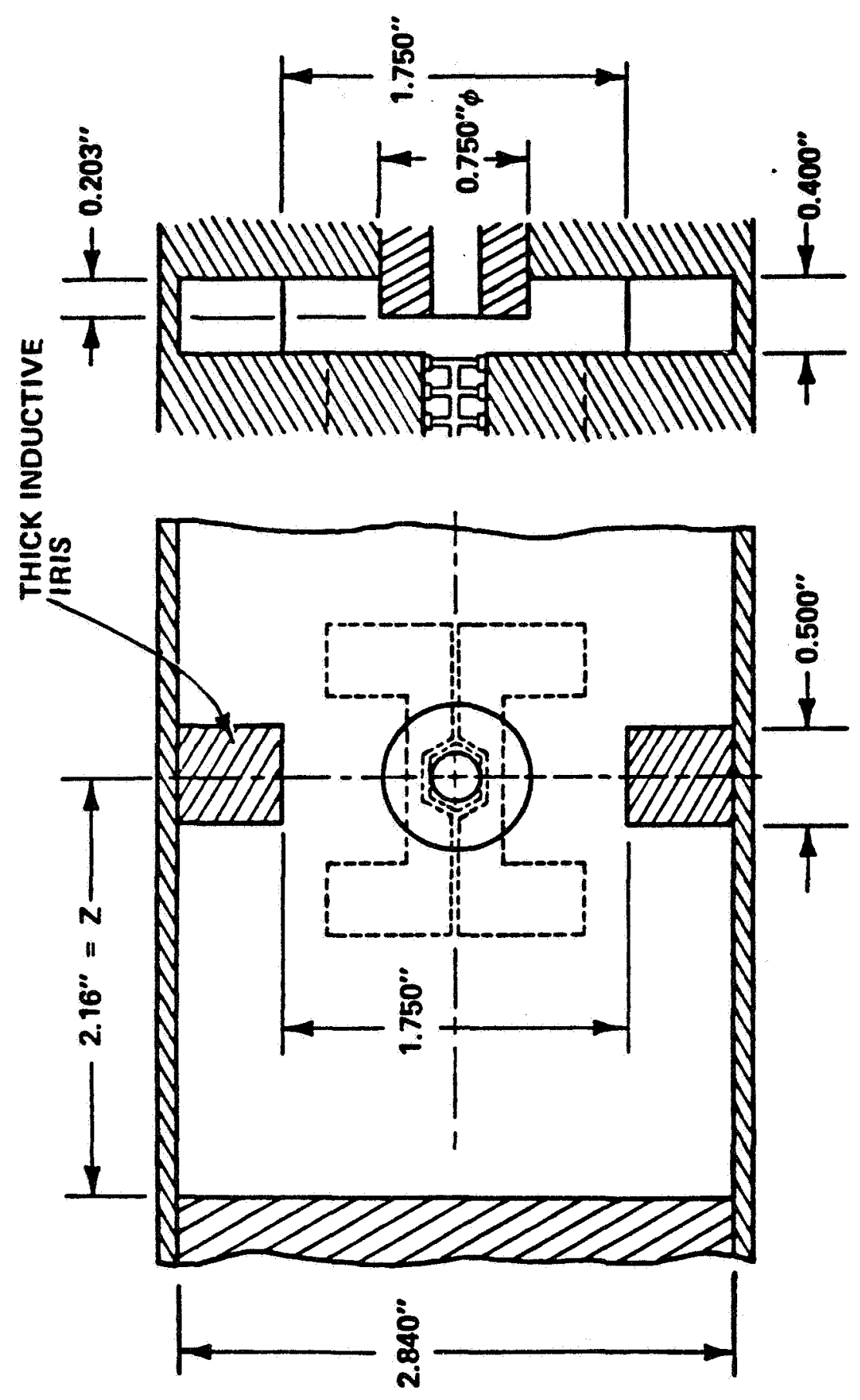

్ㅜ욤요

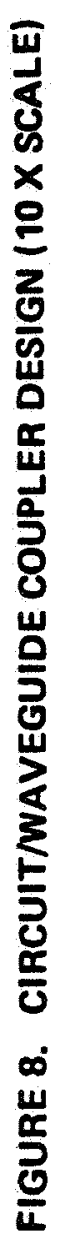




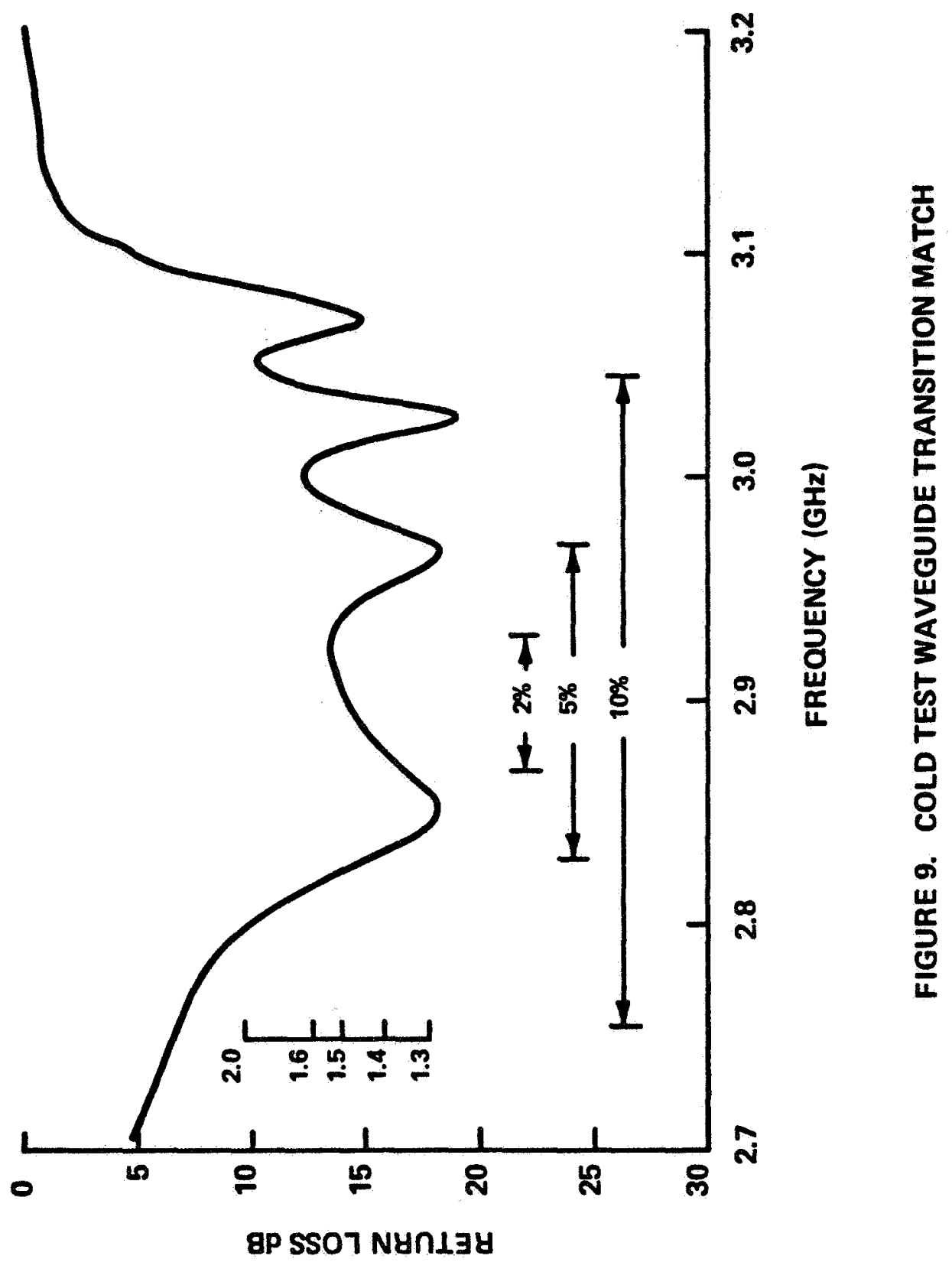




\subsection{TUBE DESIGN}

The following sections describe the important component designs and their test verifications. The Pierce gun and focusing system design and tests are discussed in Sections 3.2 .1 and 3.2 .2 , respectively - Circuit design and fabrication are discussed in Section 3.2 .3 , followed by details of tube assembly in Section 3.2 .4 .

The satisfactory completion of all component designs, fabrication, and testing was essential to the success of the final device, with various component designs evolving to achieve satisfactory fabrication processes. The design interactions are described in the appropriate subsections.

\subsubsection{Pierce Gun}

The design of the Pierce gun was based on that of a lowfrequency tube having a microperveance of 0.2 with a fairly high area convergence of 55. The new gun was tested in the beam analyzer several times at various beam voltages to establish thermal velocity properties and actual projected beam size. The gun design, its high-voltage seal assembly, and the details of the electrode spacing are shown in Figure 10. Actual beam profiles are shown in Figure 11, revealing a rectangular-profile beam at a distance of 0.375 inches from the cathode. The beam will have already been controlled by the magnetic field at this distance and remain well controlled through the rest of the magnetic circuit. This is confirmed by the excellent transmission achieved in the actual tubes. Plots of projected beam diameter versus distance from the cathode, for three cathode voltages, are shown in Figure 12, with the effect of thermal velocities revealed in the sensitivity to voltage. At $10 \mathrm{kV}$ the electrostatic beam minimum is 0.0185 inches, indicating a filling factor of 0.75 , but with magnetic compression this would be reduced to 0.6 (diameter $=0.015$ inch).

Figure 13 reiterates the contribution of thermal velocity effects to the above data. The effects on beam diameter are very significant even at $10 \mathrm{kV}$ for a gun microperveance of 0.2 . Beam focusing may be seriously 


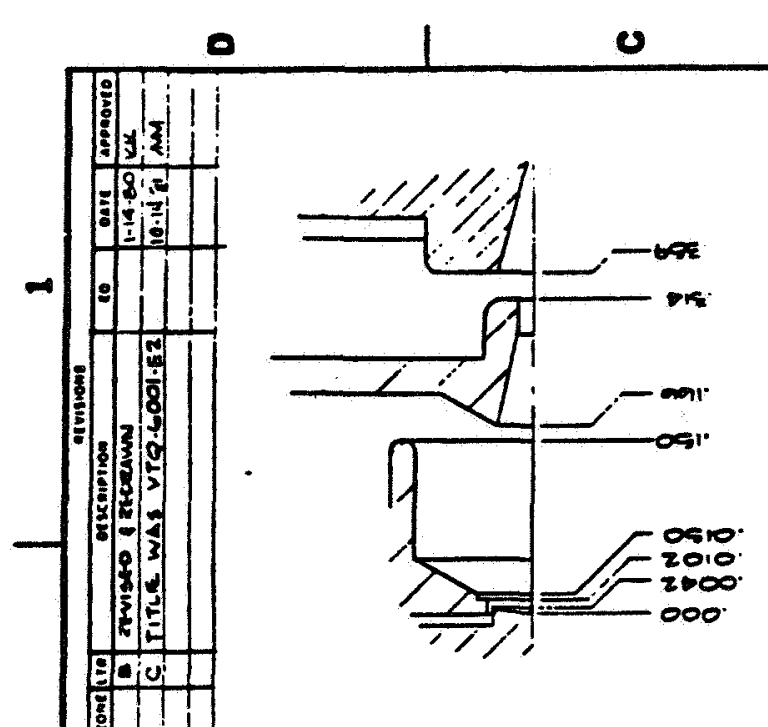

$+|c|$ Dozes $\mid \varnothing$
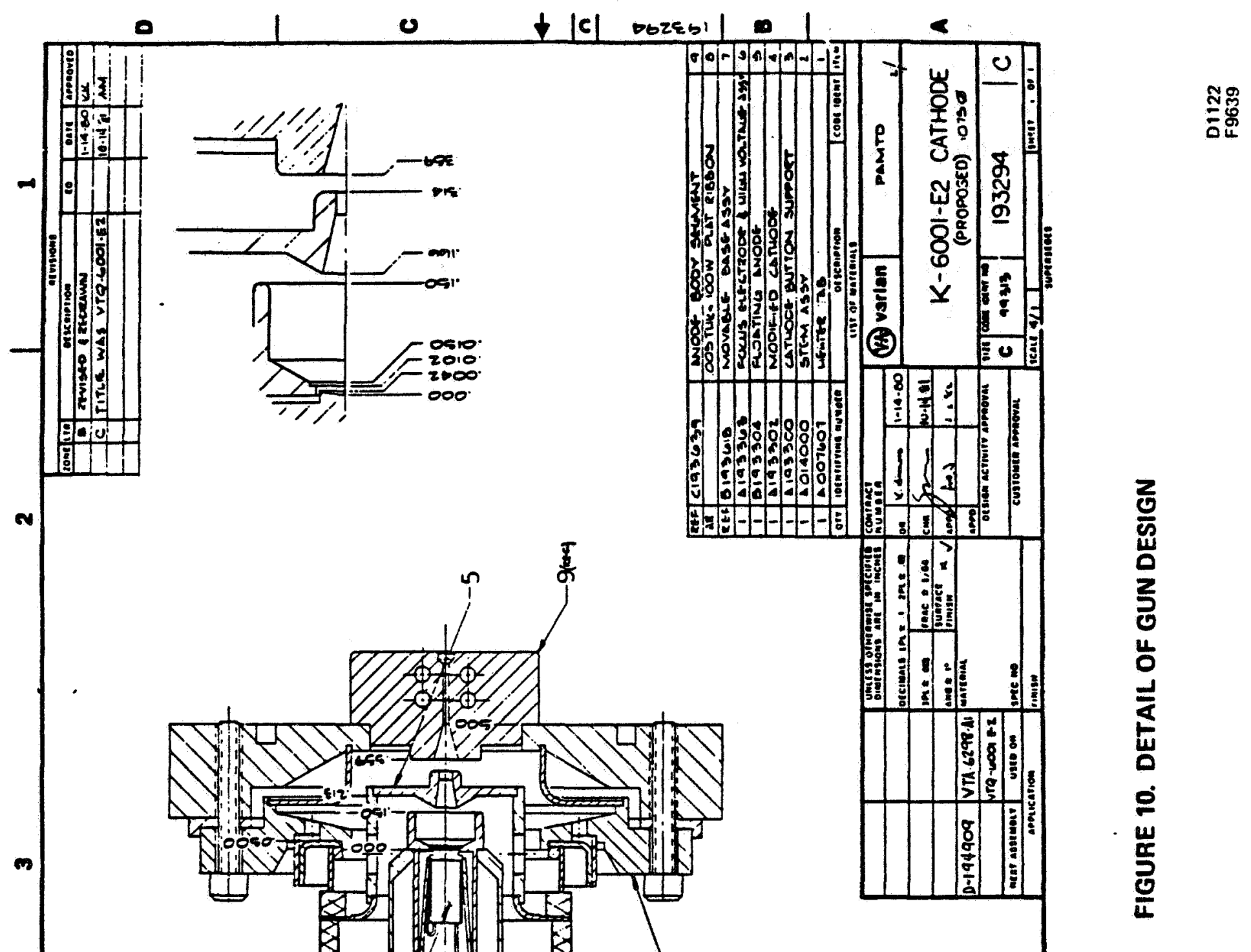

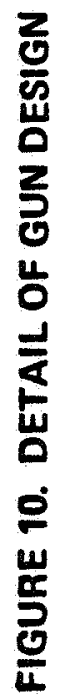


BEAM PROFILES

Cathode No. 3

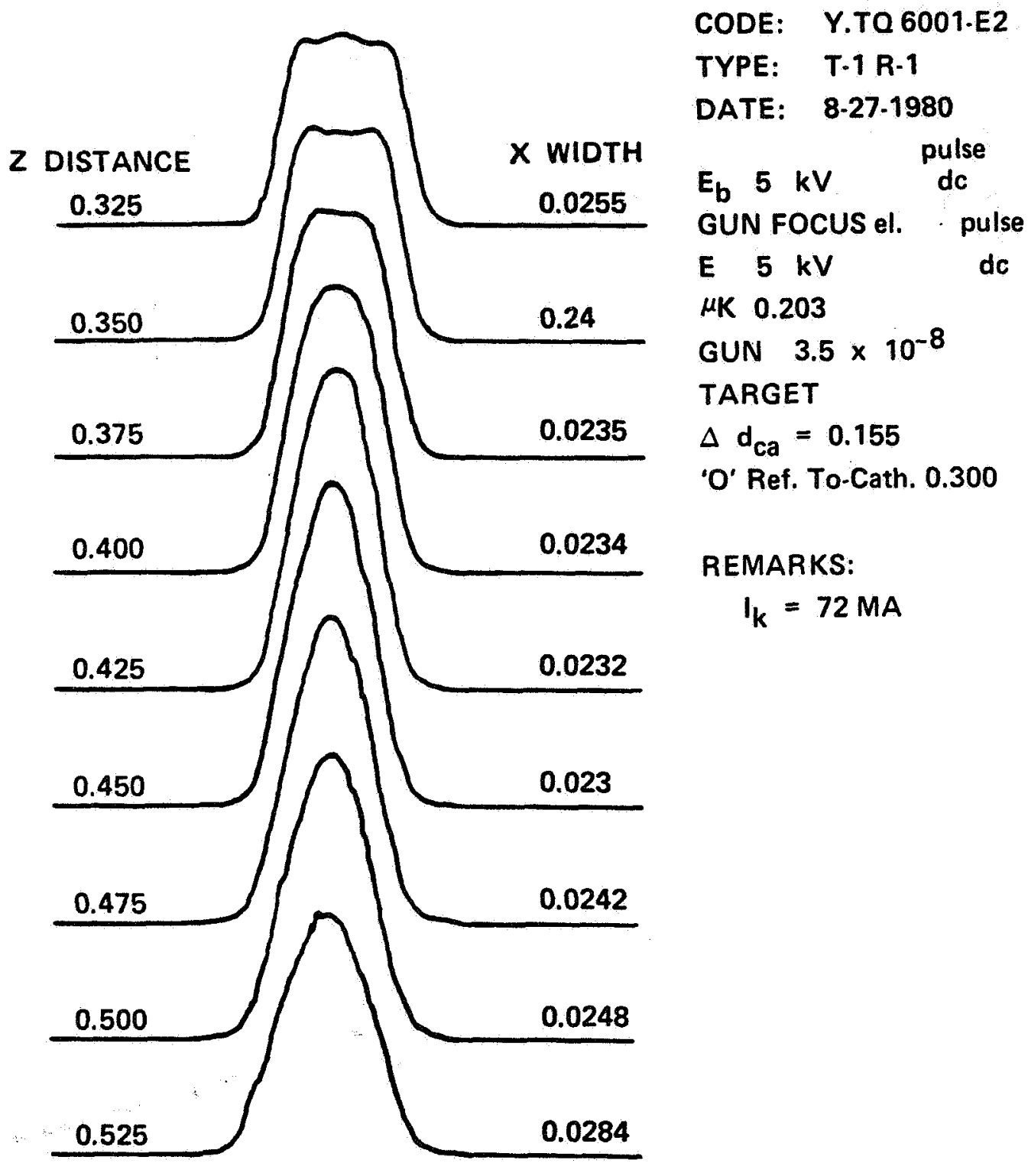

FIGURE 11. 5kV BEAM PROFILES 


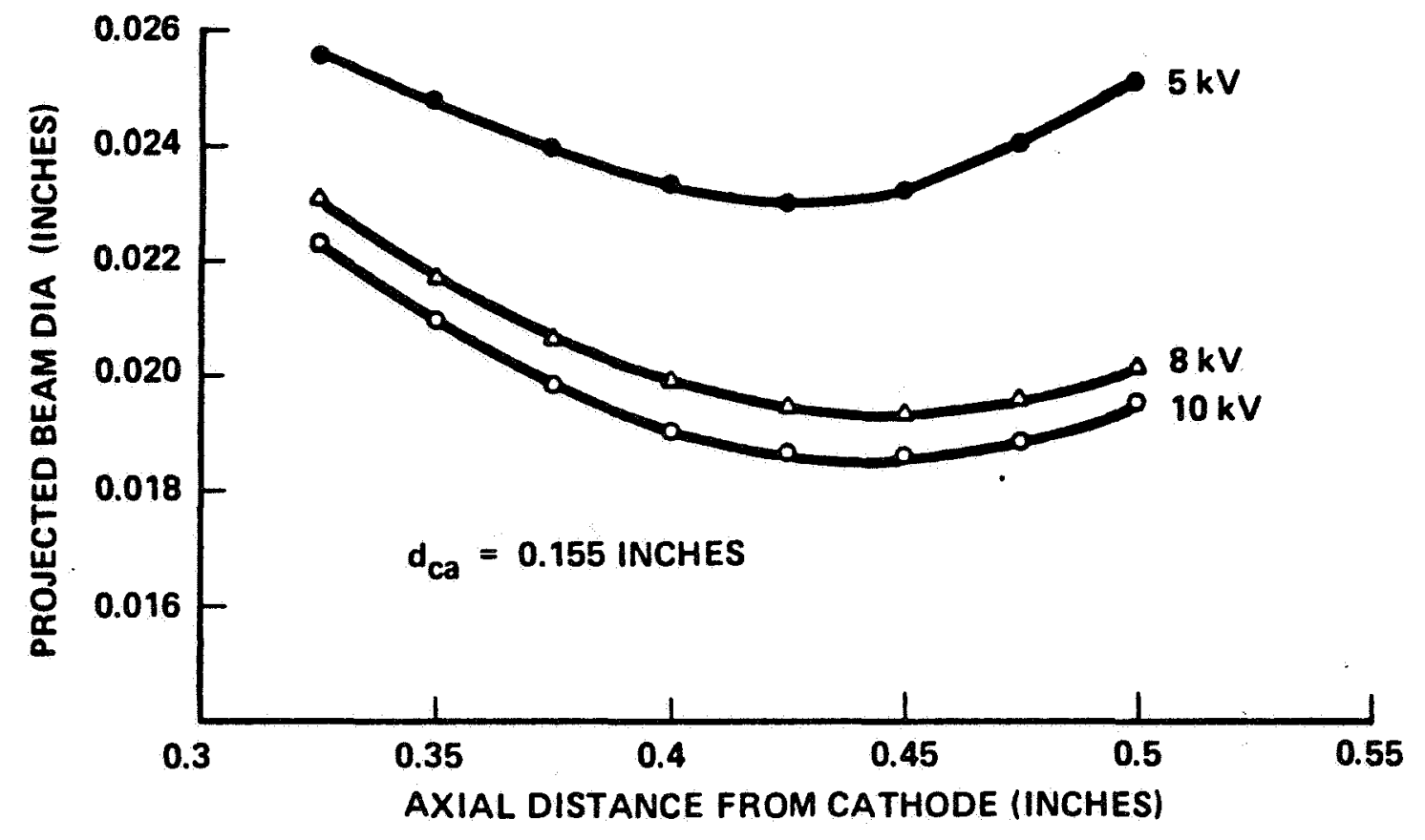

FIGURE 12. BEAM ANALYZER DATA

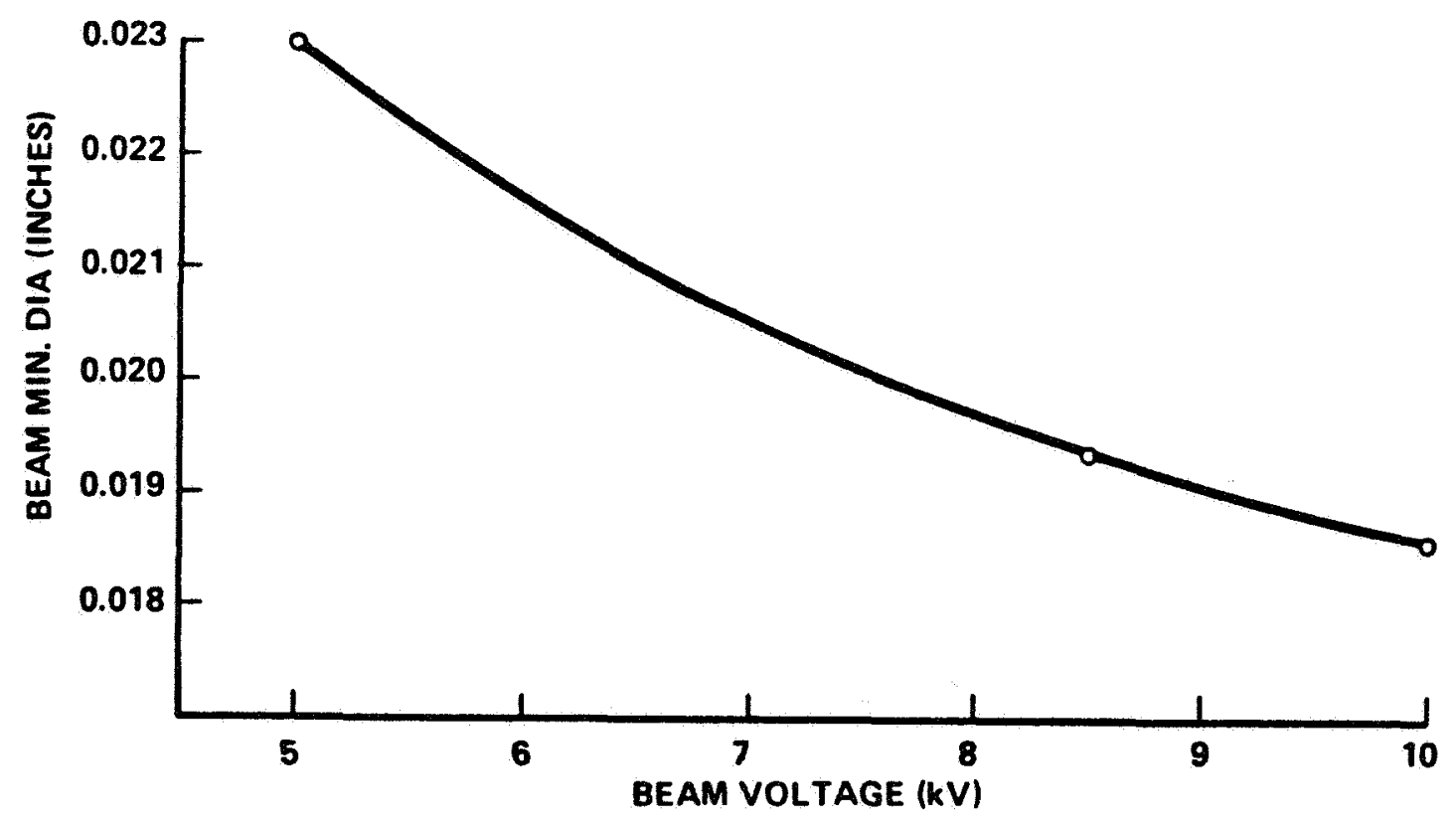

FIGURE 13. VOLTAGE DEPENDENCE OF BEAM DIAMETER DUE TO THERMAL VELOCITY EFFECTS 
affected if changes in cathode emissivity change thermal velocities over the life of the cathode.

\subsubsection{Focusing Design}

The selected focusing system made use of an existing radially magnetized permanent magnet comprising two radially magnetized $\mathrm{SmCo}_{5}$ rings - one placed around the gun and the other around the collector. An iron casing completes the flux path. The magnet assembly is shown in Figure 14 .

An actual field plot is shown in Figure 15, indicating an axial field of 3120 to 3700 gauss. The "saddle" in the axial field was predicted in computer design and can be reduced (by refinements in magnet design and material). Time constraints did not permit such refinements for the present program. The axial field is twice the Brillouin value and is provided over the magnet's $59.8 \mathrm{~mm}$ (2.355 inches) gap.

The focusing of the microperveance-0.2 gun in its magnet was verified by building a "beam stick" with a drift region 2.5 inches long and minimum tunnel diameter of $0.5 \mathrm{~mm}(0.020$ inches). The beam transmission at $10 \mathrm{kV}$ was $96 \%$, which was achieved by moving the gun 0.040 " into the magnet. Moving the gun changed the magnetic field entrance conditions. This was the maximum distance the gun could be moved toward the magnet and the transmission was still increasing indicating that further movement of the gun toward the magnet pole piece would increase the transmission beyond that achieved in this test. Beam-stick subassemblies are shown in Figure 16.

\subsubsection{RF Circuit Design}

Three main technological developments were achieved, permitting successful manufacture of the total circuit: fabrication of the Amzirc ladder elements, active brazing of diamond cubes to the ridge and to the ladder rungs, and fabrication and assembly of complete circuit sections. These developments are outlined in Section $3.2 .3 .1,3.2 .3 .2$ and 3.2.3.3, respectively. 


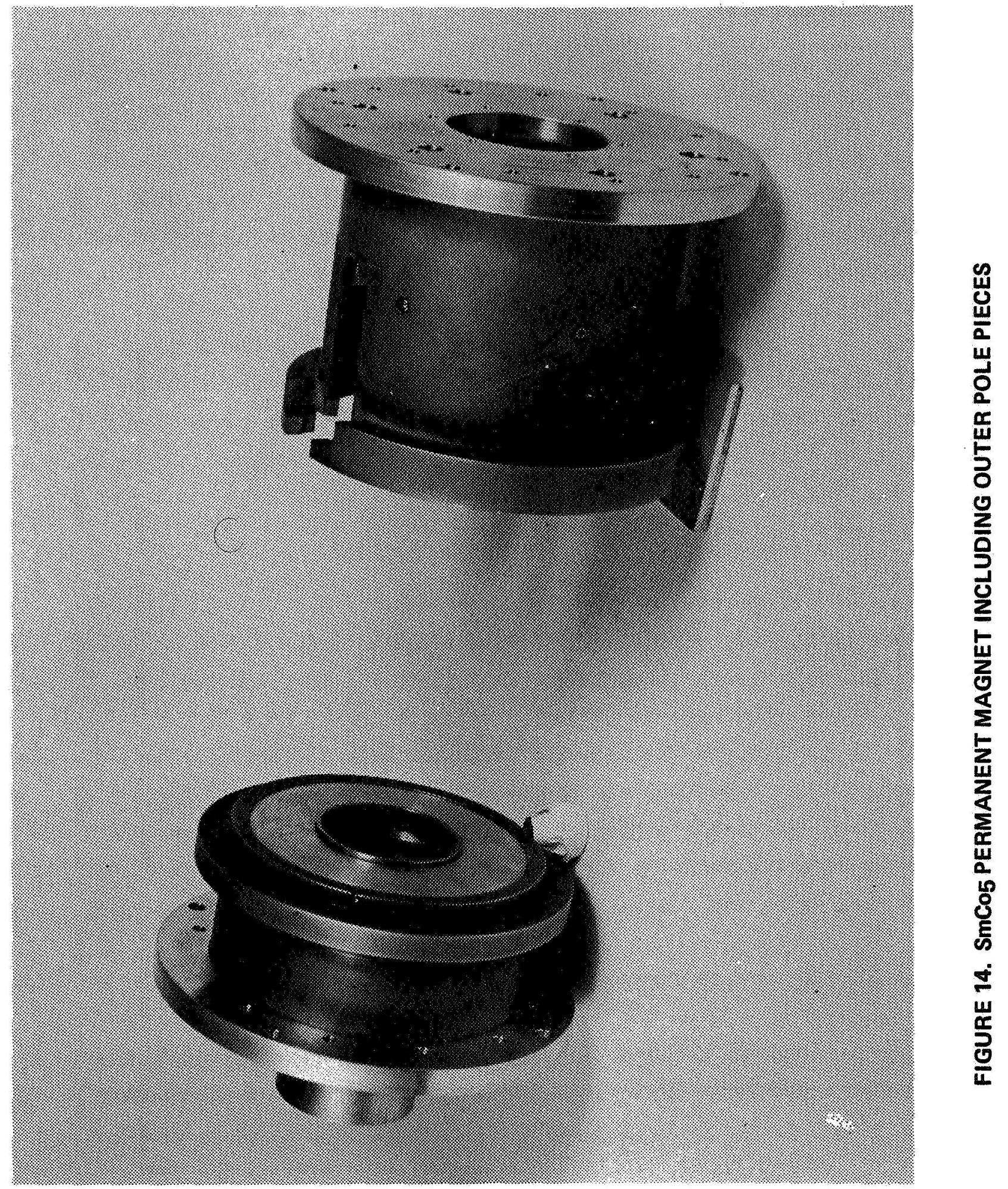

ORTGUA. FAGR WO OF FOOR BIFAITS 


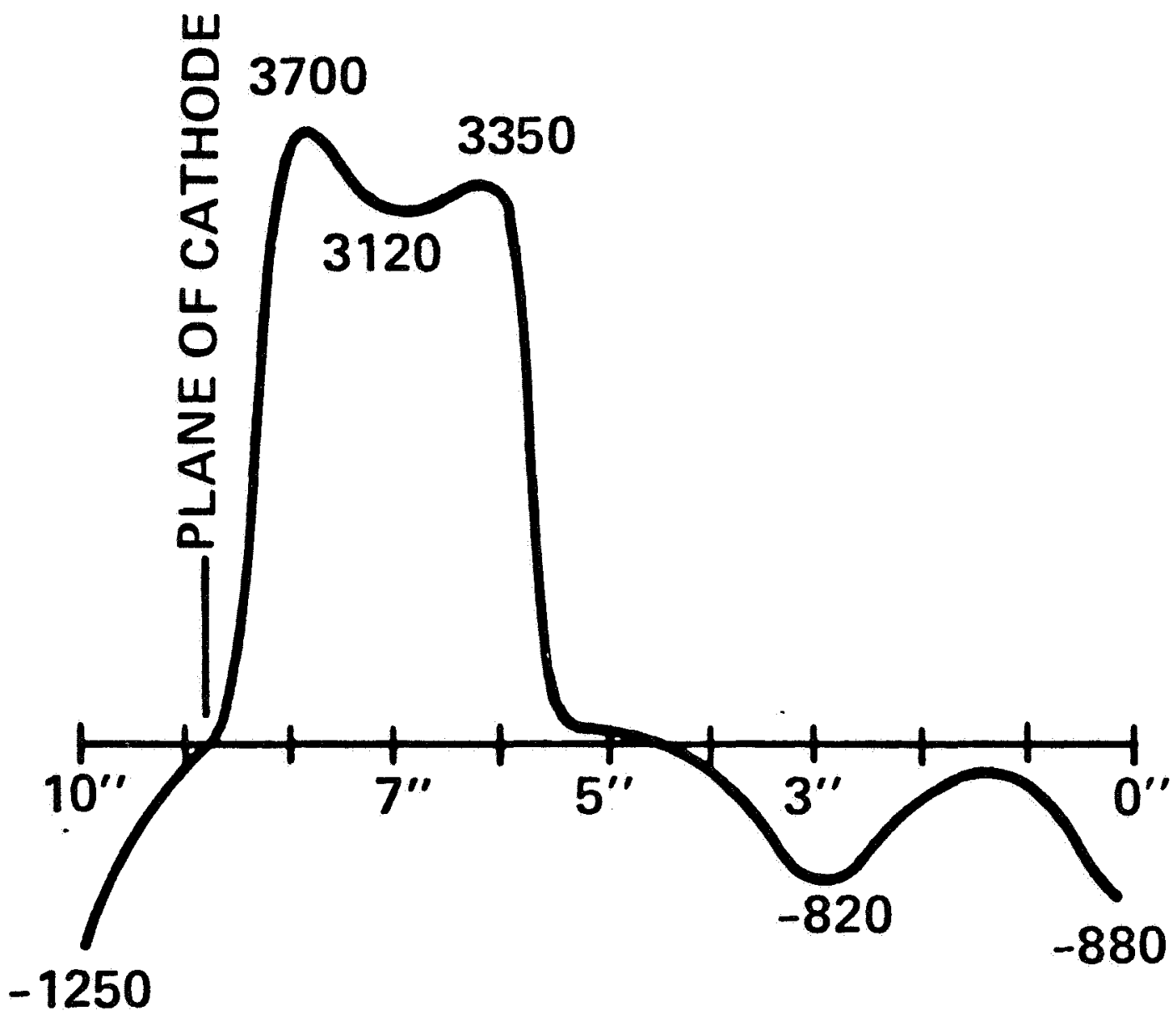

FIGURE 15. MEASURED AXIAL MAGNETIC FIELD 


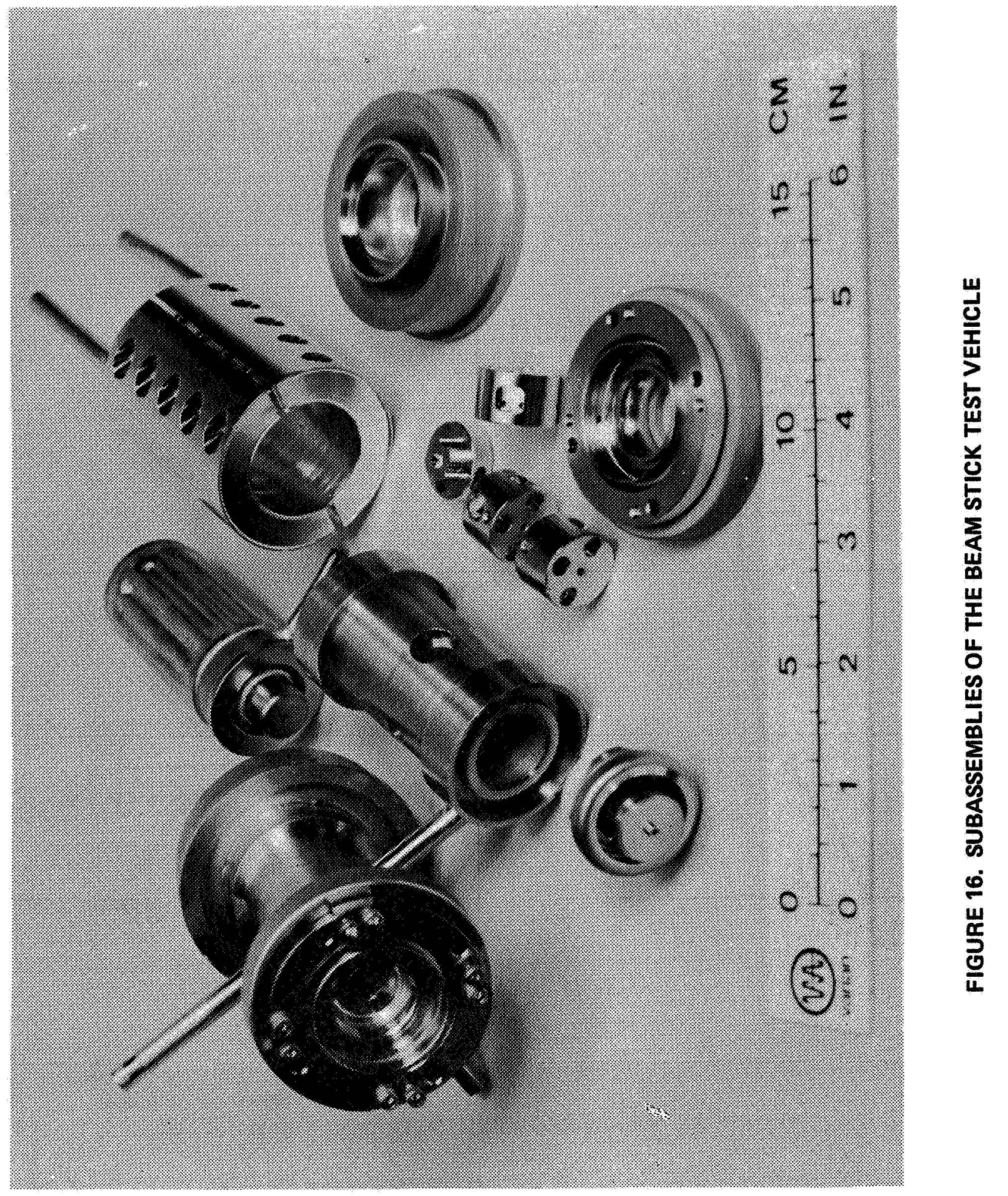




\subsubsection{Ladder Fabrication}

The success of this program critically depended on the actual-size fabrication of the shaped and chemically milled ladder elements. These were satisfactorily completed by Elcon, Inc., of San Jose, CA, as the photo of Figure 17 indicates. The tolerance on individual rung and gap dimensions was held to within \pm 0.0002 inches. The total ladder length was controlled to prevent "accumulation of tolerances" of the individual rungs and gaps. These ladders are made of Amzirc, a copper doped with zirconium that enables active-diffusion brazing. The foil thickness is $0.0635 \mathrm{~mm}$ $(2.5 \mathrm{mils})$, with the rungs $0.152 \mathrm{~mm}(6 \mathrm{mils})$ wide at a pitch of $0.318 \mathrm{~mm}$ (12.5 mils).

\subsubsection{Active Diffusion Brazing}

This section covers the technological developments which allowed the diamond cubes to be brazed to the ridge using a true activediffusion braze as detailed in section 3.2.3.2.1. The technique of then brazing the diamond cubes to the ladder is described in section 3.2.3.2.2. Figure 18 shows subassemblies with diamonds brazed to the ridge in the waveguide block, and with a ladder brazed to both diamonds and waveguide block.

\subsection{Diamond Cube/Ridge Braze}

The first critical procedure on which the program depended was the brazing of the diamond cubes to the waveguide ridge. The diamond cubes, each $0.3 \pm 0.001$ by $0.38 \pm 0.02$ by $0.2 \pm 0.02 \mathrm{~mm}$, are brazed onto each waveguide ridge with the aid of a chemically milled alignment fixture. Diamond is used because of its superior thermal conductivity. Figure 19 compares diamonds thermally with other insulators and conductors. At room temperature, Type IIA diamond as a thermal conductor is almost an order of magnitude better than copper, which is only slightly behind silver as the best metal conductor. A technique was needed to braze the diamond cubes to the copper ridge. For this purpose, the top surface of the ridge was made of Amzirc and special fixtures were designed 


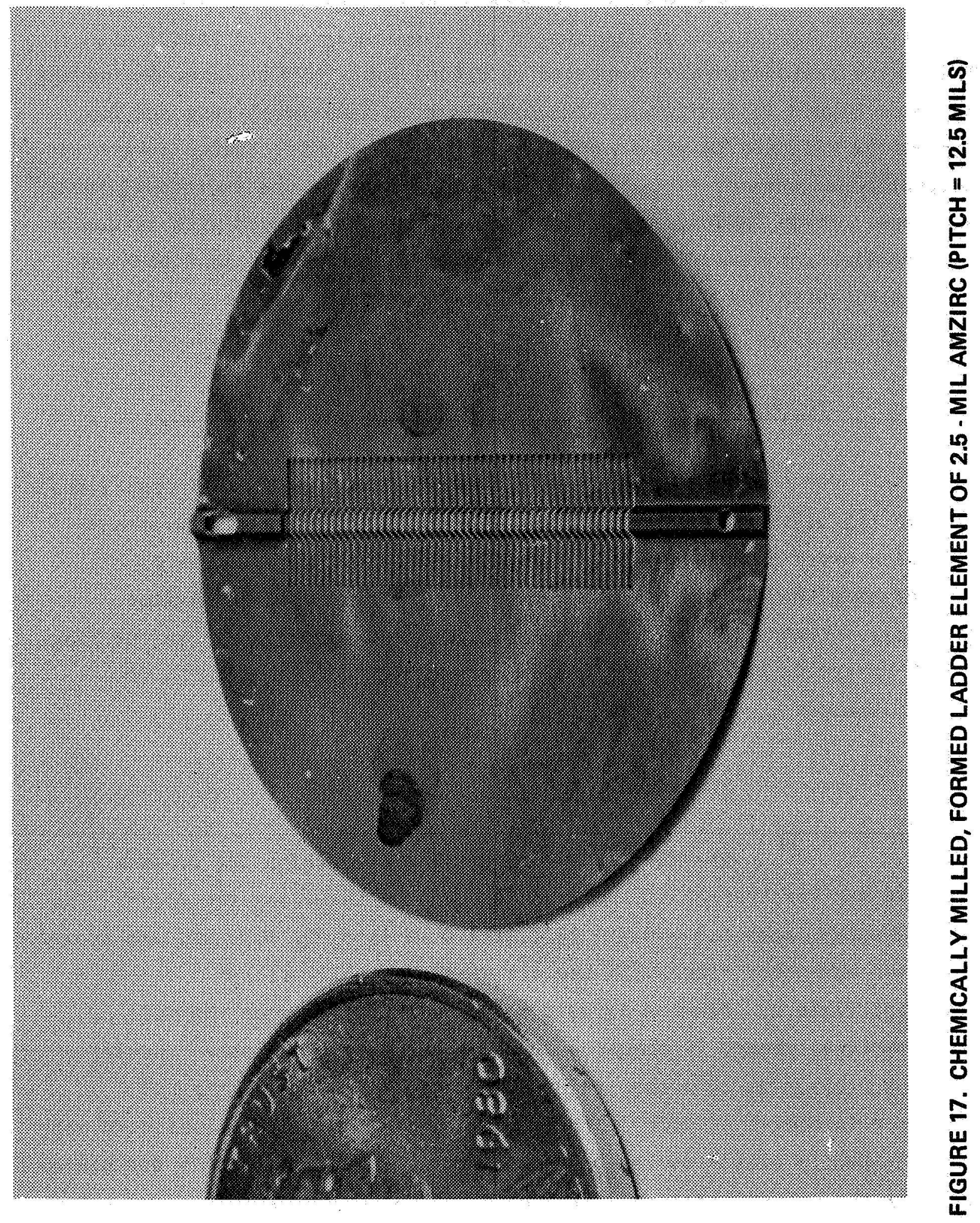

ORHCNAZ PAGE IS OE POOR QUALTTX 
OPFGME' P.GE W

OE ROOR QUALTX

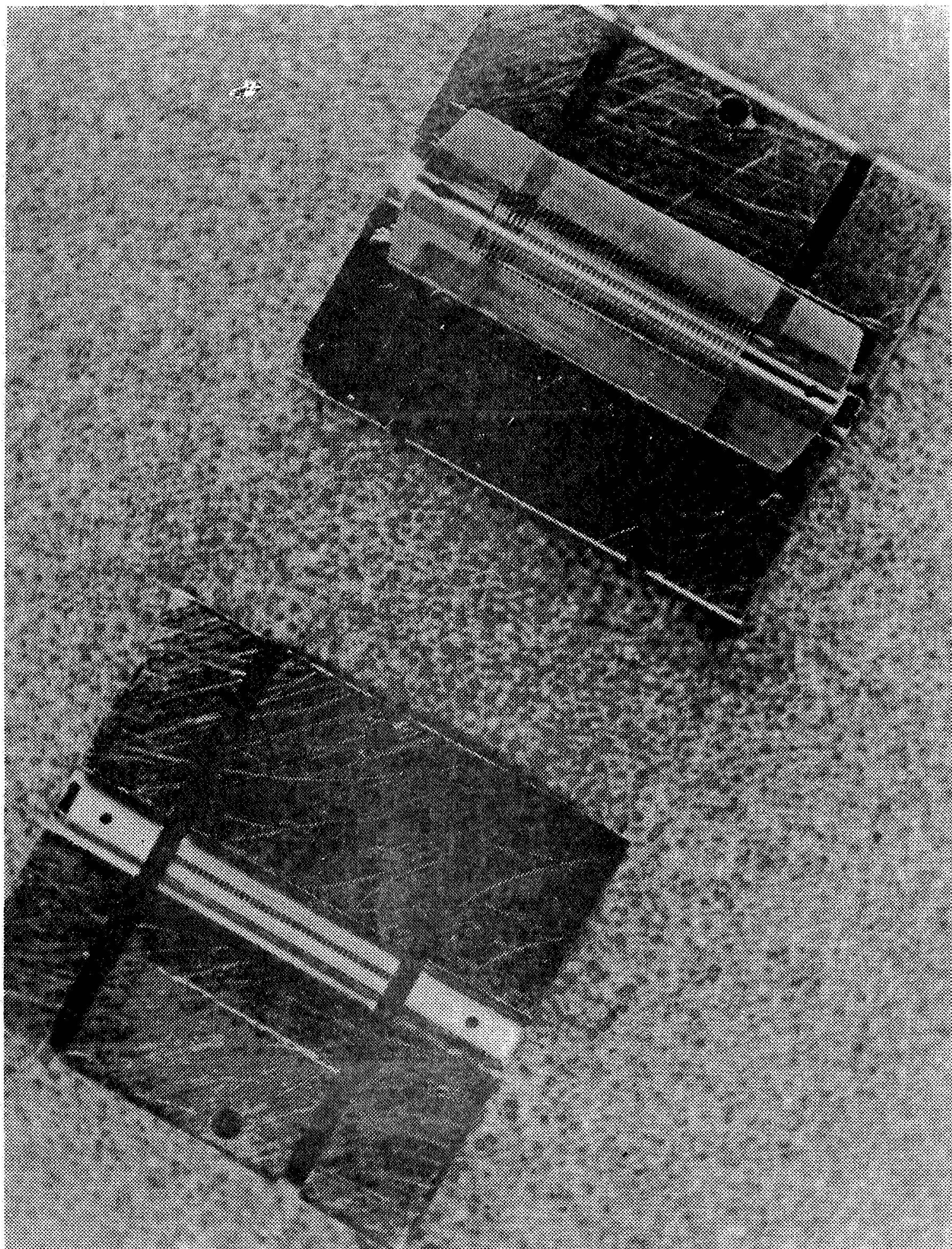

느

起

$\frac{a r}{m}$

5

뜬

嵌

㞻

是

씨

2

u

뜬

山

음

ว

욤으

$\geqslant 3$

닌

w?

饪起

안운

옹

늘

ธ응

똥

乐

므

Zu

단

40

$\infty$

$\omega$

옴 


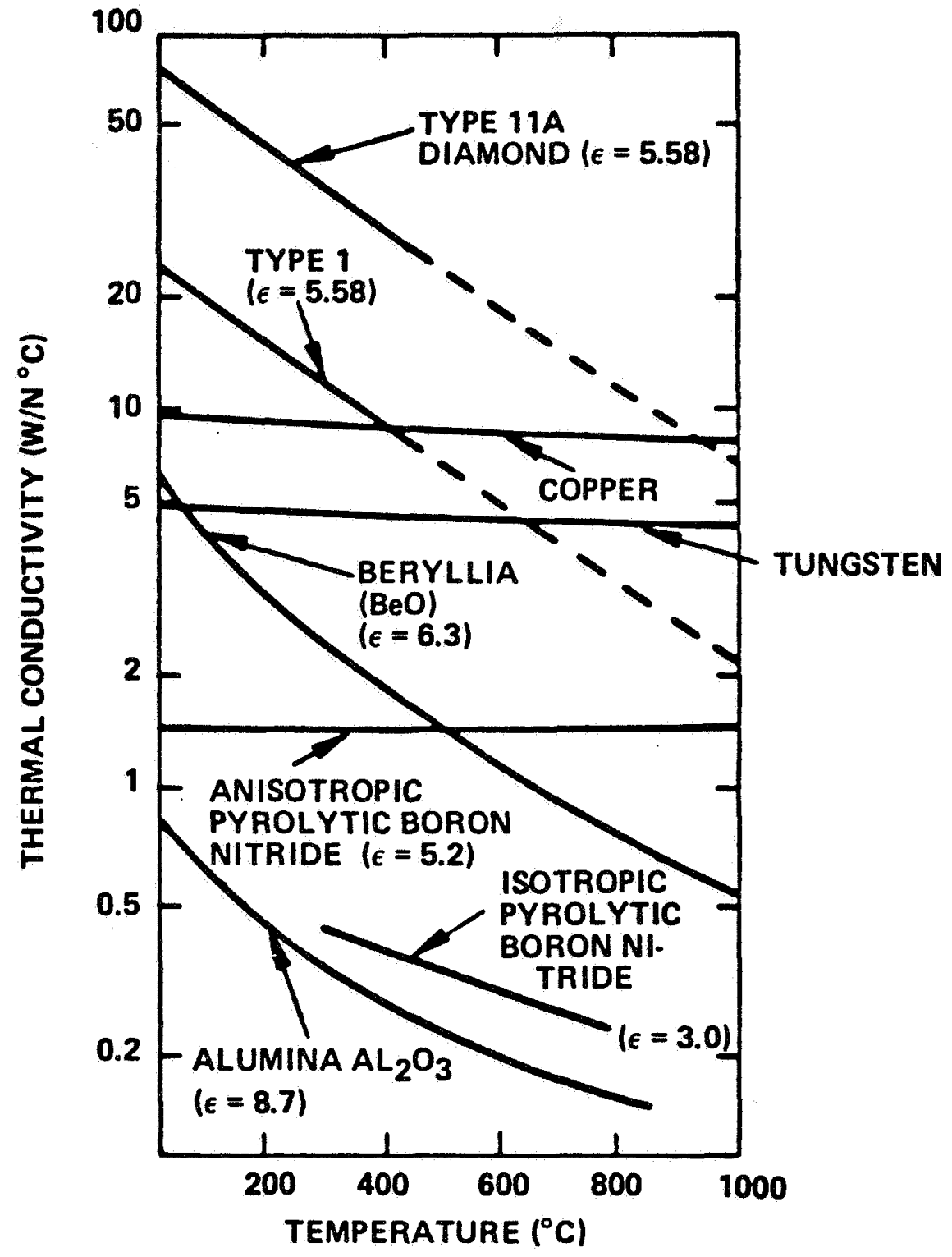

FIGURE 19. THERMAL CONDUCTIVITIES OF MATERIALS AS A FUNCTION OF TEMPERATURE 
to provide the necessary interface pressures. The braze result is shown in Figure 20. The procedure evolved through several stages with the final fixture design maintaining uniform pressure at the interfaces during the braze cycle. The fixtures are described in detail in Section 3.2.3.3.

\subsection{Diamond Cube/Ladder Braze}

Initial assumptions were that once the technology was developed to braze the diamond cubes to the waveguide ridge, it could be applied directly to the brazing of the diamond cubes to the Amzirc ladder rungs. This was not the case. Early tests showed that the pressure necessary to achieve the active diffusion braze flattened and widened the ladder rungs so that they extended beyond the mating face of the diamond cube. To eliminate the excess pressure, a gold-diffusion braze was substituted. First, a technique was developed to metalize the top face of each diamond cube with Amzirc and gold. The ladder rungs were then sintered to the metalized diamond cukes by a diffusion gold braze with a minimum of pressure. A circuit-half, consisting of a shaped ladder brazed to diamonds and waveguide block, is shown in Figure 21.

Another possible method of overcoming the problem of low contact pressure without distorting the circuit element is to make the circuit element out of dispersioned, strengthened copper. Such a material is Glidcop, a form of OFHC copper with $\mathrm{Al}_{2} \mathrm{O}_{3}$ powder dispersed through it. Actual parts were made from this material but experiments in brazing showed that the material dimensions changed during firing and brazing operations. Control of the changes was not immediately evident and further tests of the circuit elements were discontinued since the diffusion braze of the circuit element to the diamond metalized top was so successful.

The next step was to machine the waveguide-half blocks preparatory to brazing two of them into a complete TunneLadder assembly. The process involved the design and fabrication of three fixtures to protect and align the circuit halves during the machining operation. The end result was a machined half circuit section, ready to be brazed to its mate, and both ready to be brazed to the input/output waveguide transitions 


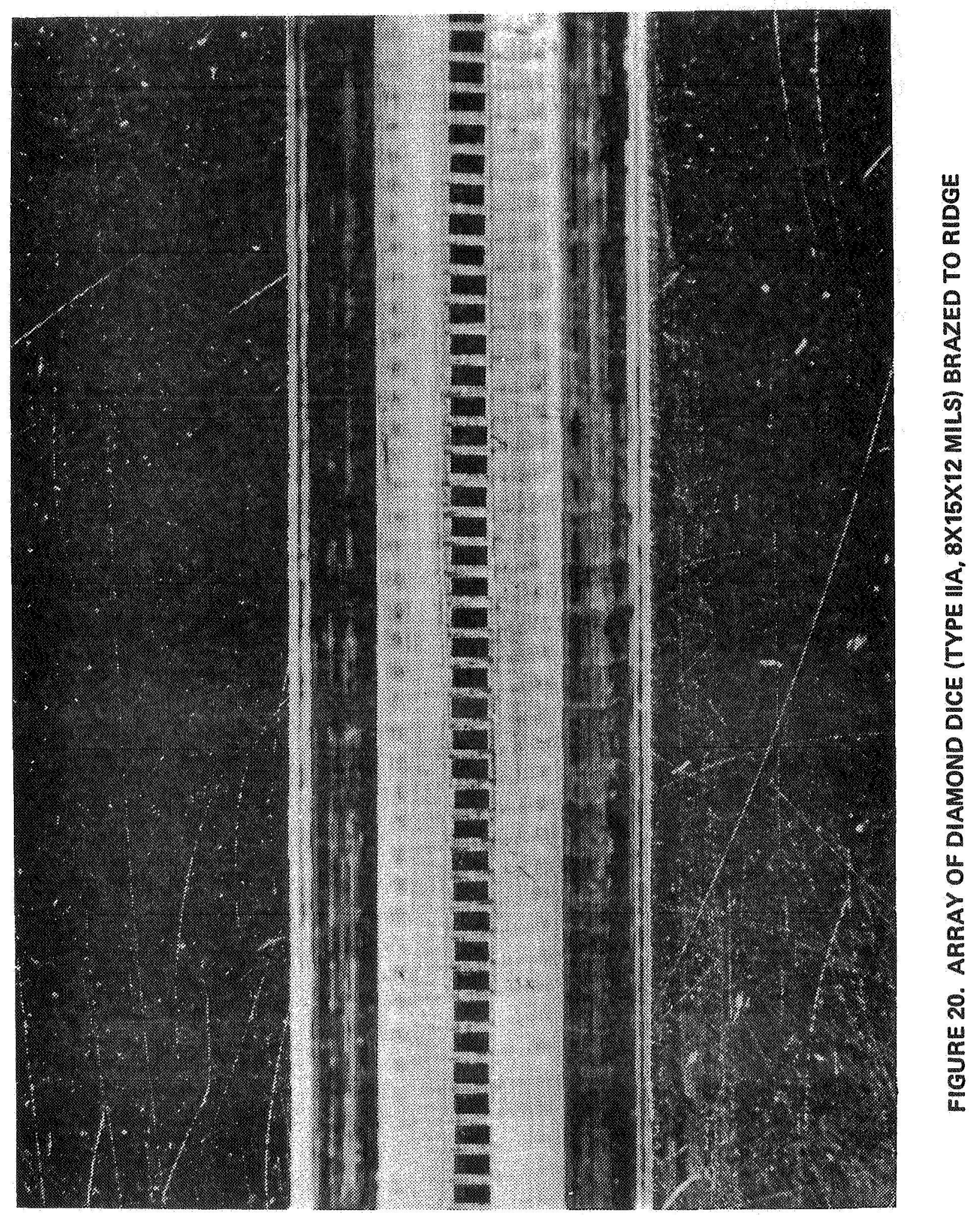

OREONIE PAGE WS

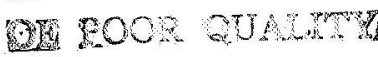




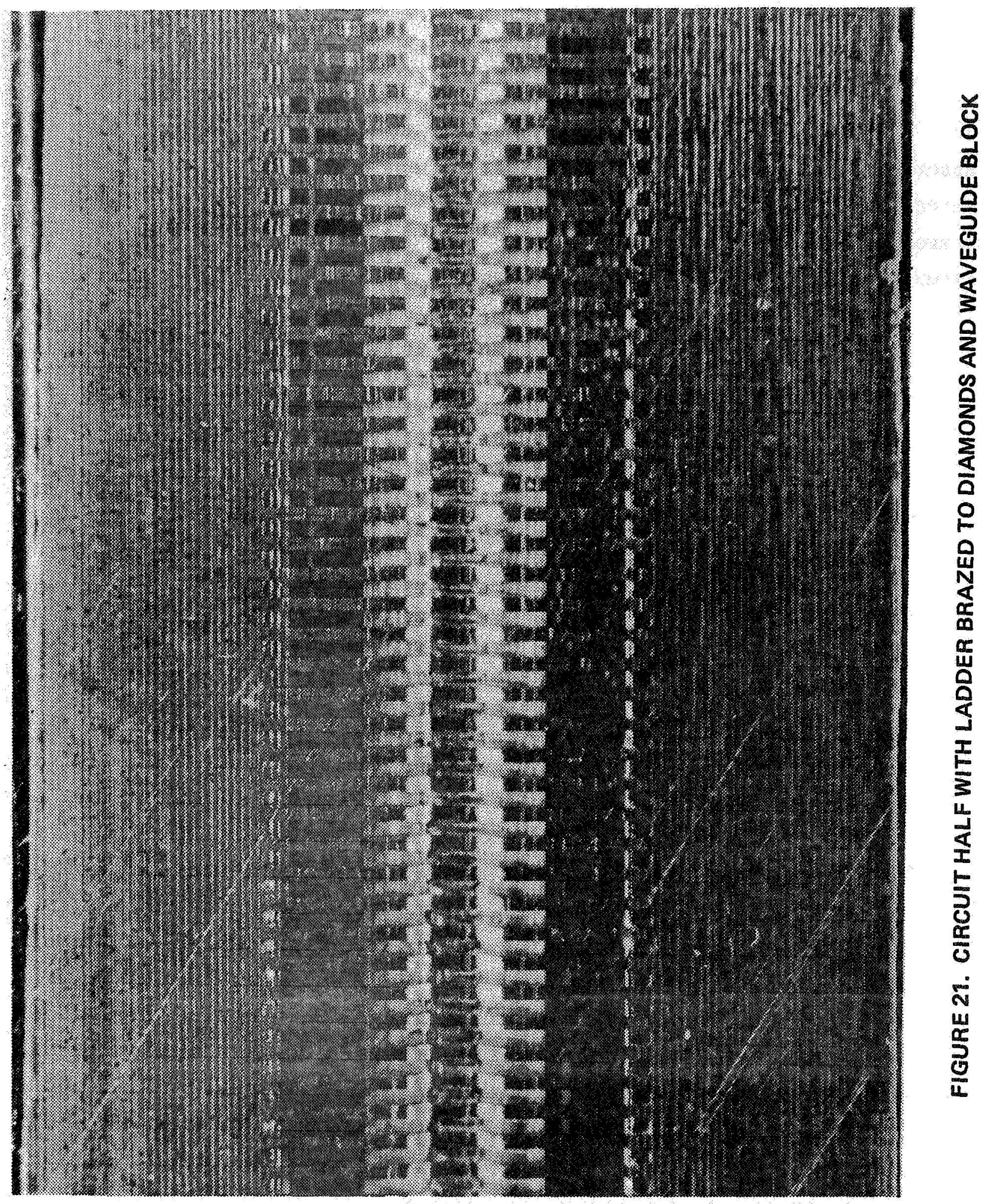


and the cooling-block subassemblies.

\subsubsection{Circuit Section Fabrication}

The detailed procedures and design of the fixtures to assemble the circuit halves is described in Section 3.2.3.3.1. The waveguide transitions and the technique used to braze them to the previously brazed Tunneladder circuit is described in Section 3.2.3.3.2. The final circuit assembly is described in Section 3.2 .3 .3 .3 .

\subsection{Brazing of Circuit Assemblies}

Brazing details for $r f$ circuit fabrication are shown in Figures 22 - 26. Figure 22 shows the brazing of an Amzirc shim to the waveguide block and the subsequent machining to produce the capped ridge. Figure 22 also shows the diamond-to-ridge braze. A detail inset shows the braze fixture, the chemically milled diamond cube spacer and an additional strip of Amzirc foil (to ensure sufficient zirconium atoms at the interface). These are heated in helium at $800^{\circ} \mathrm{C}$ in the special temperaturecompensated fixture. The last inset in Figure 22 shows the metalizing of the top of the diamond cubes. This is achieved with a gold-topped strip of Amzirc foil and speclal temperature-compensated fixture.

Figure 23 first shows the trimming and height-sizing operation required to prepare the diamond/ridge assembly for brazing to the ladder element. With the graphite fixture shown, the ladder-to-diamond braze is done also at $800^{\circ} \mathrm{C}$ in helium.

The special temperature-compensated brazing fixture is shown in Figure 24. It uses molybdenum and stainless steel parts which produce a positive pressure on the braze joint during the temperature rise and resultant expansion difference. The fixture has been highly successful; ten assemblies were brazed without any rejects due to loose diamonds (42 diamonds per braze) or weak ladder-rung brazes.

Figure 25 details the procedure for brazing diamond 


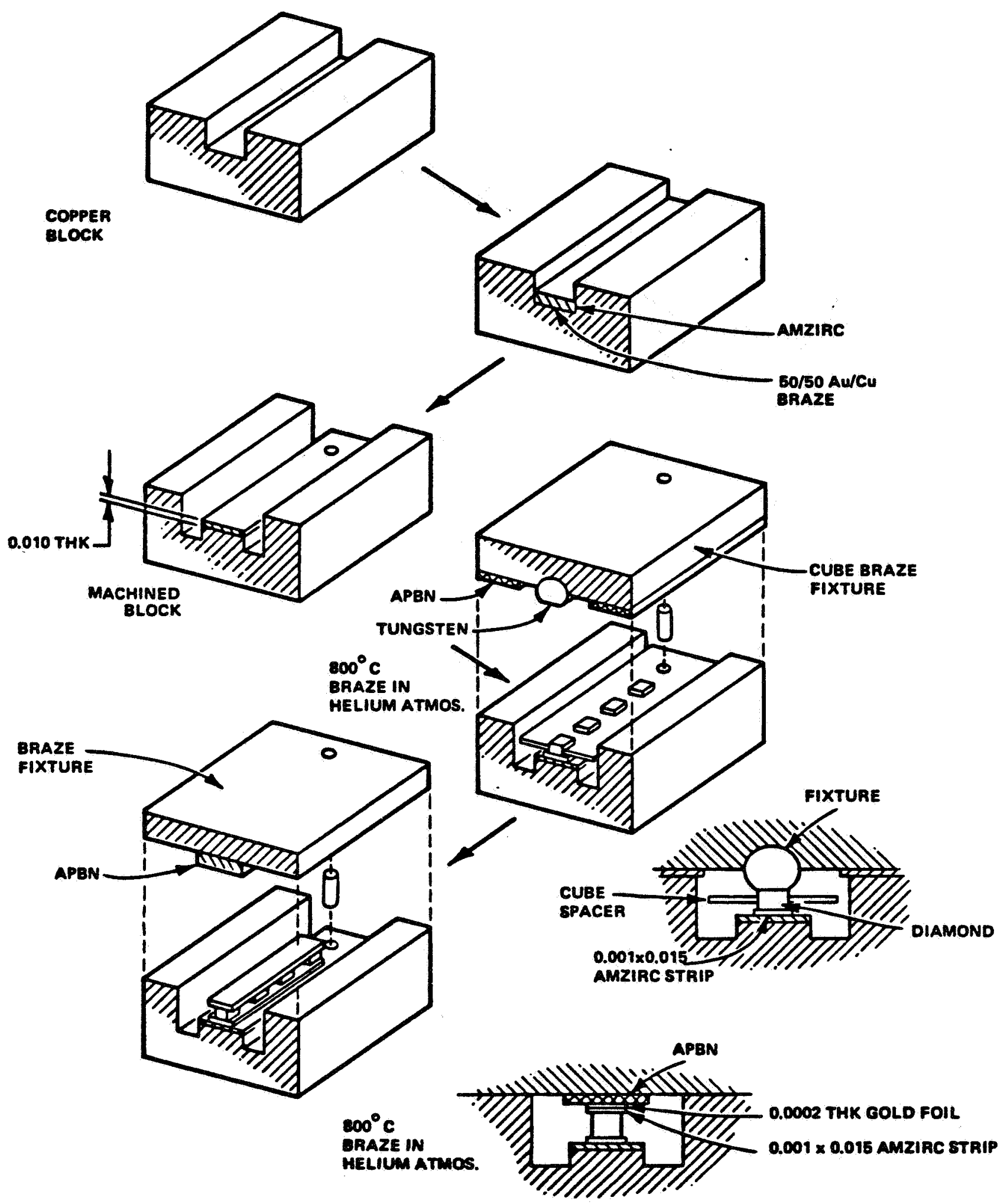

FIGURE 22. ASSEMBLY PROCEDURE THROUGH METALIZATION OF DIAMOND CUBES 


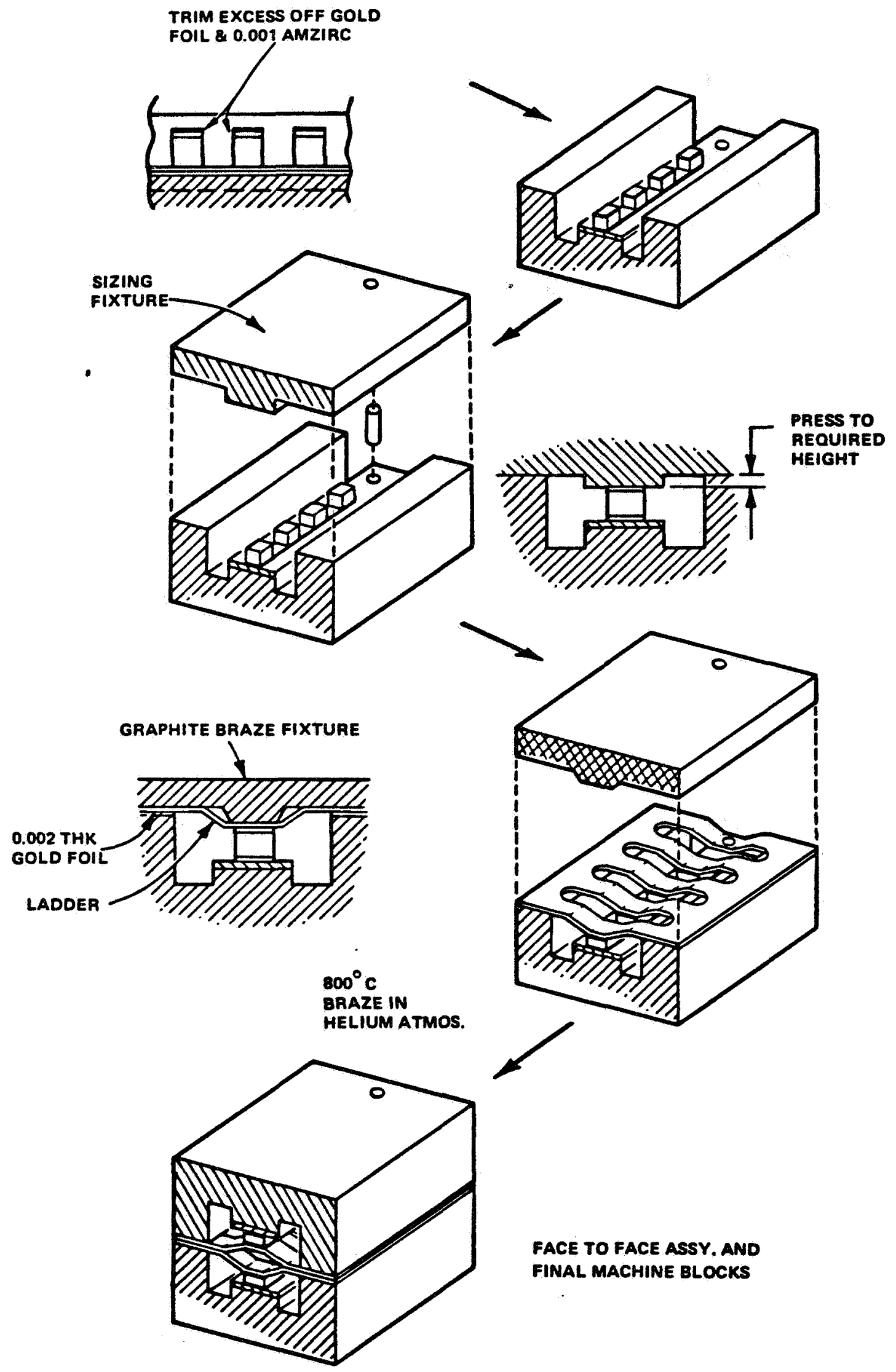

FIGURE 23. ASSEMBLY PROCEDURE THROUGH MATING OF THE TWO FINALMACHINED HALVES. 


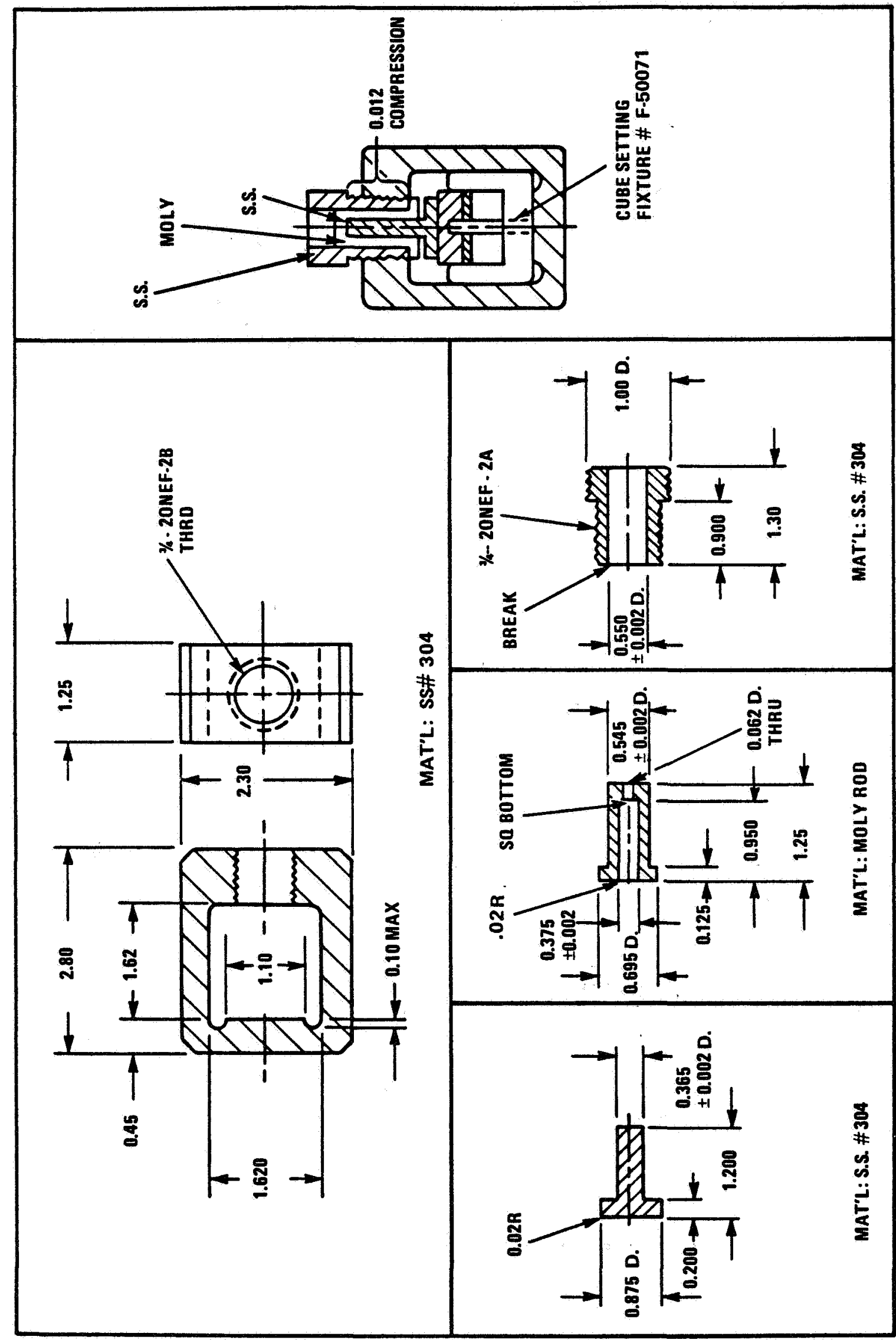

우융용

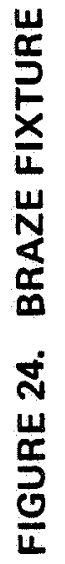




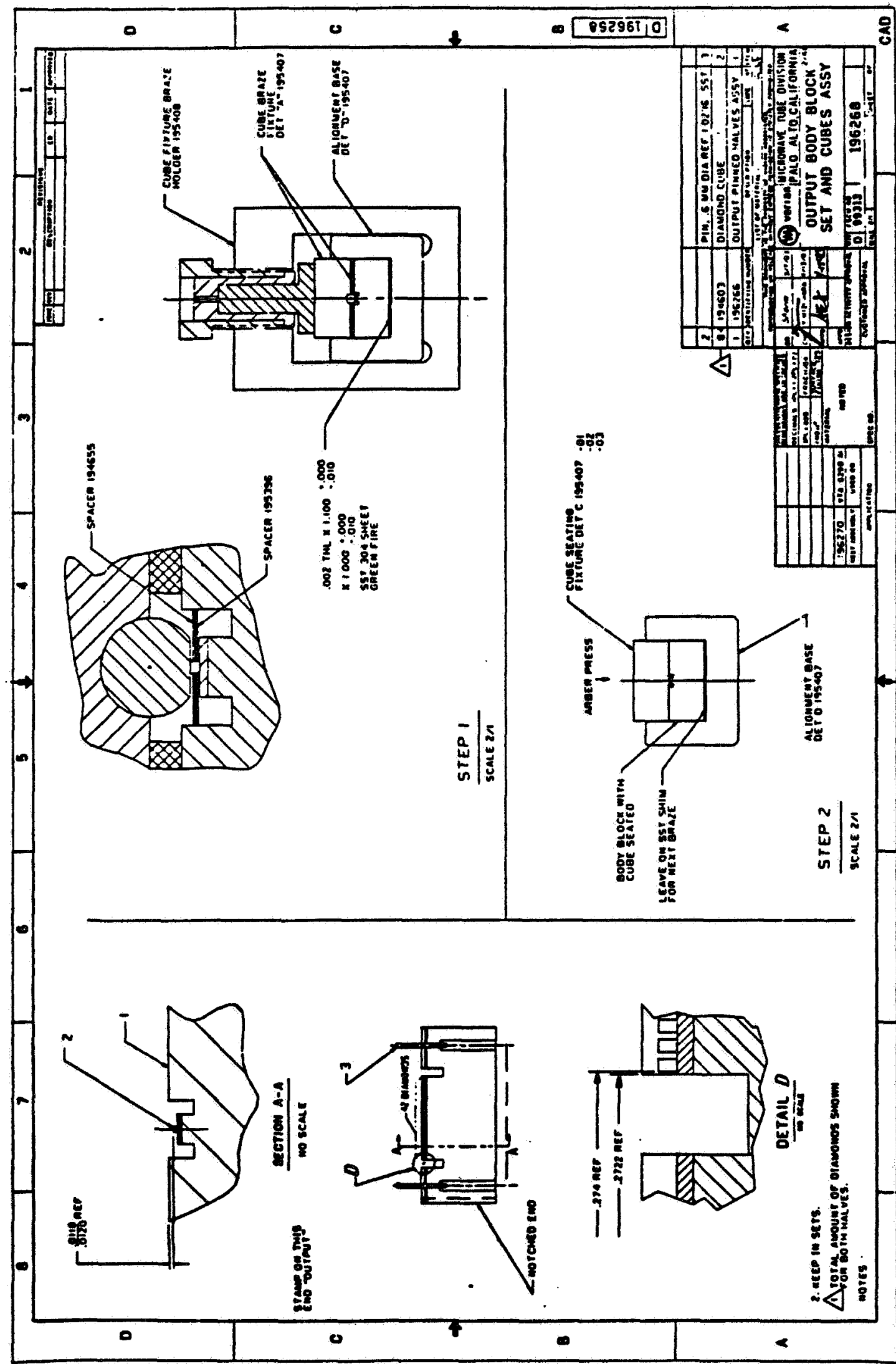

흄유

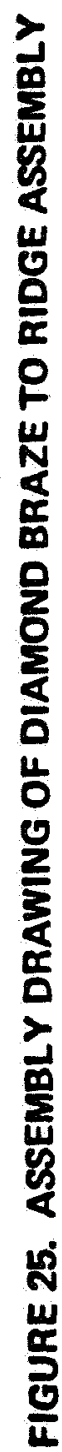


cubes to the ridge block. The machined ridge block, the spacer and the fixtures are all desiged to provide the necessary alignment and pressure.

Figure 26 outlines the procedure for brazing the ladder element to the diamonds as well as the ridge block. Shown are the details of the ladder element, the ridged block and the fixtures necessary for brazing at $800^{\circ} \mathrm{C}$ in helium.

It should be noted that the diamonds have now undergone three braze cycles at $800^{\circ} \mathrm{C}$ in helium. No loose diamond brazes were encountered in any of the assemblies, at least 10 of which were made. The brazed ladder-ridge block assembly must next be machined. The procedure and machining fixtures evolved over a period of three to six months. The blocks had to be machined so that two of them would match up, rung to rung, over the total length of the circuit. The coolant lines and part of the waveguide had to be machined to accommodate the circuit transition. The fixtures not only helped in precisely machining the circuit halves but also protected the delicate ladder structures from damage during the process.

In summary, the circuit fabrication experiments led to the following observations and conclusions concerning copper/diamond bonds:

1. An active metal must be present; the zirconium content of Amzirc provides this.

2. The brazing atmosphere must be totally contaminant-free, lest very weak bonds result. Helium is used as it has fewer contaminants than are typically encountered in "vacuum brazing".

3. The brazing temperature must be as low as possible to further minimize contamination risk; $800^{\circ} \mathrm{C}$ was selected.

4. All fixtures must be designed to avoid creating 


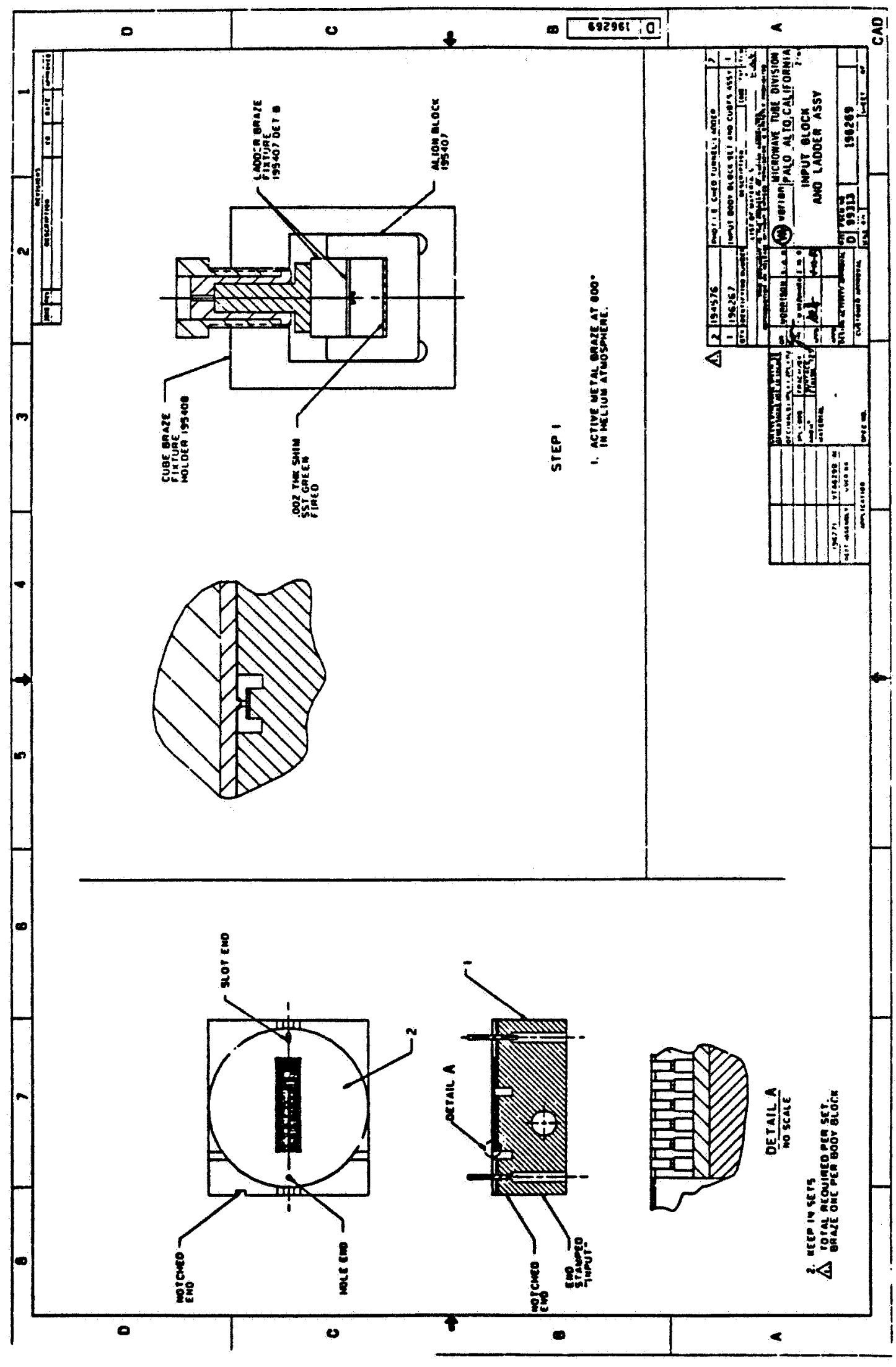

윰유

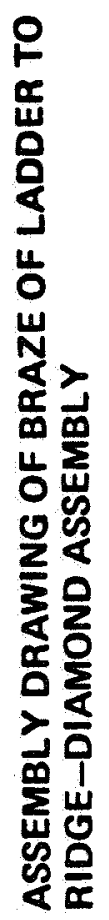

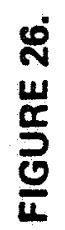


shear forces in the copper/diamond interface plane which would provoke bond failure. Chemically milled copper fixtures are therefore used for spacing, and Type 304 stainless steel fixtures (expansion coefficient same as for copper to within 1\%) for applying pressure to the diamond dice. (Although tungsten, with its ability to resist deformation under pressure, might be preferable, its thermal expansion coefficient is only about $24 \%$ that of copper, whereby the contraction difference on cooldown could break the diamond/copper bonds.)

5. Rung/diamond bonding must not cause ladder rung distortion. Given the small rung cross section the pressure needed for true active metal bonding would indeed result in distortion. The technique is therefore supplemented by gold-diffusion bonding, which is also used to attach the ladder-rung ends to the enclosing cavity.

\subsection{Waveguide Design and Brazing Technique to Join the Circuit Halves}

The next operation is the brazing of the two Tunneladder circuit halves with the waveguide transition subassemblies. For this, there was another temperature-compensated fixture, complicated by the number of subassemblies in the ensemble, but yet like a "four port" version of the previous simpler fixtures.

The input/output waveguide subassemblies each have a length of waveguide tapering from normal height to reduced height. The inductive iris and capacitive post, placed at the point of transition to the circuit, have the beam axis as the axis about which they are symmetrical. Two waveguide units get brazed to two machined Tunneladder-half blocks (which have been aligned rung to rung). The brazing is by gold diffusion in hellum at $800^{\circ} \mathrm{C}$, the fourth such firing. Again, no assembly was lost during 
this operation, for a total of four such assemblies in two tubes.

\subsection{Circuit Final Assembly Without Window Subassembly}

The final step in TWT-section assembly is the brazing of the coolant-manifold subassembly and the heliarc-baffle subassembly. This is done after matching feed waveguides to the circuit section through adjustment of the capacitive post and reduced-height waveguide short. The baffle assembly includes the heliarc flange which is heliarc-welded to the body shroud, thereby providing the vacuum seal and allowing stacking and alignment of the various tube subassemblies shown in Figure 27. These include the coolant-manifold, baffle, waveguide and circuit-block subassemblies.

\subsubsection{Tube Assembly Design}

Figure 28 shows the complete tube obtained after aligning and assembling the constituent units. In addition to the gun, input and output TWT sections and collector unit, the complete tube includes the body shroud assembly having: A beam-shaver subassembly, which protects the $r f$ input section; the vacuum window assemblies, which are brazed to the feed waveguides; the interaction-structure alignment ring; and the tail-pipe assembly, which allows expansion of the beam exiting the output section, without interception in the drift region, prior to collection. The indicated subassemblies are shown in Figure 29.

It is important to note that each circuit section is coupled at one end to either an "Input" or "output" waveguide, with a "sever" waveguide at the other end. The sever-waveguide ports enabled measurement of the insertion loss of each section and of the $\mathrm{rf}$ power delivered to both sever loads. VSWR data for the "double-ended" input and output section matches are shown in Figures 30 and 31 for $S / N$ 101. VSWR data for S/N 102 were essentially the same, if not slightly better. These data show that over the 


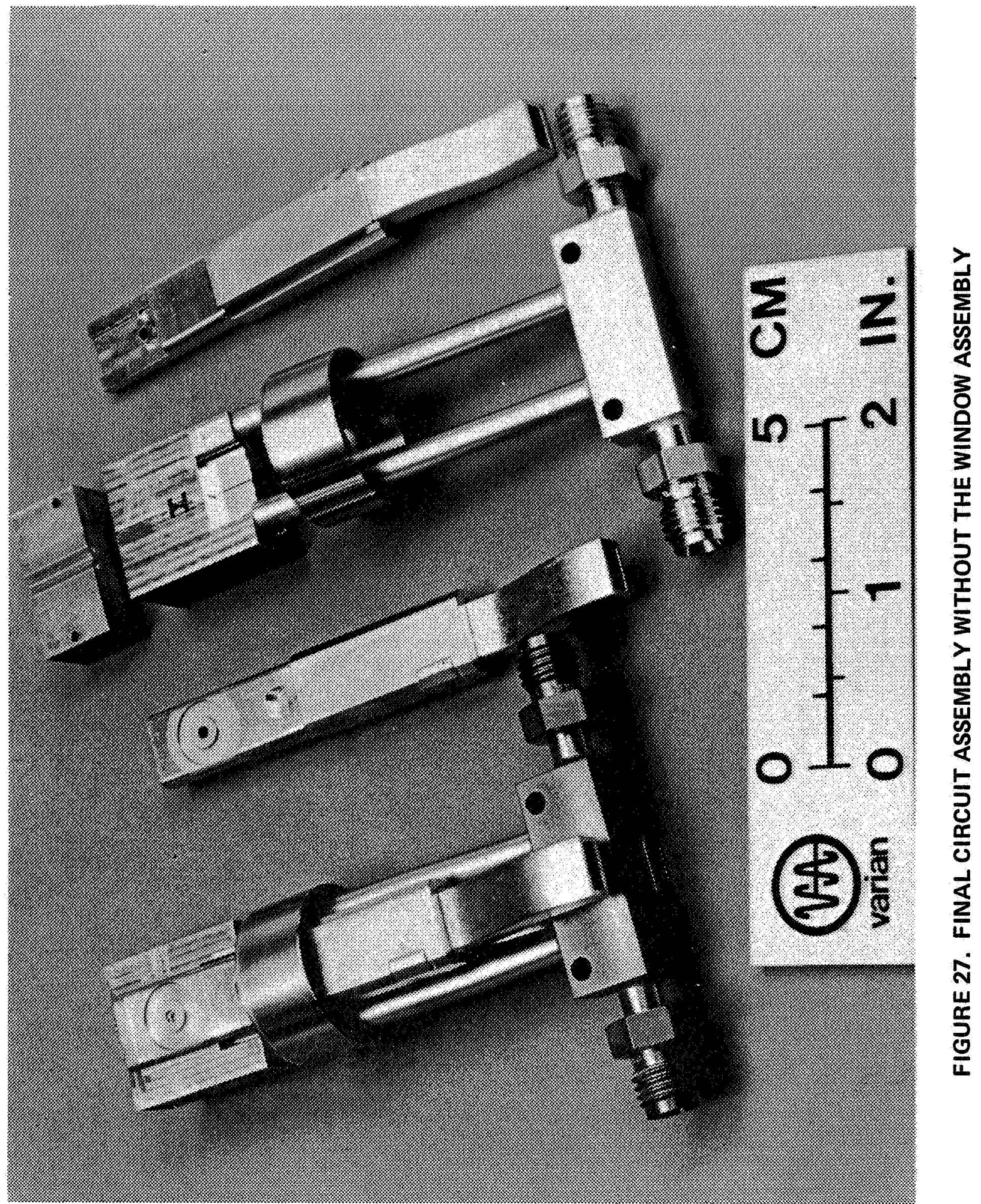

-

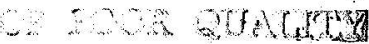




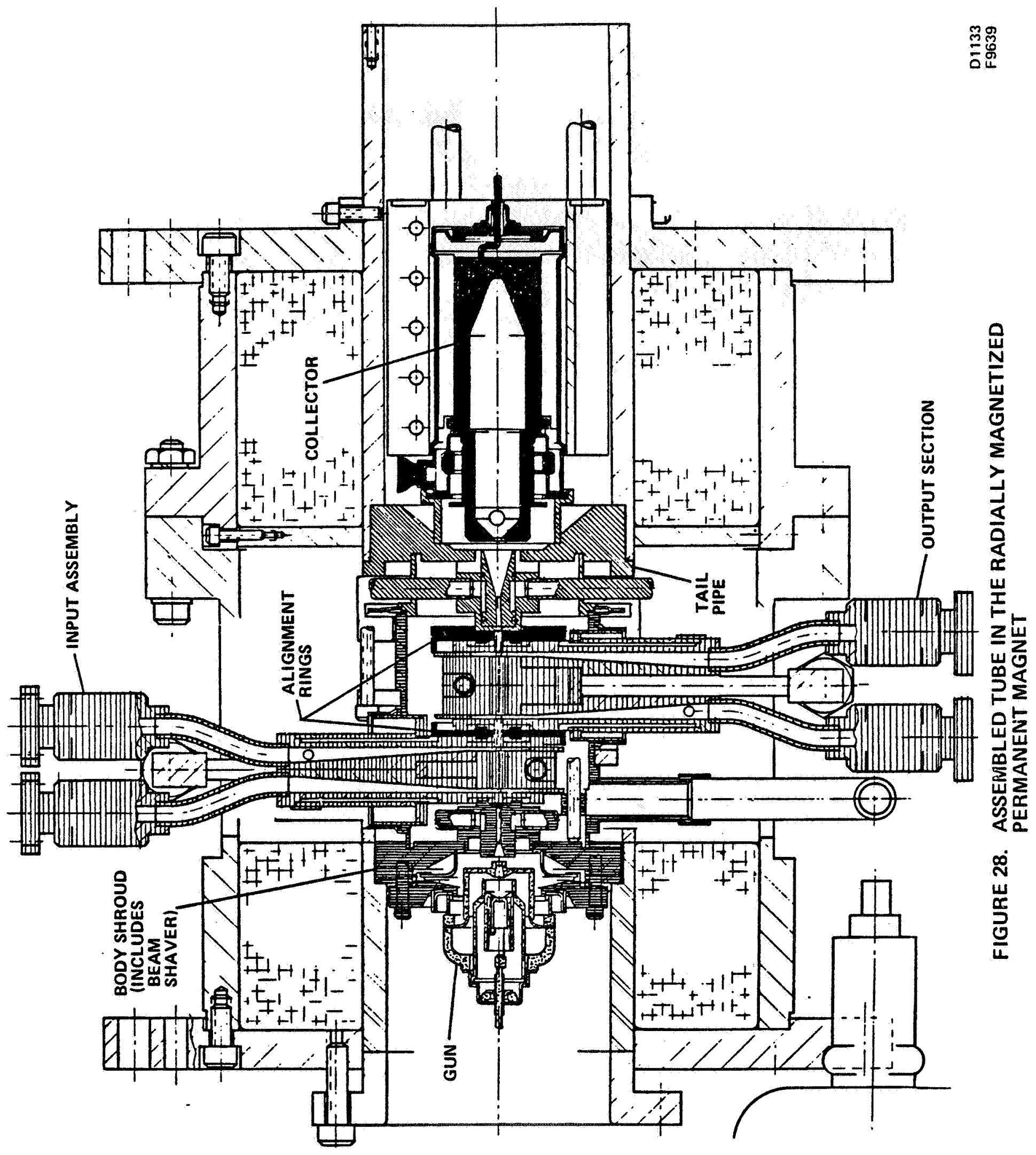


ORIGNAE PAGE IS

OF POOR QUALITY

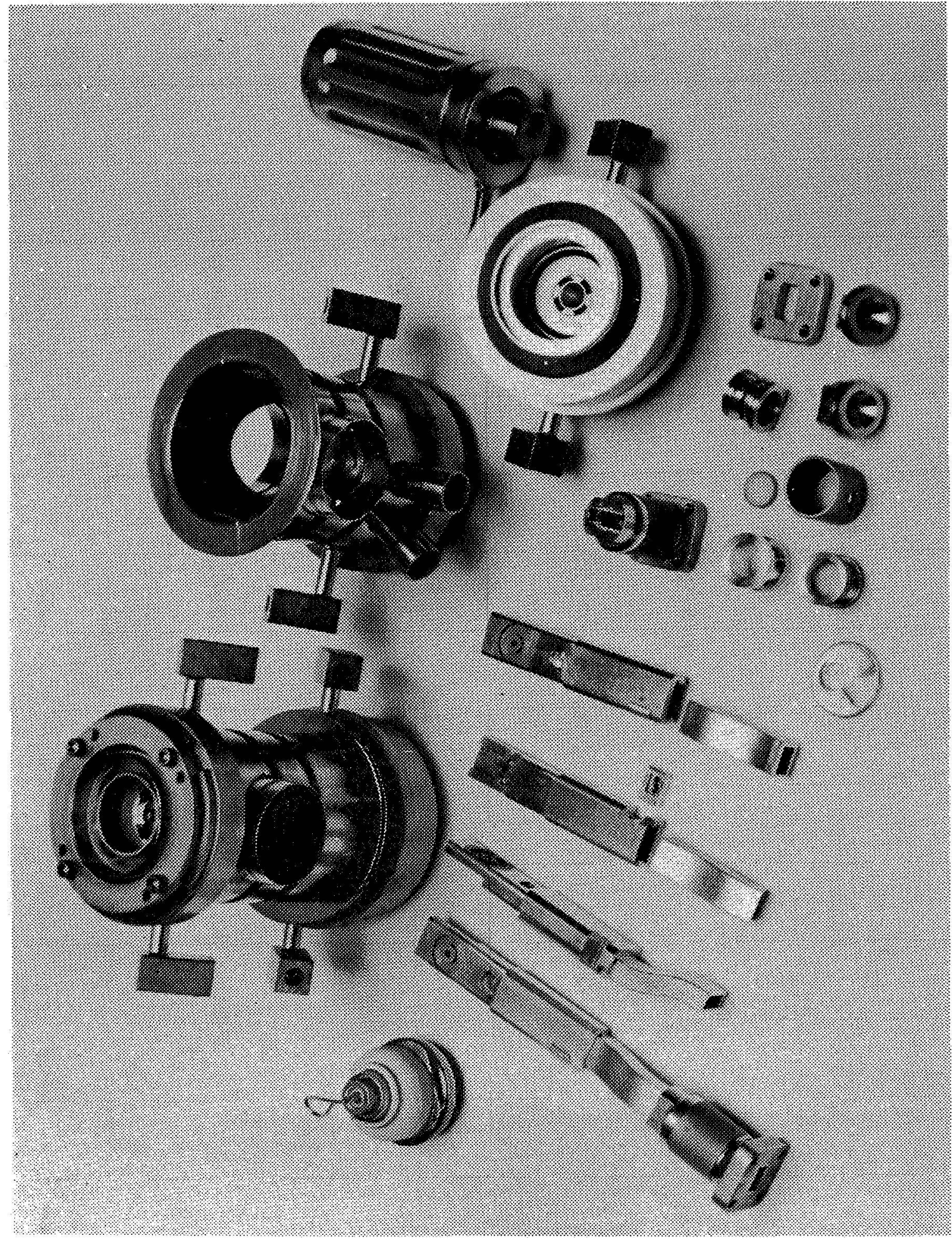

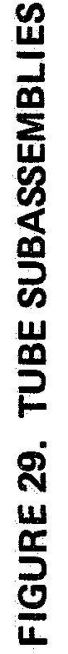




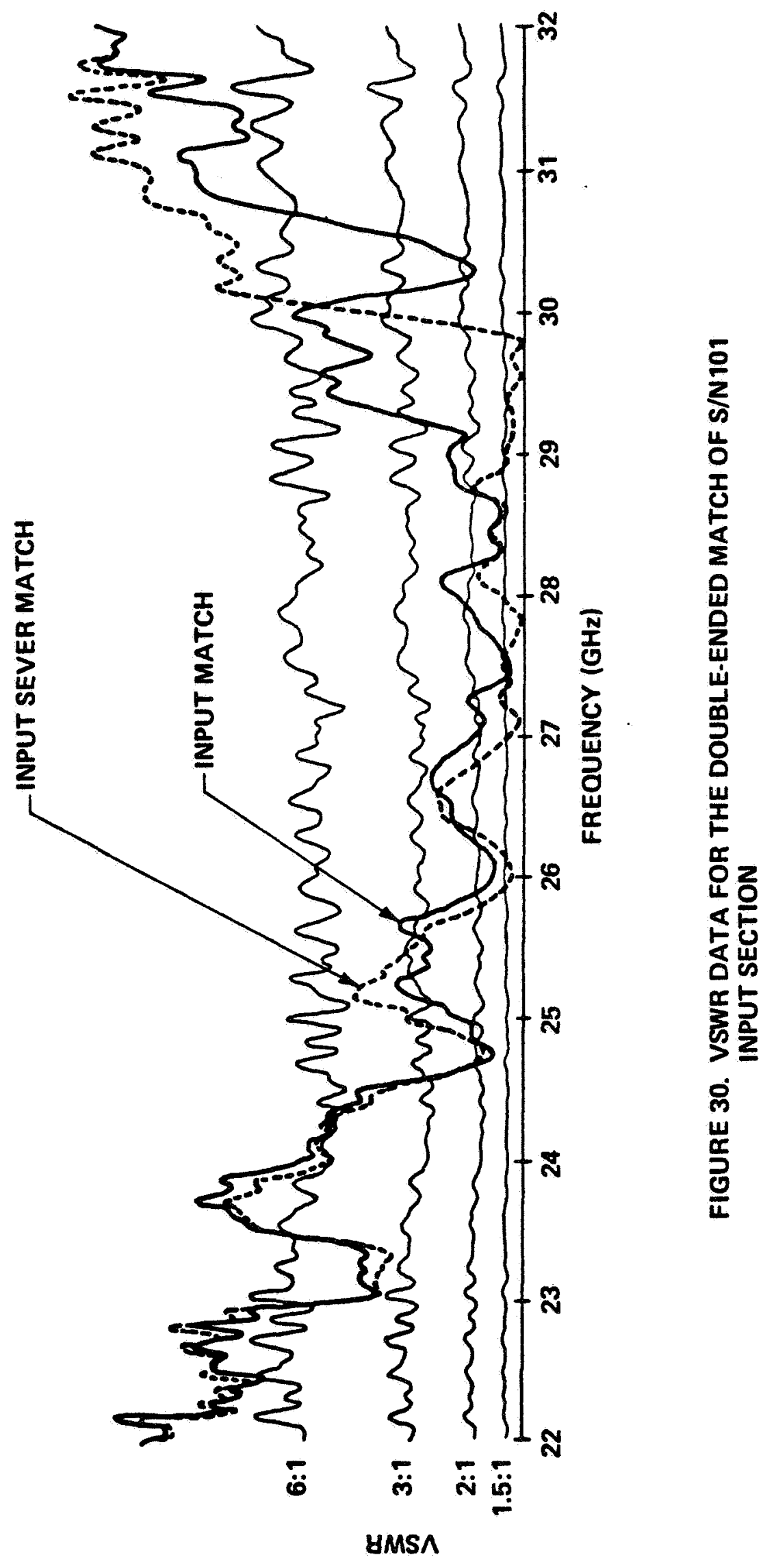

흥유 


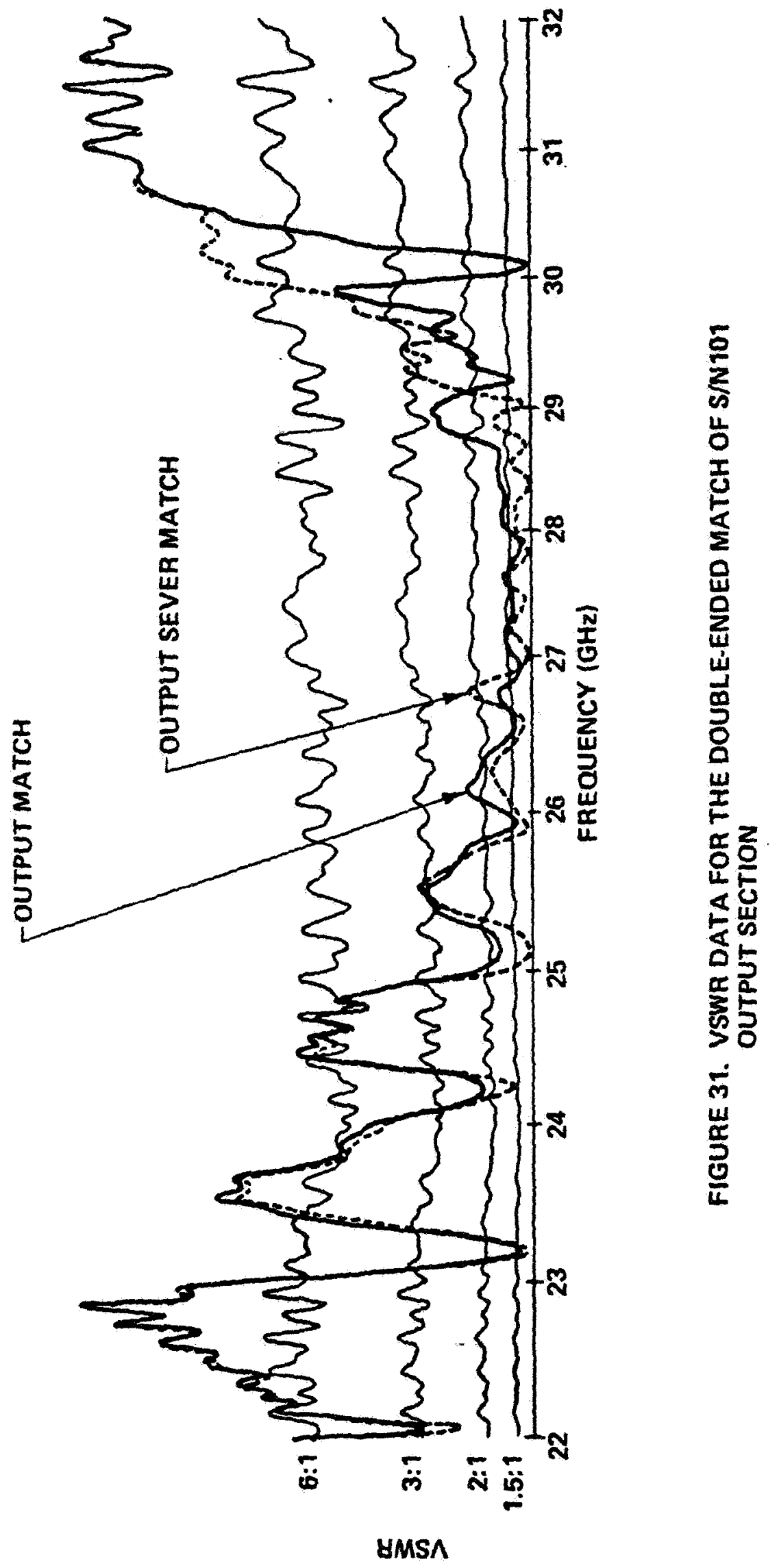


operating band the match VSWR was better than 2:1 for the output section and nearly as good for the input section.

Insertion losses measured through each section are shown in Figures 32 and 33 . The loss levels for each section are higher than expected, partly as a result of the extra brazing cycles experimentally inflicted on this initial tube (which promoted decrease of copper conductivity through absorption of gold), and also because the resistance of interfaces was neglected in the original projections. The adverse contribution of $\mathrm{S} / \mathrm{N} 101$ 's extra brazing cycles appears to be substantiated in the observation of 1 to $2 \mathrm{~dB}$ less insertion loss in each section of $\mathrm{S} / \mathrm{N} 102$ before exhaust.

The completed Tunneladder TWT, ready for exhaust, is shown in Figure 34. Improvements in the assembly procedure and mechanical design permitted faster assembly and greater vacuum integrity for $S / N 102$. The changes were made to the tube shroud assembly and the input and output sections. The changes to the tube section's assembly and subassemblies procedure allowed the brazing of the circuit halves, the waveguide assembly and the coolant subassembly to be achieved in one braze cycle. The mechanical changes to the shroud assembly improved the vacuum integrity. The first tuke ( $S / N$ 101) had a small apparent leak which degraded the vacuum enough to disallow CW operation; a "virtual leak" is suspected since treatment with GEVAC was ineffectual. The second tube (S/N 102) was free of such problems; it was operated $\mathrm{CW}$ for both dc and $\mathrm{rf}$ power.

\subsection{EXPERIMENTAL DATA}

As required, two tubes were completed and tested under the present program. Their performance with respect to instantaneous "hot" bandwidth was better than predicted, while it was close to the computer predictions with respect to power, gain and efficiency. The performances of $S / N 101$ and $S / N 102$ are discussed in detail in Sections 3.3 .1 and 3.3 .2 , respectively. 


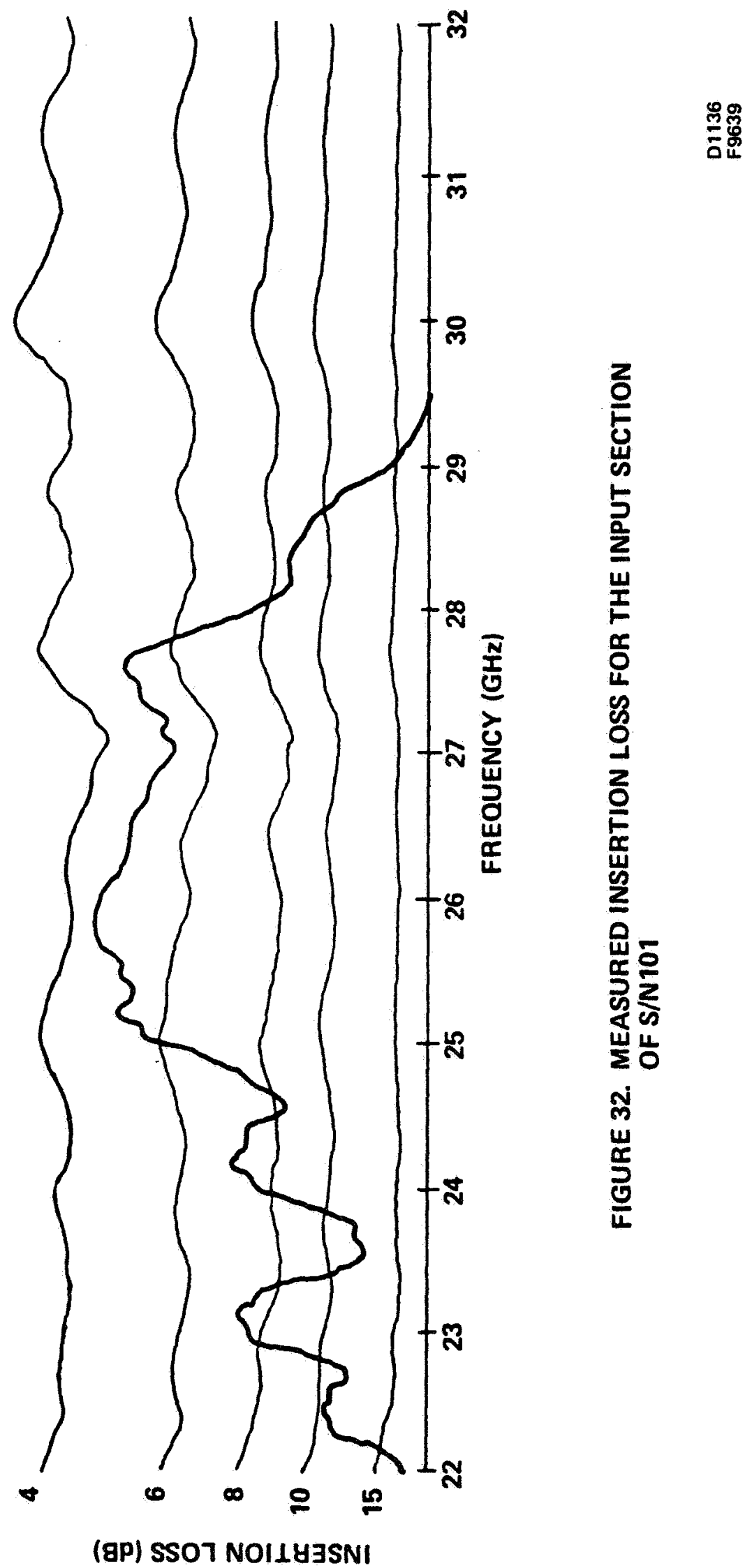




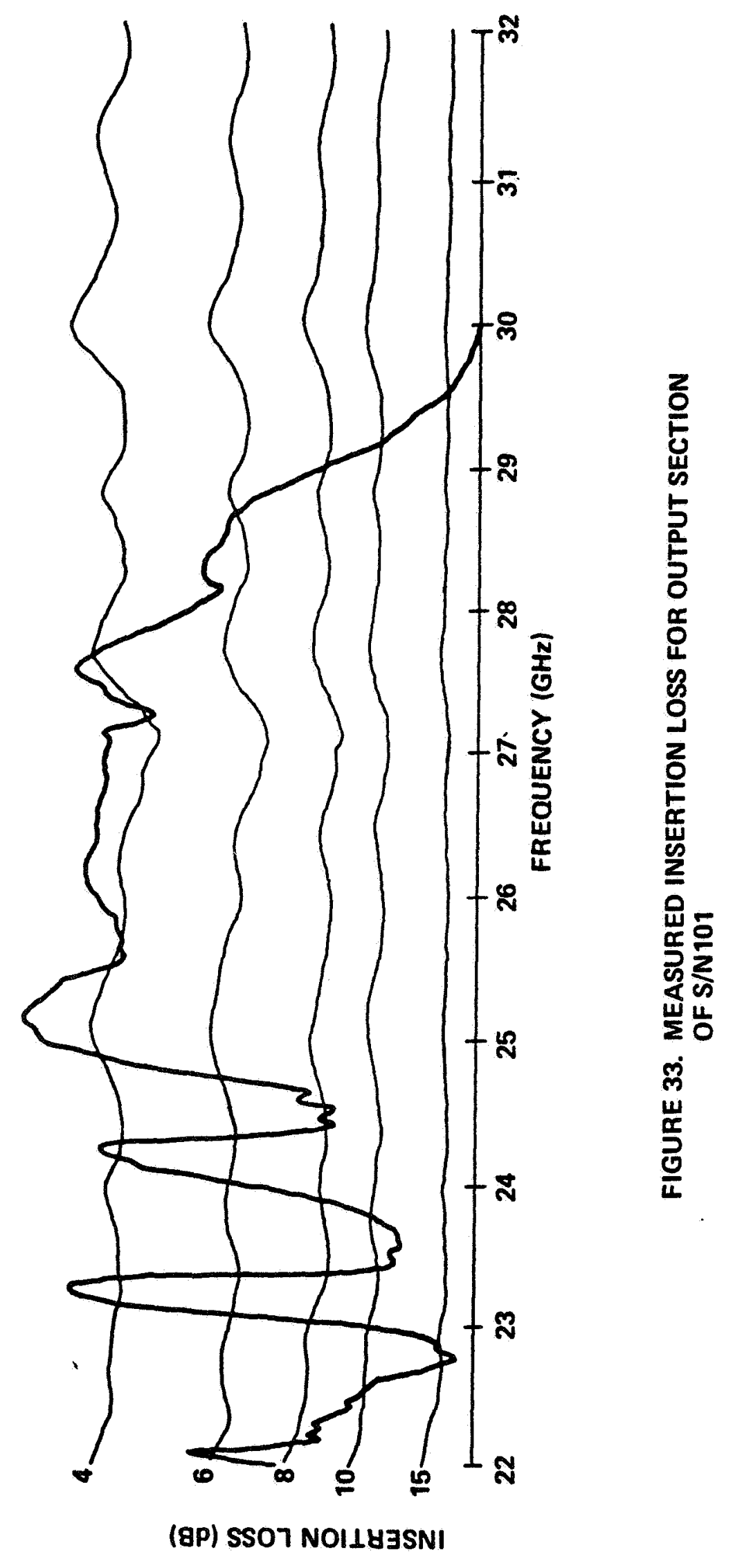

象骂 
ORIGINAE PAGE IS
OE POOR QUALITY

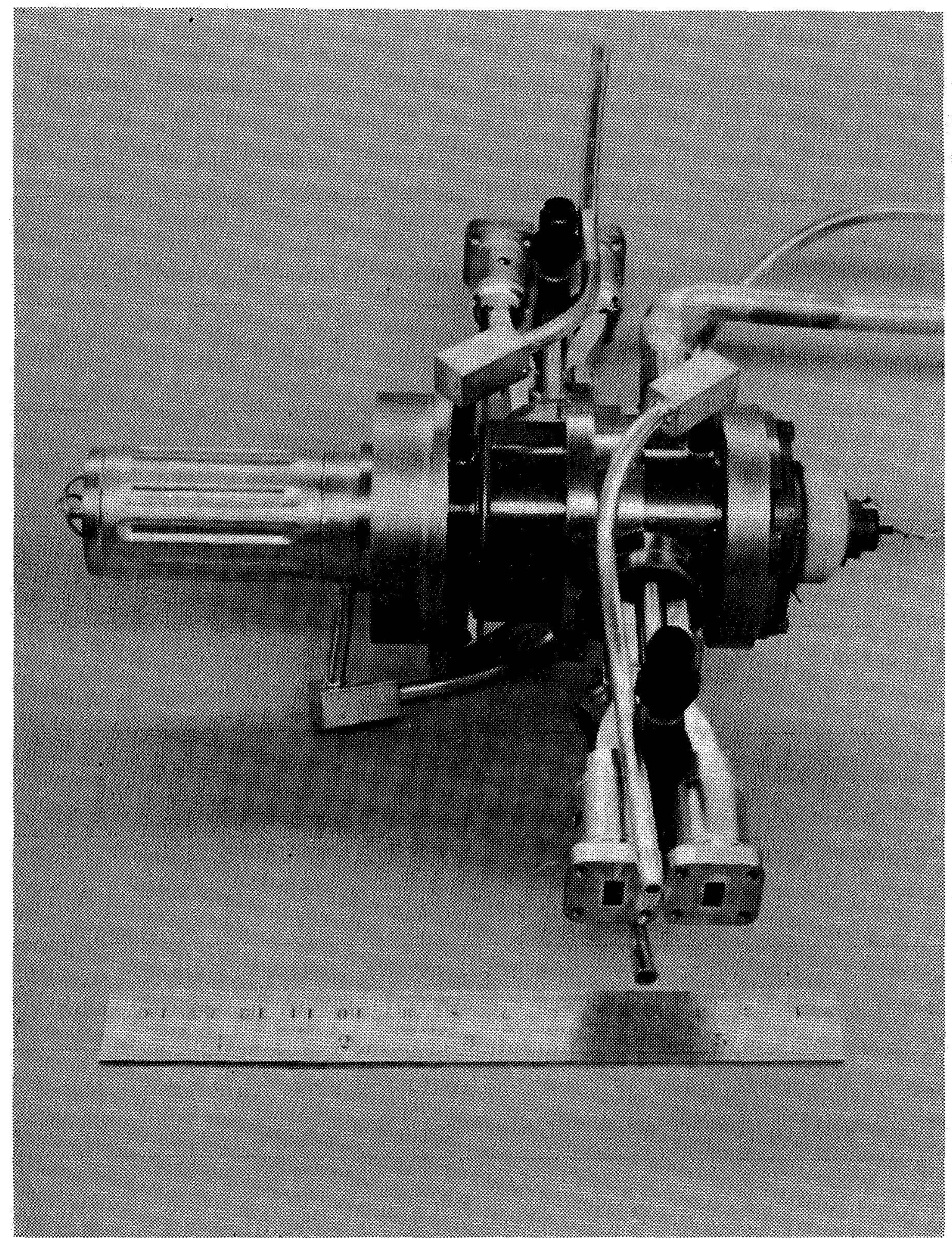

FIGURE 34. COMPLETED TUBE READY FOR EXHAUST 


\subsubsection{Performance Data for $S / N 101$}

This tube was tested extensively under pulsed power, with

results as shown below. Efforts to operate $C W$ were unsuccesssful because of changes in body current with duty cycle due to the gas pressure. During bakeout an unrepairable leak had developed in one of the heliarc welds which functioned in the manner of a virtual leak during the "duty run." Body current increased with duty factor until further increase became impossible. The obtaining of $\mathrm{CW}$ performance data had to await the completion of $\mathrm{S} / \mathrm{N} 102$. Figure 35 shows $S / N 101$ in the test station.

\subsubsection{Focusing Data}

The initial focusing was $60 \%$ and was increased to $96 \%$ by moving the gun assembly $0.040^{n}$ towards the magnet pole piece. If the gun could have been moved even closer to the magnet polepiece, further improvement might have been possible. These results (along with those of the beamstick) indicate that to improve focusing beyond that achieved on this program will require a study of the gun-magnet design. It is recommended that in future work the gun-magnet pole piece design be studied to optimize the transmission. Figure 36 shows the measured beam transmission which was later improved to $98 \%$, minimum, by some shunting of the magnetic field around the gun. The curve indicates certain low-power instabilities in the output circuit which have no bearing on normal performance since they occur only at beam voltages well below the $10 \mathrm{kV}$ at which the tuke is normally operated. The data of Figure 37, showing the frequencies of the observed tunable oscillations, indicate a phaseshift-sensitive oscillation traceable to circuit mismatch. For each voltage there is a frequency such that the gain and phase shift reinforce the circuit wave. Oscillation of this type could not occur in later models having better and broader-band end matches.

\subsubsection{Power Output versus Frequency}

Test data on power output versus frequency for various input drive powers are shown in Figure 38 and indicate the tube's hot 


\section{ORIGINAT PAGE IS
OF POOR QUALITY}

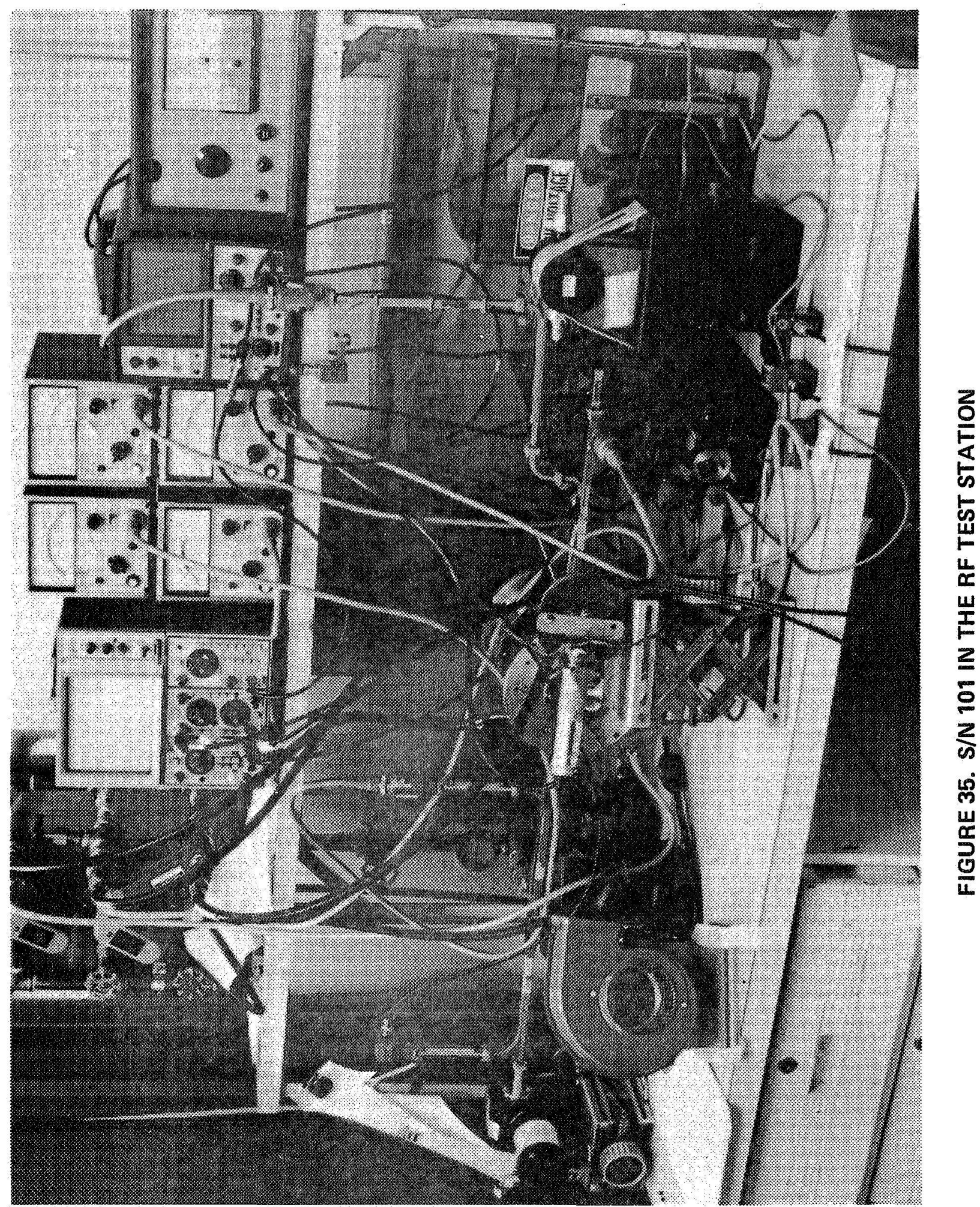




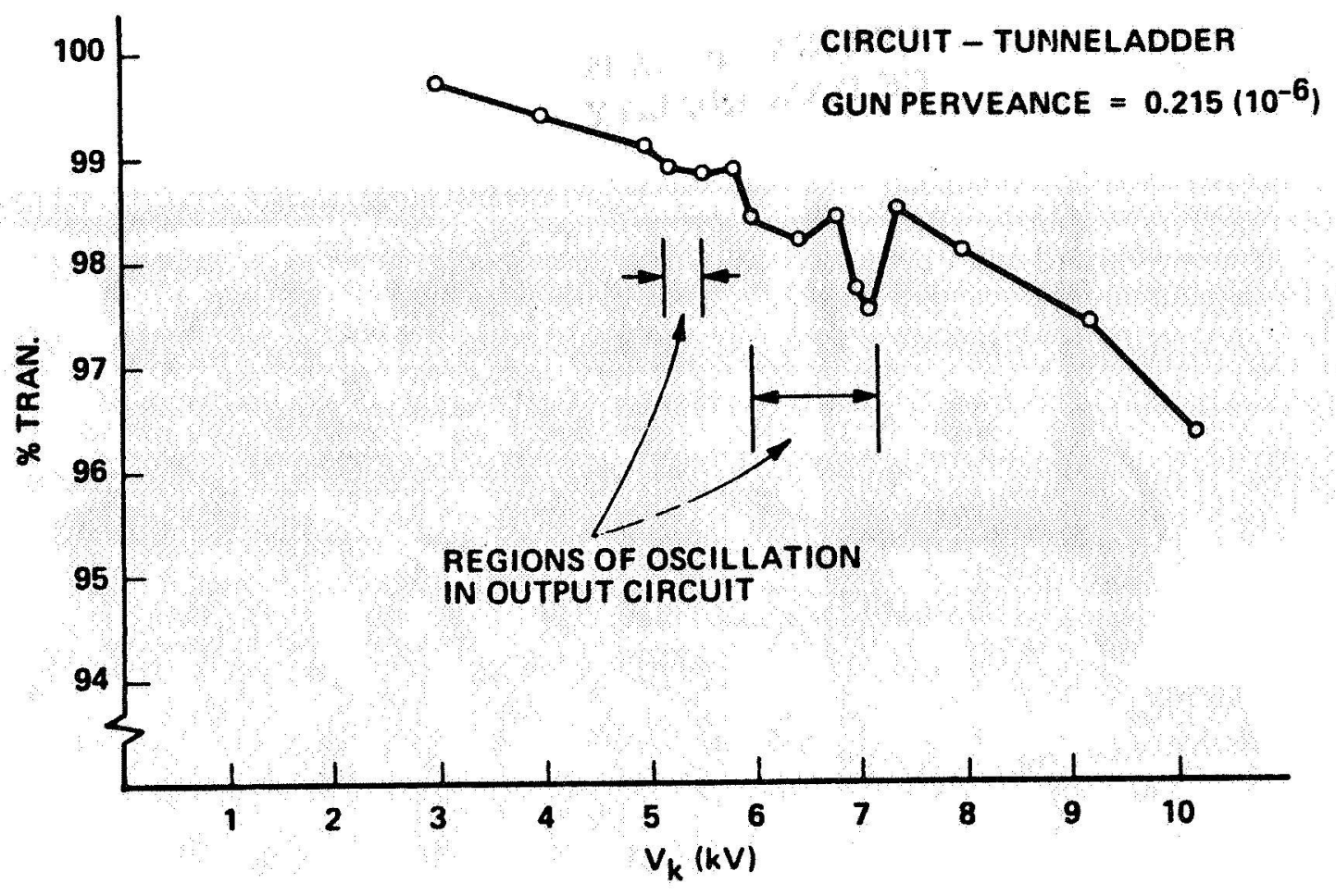

FIGURE 36. BEAM TRANSMISSION FOR S/N101

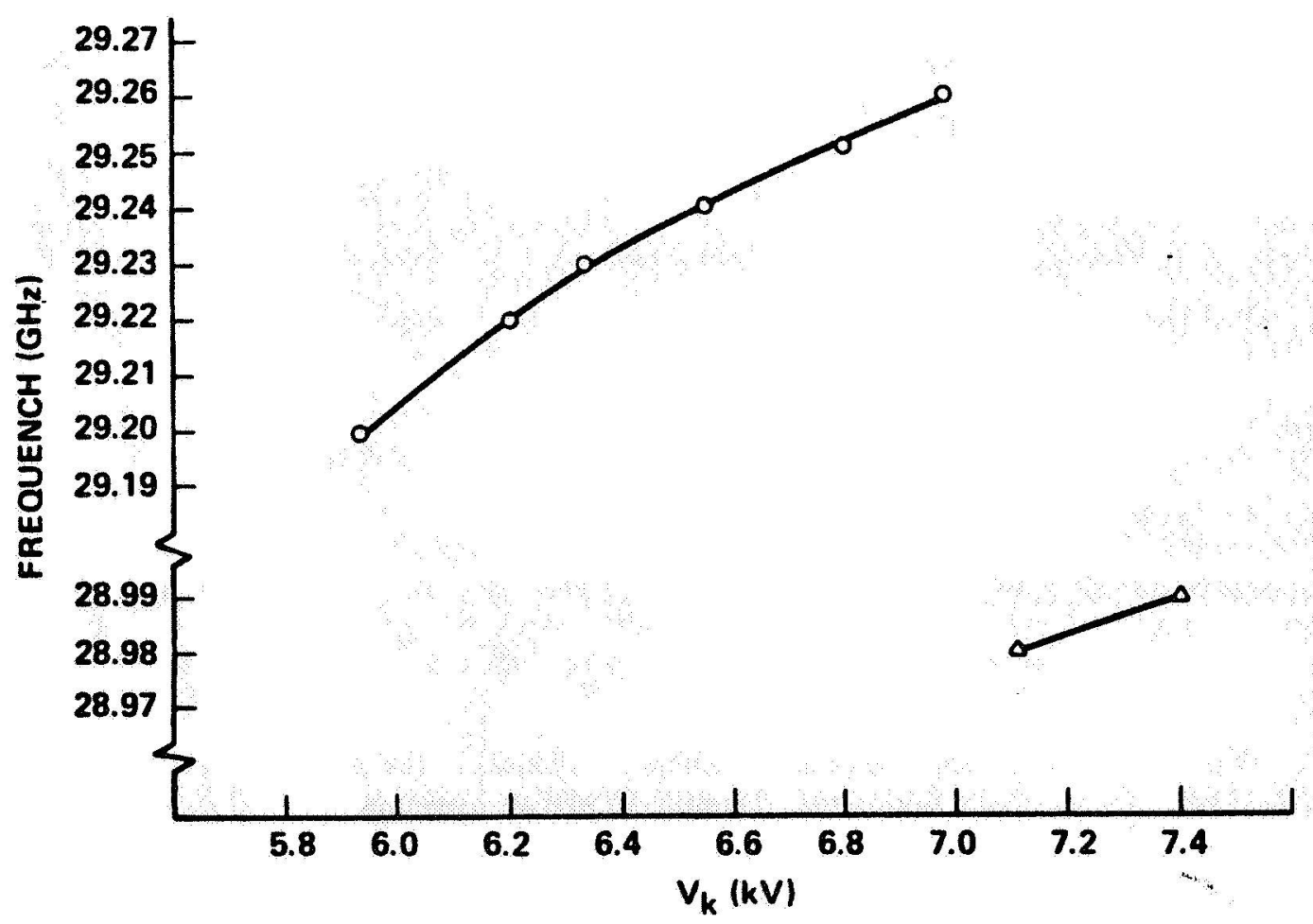
LOWER VOLTAGES 


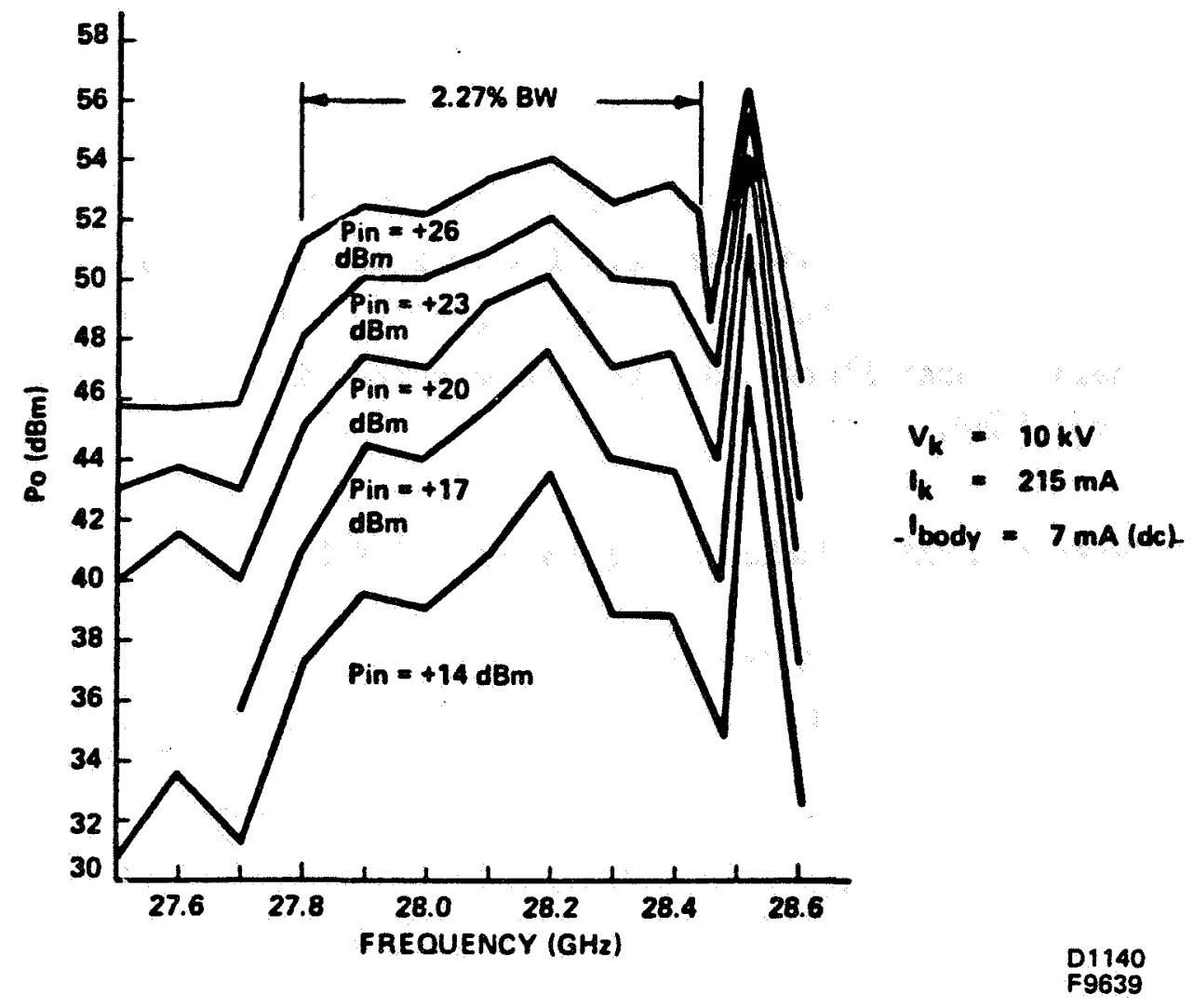

FIGURE 38. POWER OUTPUT VS FREQUENCY FOR DIFFERENT INPUT DRIVES

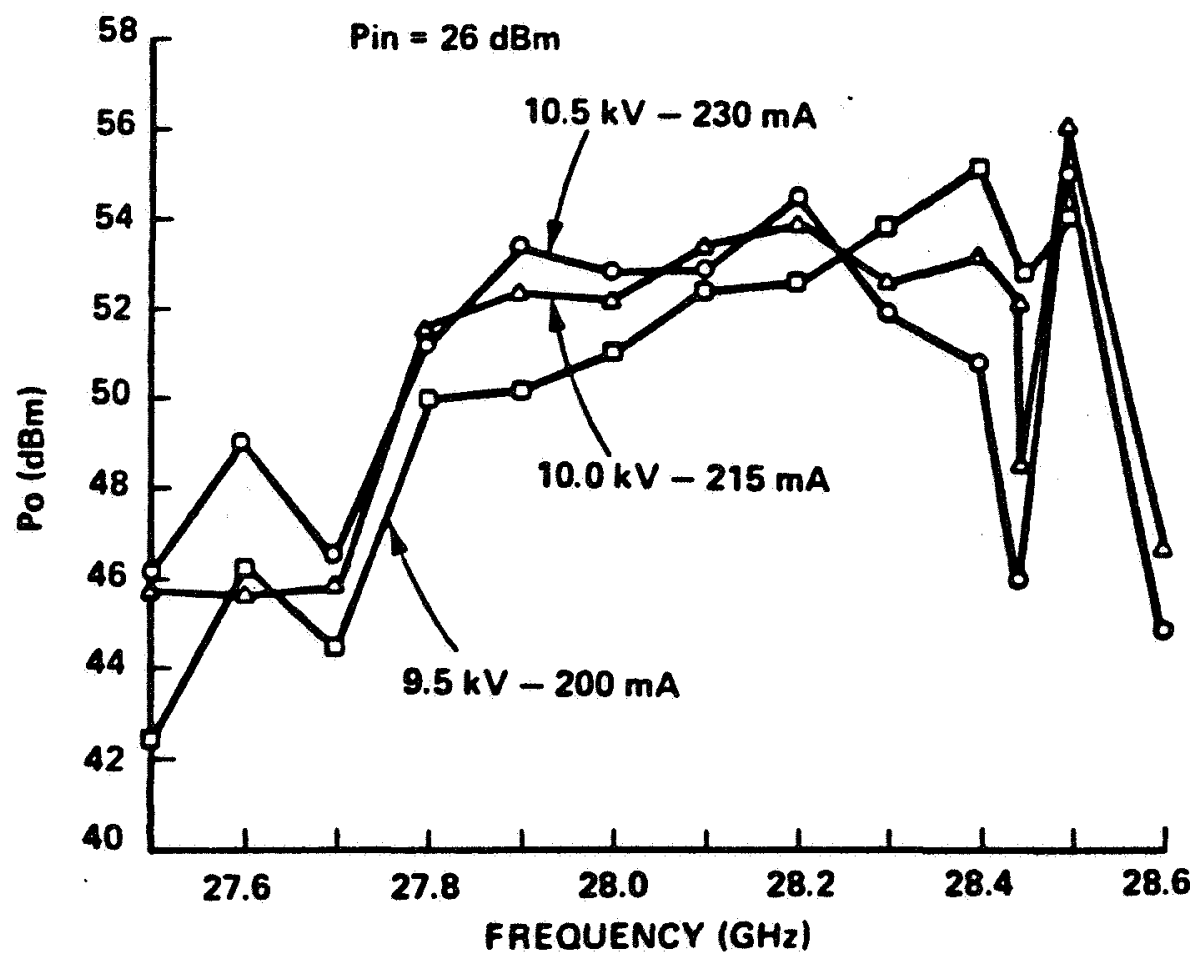


bandwidth. All test data substantiate predicted performance, but show a considerably wider actual bandwidth: $2.27 \%$ with $2 \mathrm{~dB}$ of gain flatness at +26 dBm input drive, where tube operation is still in the linear region. Operation remains almost linear when the power output is 200 watts over part of the indicated band.

\subsubsection{Power Output versus Tuning Voltage}

Figure 39 (see page 57) shows the effect, for one drive level, of voltage tuning on the output power versus frequency response. This response is essentially as predicted -- lower and higher beam voltages favoring gain at higher and lower frequencies, respectively, so that with voltage tuning an effectively broader band of frequencies can be covered.

\subsubsection{Output Power versus Input Drive}

The "transfer curve" for $28.2 \mathrm{GHz}$ is shown in

Figure 40, revealing several important performance parameters of the "TunneLadder" TWT.

- A measured gain of $31 \mathrm{~dB}$, or a gain per unit length of $52 \mathrm{~dB} / \mathrm{in}$. These values are close to the predicted ones and are considerably higher than those achieved with space-harmonic interaction.

- A measured efficiency (measured output power divided by beam power) of $17.5 \%$. Assuming a circuit efficiency of $80 \%$, the "electronic efficiency" would be over $21 \%$ - or near the predicted value of $24 \%$.

- A transfer curve indicating linear amplification at $200 \mathrm{~W}$ rated output power.

The superior performance indicated by these parameters can only be achieved with a "fundamental/forward" interaction structure. 


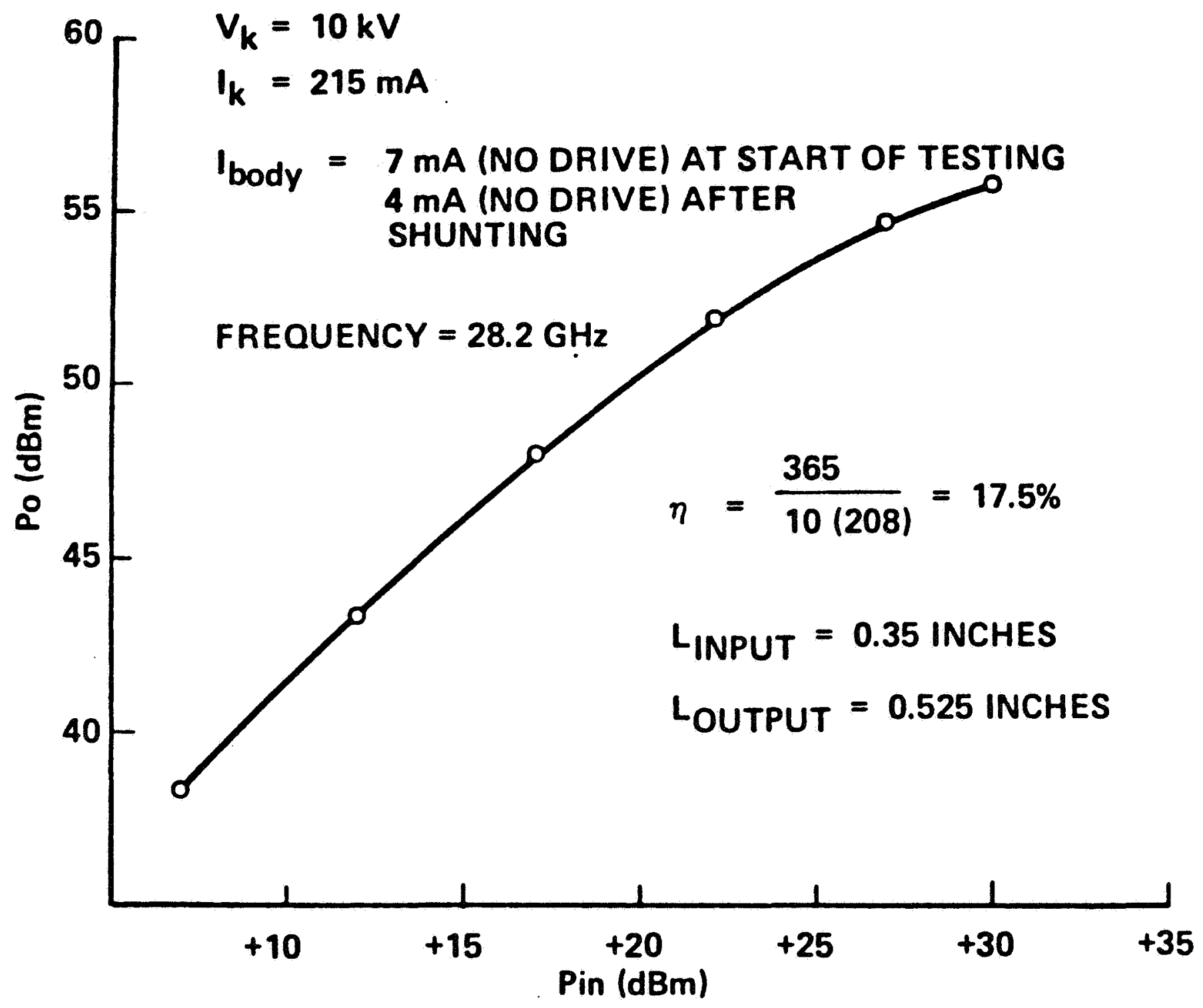

FIGURE 40. OUTPUT POWER Vs INPUT DRIVE 


\subsubsection{Collector Data}

To conclude the test data for $S / N 101$, beam interception versus drive power is shown in Figure 41. This indicates that the Tunneladder TWT can operate at an overall efficiency of $30 \%$, or higher, depending on the minimization of beam interception "under drive." Experiments to date show that the electron-optical design has not been optimized for this. Changes in gun- and gap-region magnetic fields and improved collector entrance conditions and lens design could easily improve overall efficiency.

\subsubsection{Performance Data for S/N 102}

This tube was tested in both pulsed and $\mathrm{CW}$ operation; unlike $S / N$ 101, Tunneladder TWT $S / N 102$ was leak-tight and exhaust processed at $550^{\circ} \mathrm{C}$ for over 40 hours to be extremely clean. It showed little or no evidence of gassiness under all test conditions. S/N 102 was tested with the same setup, shown in Figure 35 , as for $S / N 101$.

In order to ensure that the tube would be sufficiently characterized before risking damage, most of the performance data were taken under pulsed operating conditions. As an overall observation, these data indicate that the electronic performance of $S / N 102$ is very similar to that of $S / N$ 101. Initially, a maximum tube gain of $18 \mathrm{~dB}$ was observed, but after running the tube for several hours at $1 \%$ duty, the maximum gain increased to $26 \mathrm{~dB}$, which was high enough for operation with the power output

"saturated." The initial increase in gain can be explained by the changing beam diameter due to ion focusing of the beam. The pumping speed in the circuit is extremely slow due to the small tunnel diameter. The slow pumping speed would allow ion focusing to occur until the pressure in the tunnel region improved and the beam diameter increased to its normal size. The beam increase would be accompanied by a corresponding increase in gain. Nevertheless, gain/bandwidth performance is somewhat low, indicating some internal problem, such as excess loss at the output sever. If there was excess loss in the output this would explain the lower electronic efficiency 


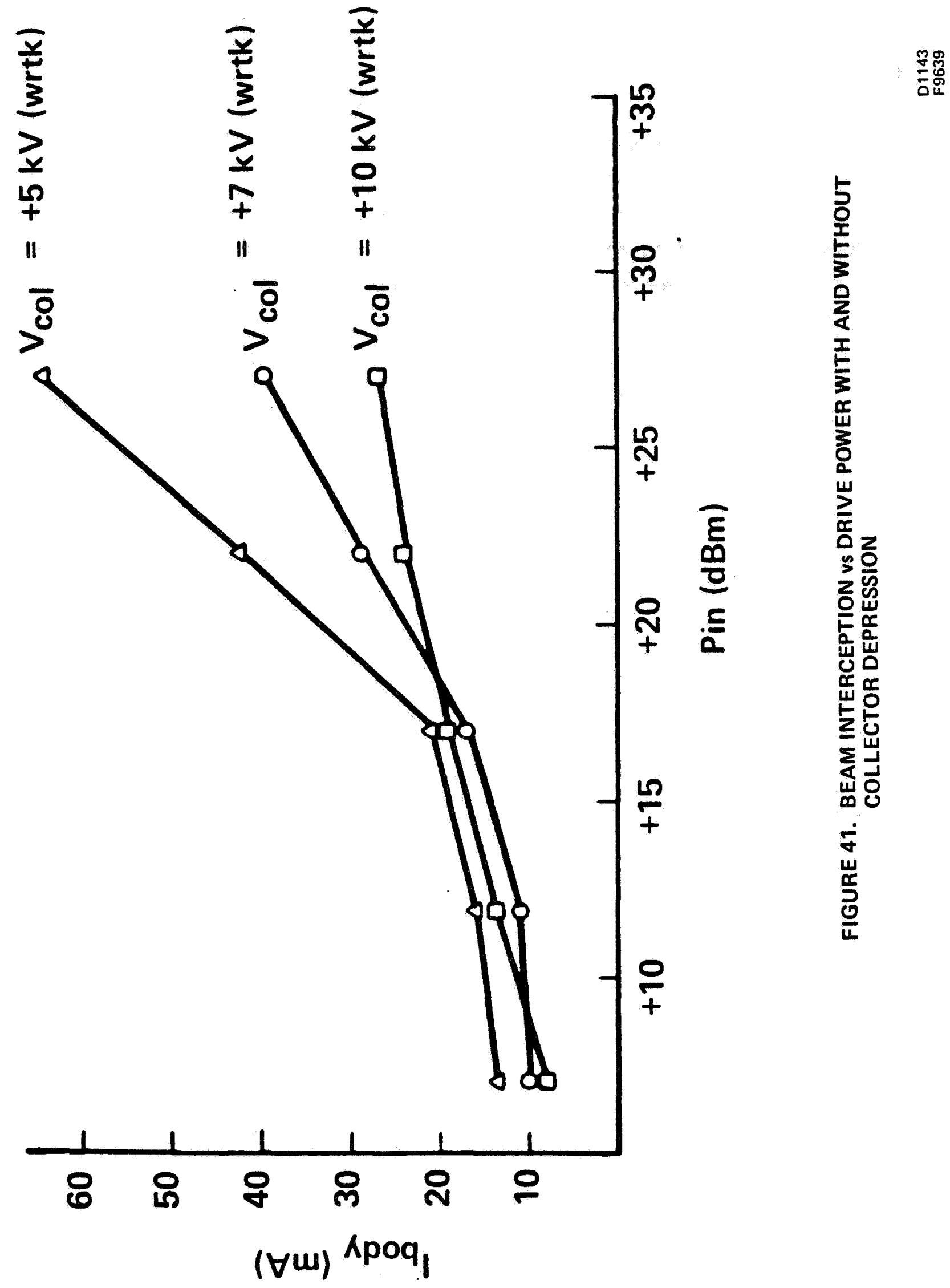


and the lower overall gain. The excess loss would also improve the stability but only as a second order effect compared to gain and match.

\subsubsection{Focusing Data}

Beam transmission data are shown in Figure 42. This performance was subsequently improved somewhat, first with shunts, and later with a gun coil. However, the transmission for $S / N 102$ was never as good as for $S / N 101$, and was even worse ( $92.8 \%$ at $8.1 \mathrm{kV})$ under $\mathrm{CW}$ operating conditions. On the other hand, no instabilities were detected for this second tube at any voltage.

\subsubsection{Power Output vs Frequency}

Test data indicating the relationship between frequency and power output, at saturation and below, are shown in Figure 43. The gain flatness for $S / N 102$ is much poorer than for $S / N$ 101, as the 2-dB bandwidth is only 1.4\%. However, the 3-dB bandwidth for saturated power output is $2.8 \%$, which is comparable with results for $S / N 101$. Power output in this case exceeds $160 \mathrm{~W}$.

\subsubsection{Pówer Output vs Tuning Voltage}

The effect of voltage tuning on output power vs frequency at constant drive power is shown in Figure 44. The increase in effective bandwidth seen in $S / N 101$ is not as evident here, perhaps due to the same problem that resulted in the lower gain relative to $S / N 101$.

\subsubsection{Output Power vs Input Drive}

Transfer curves for $27.6,28.4$ and $28.6 \mathrm{GHz}$ are shown in Figure 45. The curve for $28.4 \mathrm{GHz}$ can be compared with that for $28.2 \mathrm{GHz}$ for $S / N$ 101, yielding the following observations:

- The gain is $26 \mathrm{~dB}$, or $5 \mathrm{~dB}$ lower than for $\mathrm{S} / \mathrm{N} 101$. However, if the output sever is "tuned" for narrow- 


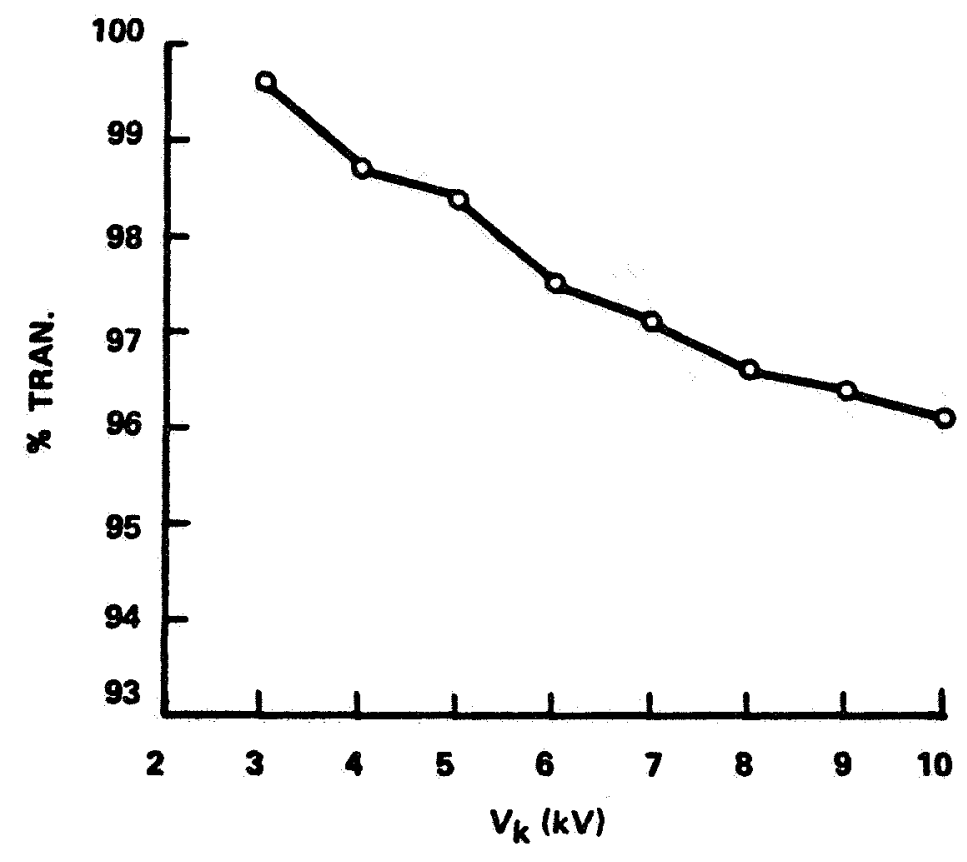

FIGURE 42. BEAM TRANSMISSION FOR S/N 102

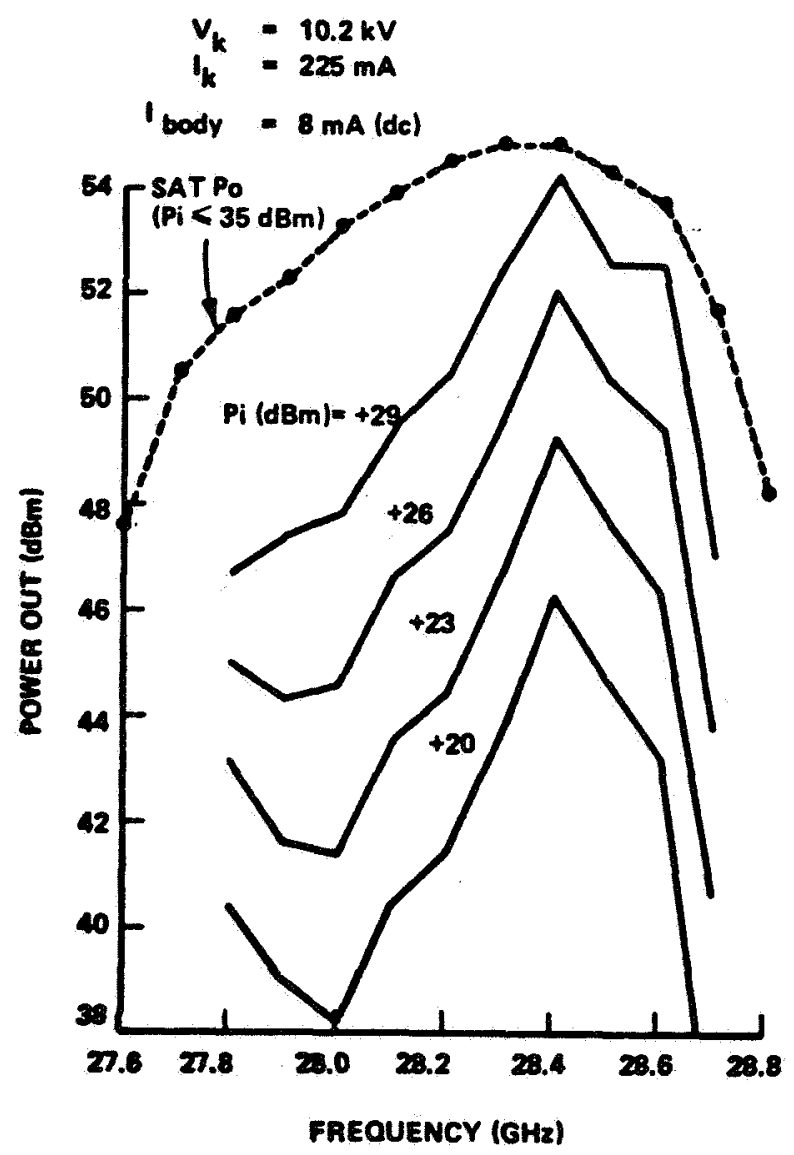

FIGURE 43. POWER OUTPUT VS FREQUENCY FOR DIFFERENT INPUT DRIVES 


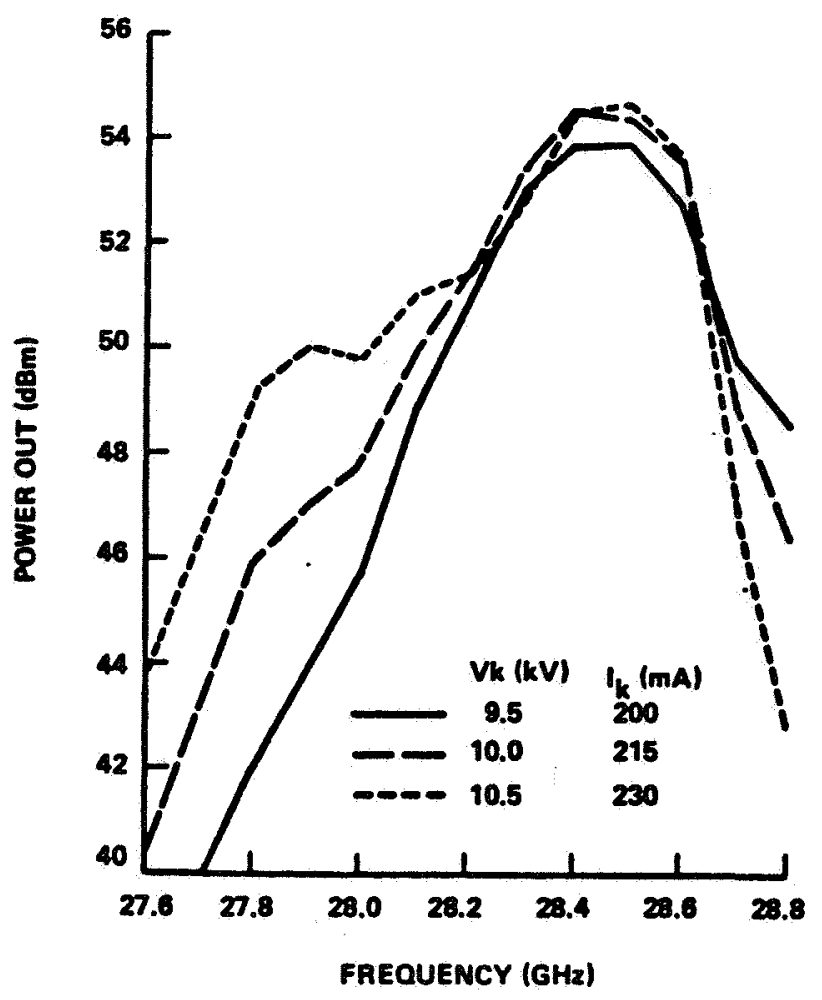

FIGURE 44. EFFECT OF VOLTAGE TUNING ON OUTPUT POWER VS FREQUENCY

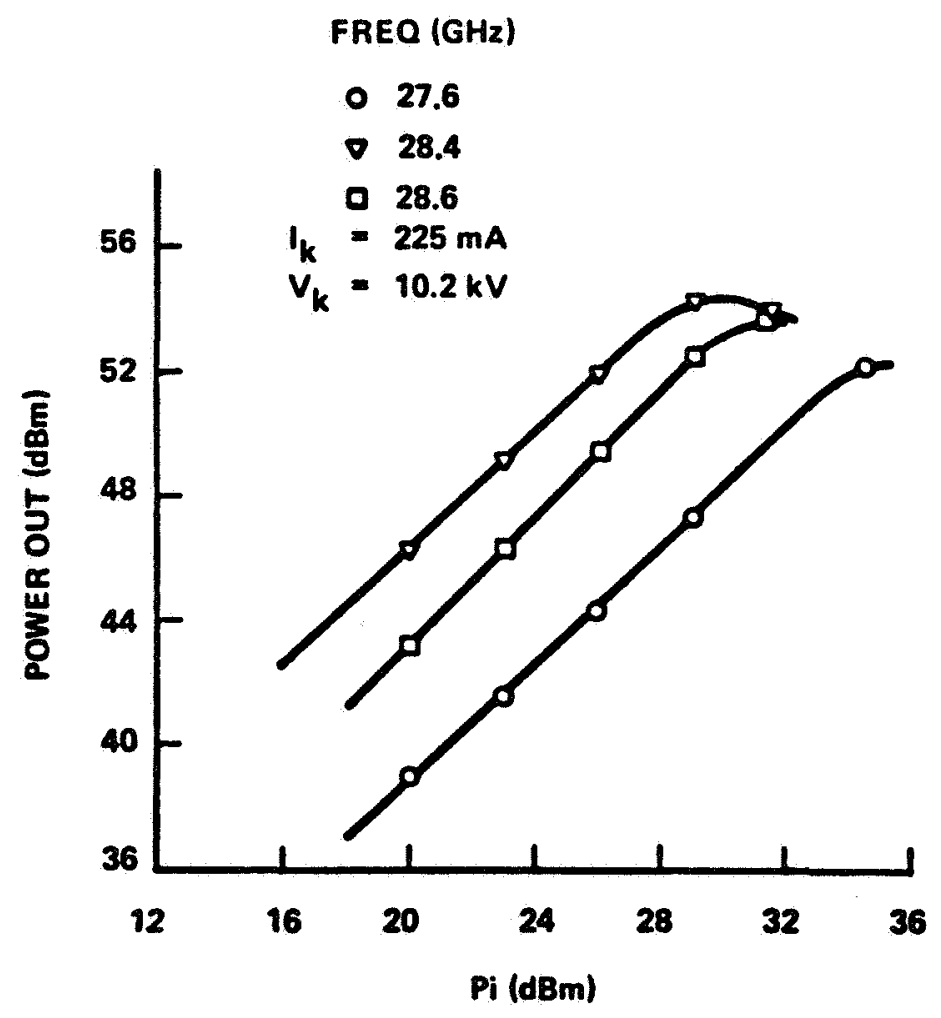

FIGURE 45. OUTPUT POWER vS INPUT DRIVE 
band gain performance, the total and per-unit-length gains for both tubes are nearly identical.

- The measured efficiency was $13.8 \%$, which would correspond to an estimated "electronic efficiency" of 17.2\%. This is much lower than for $S / N 101$, and may be due to undetected loss or poor match in the output section.

- Despite the lower efficiency, the transfer curve is still linear at the level of $200 \mathrm{~W}$ power output.

\subsubsection{CW Test Data}

The duty factor was increased slowly to minimize the possibility of damage to the tube by high average power. The water cooling was employed for all duty factors above $10 \%$. However, the tube perfomed quite adequately. under $\mathrm{CW}$ operating conditions, Indicating an excellent average-power handling capacity for the circuit and body. Unfortunately, the $r f$ driver source that had been used for the low-duty testing had been damaged in the interim and was thus not available for CW testing up to saturation. In lieu of simply driving the tube to saturation, the required power was fed back from the output into the output-sever port, placing the output section in a loop. But since the tube could then automatically drive itself to saturation, the cathode voltage was lowered - to avoid the risk of unnecessary circuit damage from too great a combination of $\mathrm{rf}$ and beaminterception heating. The performance tabulated below was obtained under these circumstances. ( $R F$ frequencles here were measured with a spectrum analyzer.)

Cathode Voltage $-8.2 \mathrm{kV}$

Cathode Current $159 \mathrm{~mA}$

Body Current $18 \mathrm{~mA}$

RF Output Power $51.8 \mathrm{dBm}$ (151 W)

RF Frequency $28.55 \mathrm{GHz}$ 
Assuming a circuit efficiency of $80 \%$ and $10 \%$ reduction in the electron energy of the body current, the total power dissipated in the body would be 171 watts. There were no gas pressure, defocusing, or output power changes to indicate that the circuit or body was in any way adversely affected by this level of power dissipation. The tube operated in this fashion continuously for over one hour. 


\section{CONCLUSIONS AND RECOMMENDATIONS}

\subsection{CONCLUSIONS}

Two Tunneladder millimeter-wave (29 GHz) traveling-wave tubes were fabricated and tested. Performance of both tubes was essentially as predicted - and exceeding predictions as regards "hot" bandwidth.

The technology listed below was developed for the fabrication of these tubes:

- Chemical milling of the formed ladder elements

- Brazing of the diamond cubes to the Amzirc ridge

- Metalizing the uppermost face of the diamond cubes

- Erazing of the formed ladder elements to the upper surfaces of the diamond cubes and the waveguide-half block

- Machining and brazing the two waveguide-half blocks.

In addition, Tunneladder design features incorporated the principles of:

- "Forward/fundamental" interaction for high interaction impedance, gain per unit length and efficiency

- An intentionally dispersive slow-wave circuit to further augment interaction impedance when a small "hot" bandwidth will satisfy the applications need

- The nonaxisymmetric beam tunnel such that high $r f$ axial fields are brought close to the beam to enhance interaction while the evacuation (via diamond supports) of beam-interception heating is maximized at that place

- ... and such that the portion of the interaction structure subject to the greatest rf heating is elsewhere, with a separate evacuation path for this heat -- thereby completing separation of 
the two kinds of heat input and removal for the interaction circuit

The success of the two $29 \mathrm{GHz}$ Tunneladder TWTs, which brought these principles together for the first time, has given them validity. As far as is known, these tubes are also the first ever to successfully incorporate "photo-etching" or "chemical milling" of the periodic structure - which process, in this case, is also implemented in three dimensions.

\subsection{RECOMMENDATIONS}

A recommendation to continue the program is unnecessary, as the follow-on program is in progress.

The following changes are recommended to simplify the assembly procedure and to decrease the cost of the tube:

- The waveguide-transition design was part of the waveguide-shroud heliarc assembly. Making this a separate braze would reduce the complexity of the waveguide-coolant shroud heliarc assembly braze to the brazed input and output section. It would eliminate the changes in match due to possible misalignment during the complicated braze to the circuit sections (electrical as well as coolant line brazes).

- Eliminate the sever external waveguide assemblies (2) and provide a sever termination at each end of tube sections. This will greatly reduce the cost and complexity of the sections. It eliminates two window assemblies and simplifies the section assembly and braze cycle.

It is recommended that a PPM version be developed. The size, weight and cost improvements make the "forward/fundamental" Tunneladder millimeter-wave TWT a very attractive device for applications other than in ground terminals. 


\section{REFERENCES}

1. H. Kosmahl, R. Plamer, "Harmonic-Analysis Approach to the

'Tunneladder': A Modified Karp Circuit for Millimeter-Wave TWTAs," IEEE Trans. Electron Devices, vol. ED-29, pp. 862-869, May 1982.

2. A. Karp, "Design Concepts for a High-Impedance Narrow-Band $42 \mathrm{GHz}$ Power TWT Using a "Fundamental/Forward" Ladder-Based Circuit," Final Report, Varian Associates, Palo Alto, CA, February 1981 (NASCR-165282).

3. A. Karp, "Traveling-Wave Tube Experiments at Millimeter Wavelengths with a New, Easily Built, Space-Harmonic Circuit," Proc. I.R.E., vol. 43, pp. $41-46,(1955)$.

4. A. Karp, "Millimetre-Wave Valves," pp. $73-128$ in Fortschritte der Hochfrequenztechnik, Vol. 5, M. Strutt et al., eds., Academic Press MBH, Frankfurt/Main, 1960.

5. Ibid., Fig. 30 (d), p. 116.

6. Ibid., Fig. 30 (e), p. 116.

7. Ibid., biliography items $118-123$, p. 127.

8. A. Karp, "Backward-Wave Oscillator Experiments at 100 to 200 Kilomegacycles," Proc. I.R.E., vol. 45, pp. 496 - 503 (1957).

9. L. D. Cohen, "Eackward-Wave Oscillators for the 50- to 300-GHz Frequency Range," IEEE Trans. Electron Devices, vol. ED-15, pp. 403 404 , June 1968.

10. See Reference 4, Fig. $30(\mathrm{c}),(f)$ and (h), p. 116.

11. Ibid, bibliography items $130 \mathrm{a}, 131$, p. 127.

12. J. R. Pierce, Traveling-Wave Tubes, D. Van Nostrand Co., New York, 1950: Figure 5.7, p. 90 .

13. J. R. Pierce, "Propagation in Linear Arrays of Parallel Wires," I.R.E. Trans. Electron Devices, vol. ED-2, pp $13-24$, (1955).

14. See Reference 4, bibliography items $125,127,128$, p. 127.

15. H. G. Kosmahl and T. O'Malley, "Harmonic Analysis of the Forward-Wave Karp Circuit as a Millimeter-Wave Amplifier in the 100 - $500 \mathrm{~W}$ Range", Microwave Power Tube Conference, Monterey, CA, 3 May 1978. 


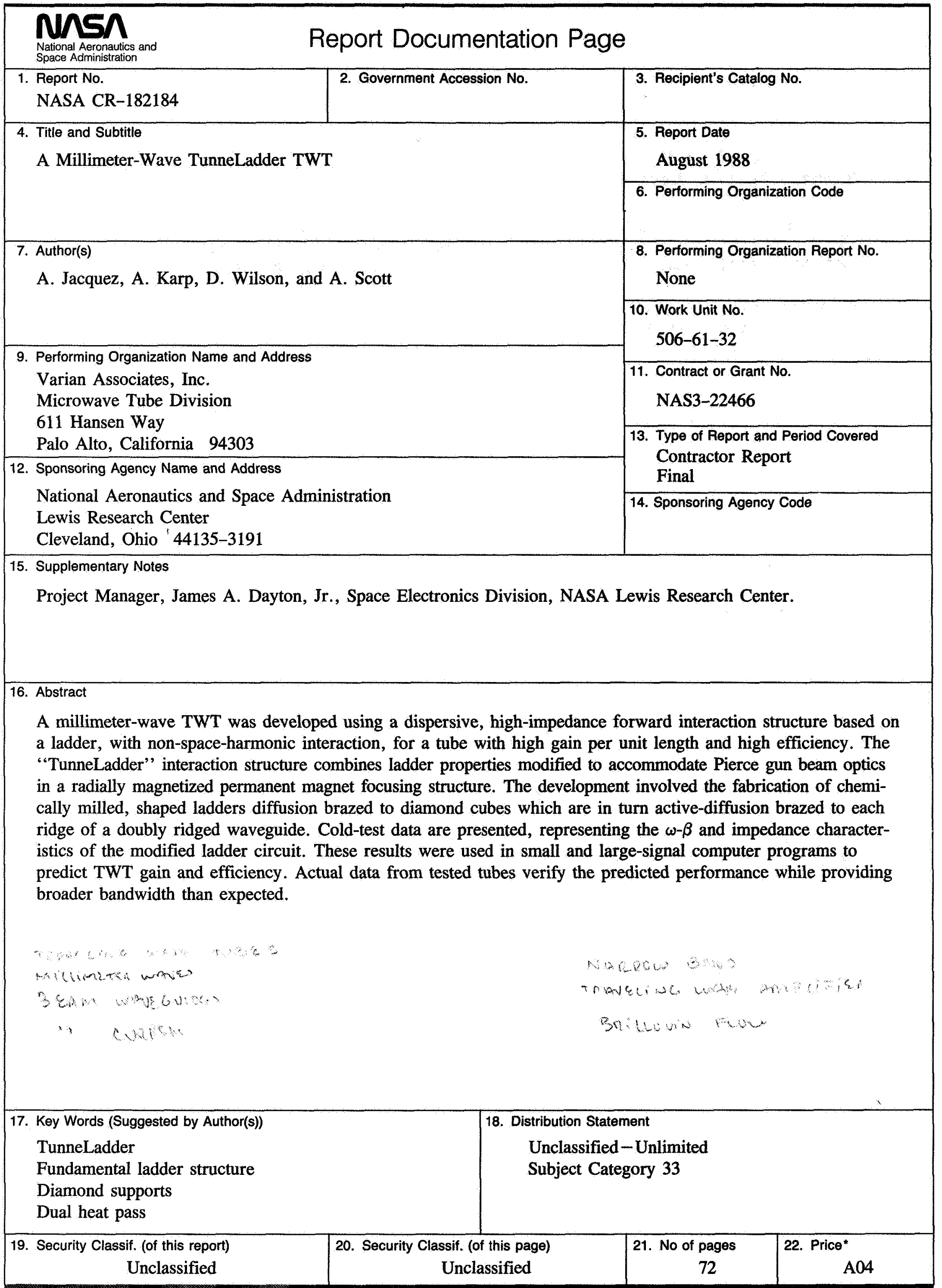


National Aeronautics and Space Administration

Lewis Research Center

Cleveland, Ohio 44135

Official Business

Penalty for Private Use $\$ 300$
FOURTH CLASS MAIL

ADDRESS CORRECTION REQUESTED
|||||

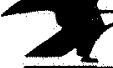

U.S.MAIL

Postage and Fees Pard

National Aeronautics and Space Administration

NASA 451 